\title{
Thermal Analysis of AlGaN/GaN HEMT monolithic integration with CMOS on Silicon $<111>$ Substrates
}

\author{
Pietro Natale Alessandro Chyurlia, B.Eng. \\ A thesis submitted to the Faculty of Graduate Studies and \\ Research in partial fulfillment of the requirements for the degree of \\ Master of Applied Science \\ In \\ Electrical Engineering
}

Ottawa-Carleton Institute for Electrical Engineering

Department of Electronics, Carleton University

Ottawa, Canada

September 2006

(C) copyright

2006, Pietro Chyurlia 


$\begin{array}{ll}\begin{array}{l}\text { Library and } \\ \text { Archives Canada }\end{array} & \begin{array}{l}\text { Bibliothèque et } \\ \text { Archives Canada }\end{array} \\ \begin{array}{l}\text { Published Heritage } \\ \text { Branch }\end{array} & \begin{array}{l}\text { Direction du } \\ \text { Patrimoine de l'édition }\end{array} \\ \begin{array}{l}\text { 395 Wellington Street } \\ \text { Ottawa ON K1A ON4 }\end{array} & \begin{array}{l}\text { 395, rue Wellington } \\ \text { Ottawa ON K1A ON4 } \\ \text { Canada }\end{array}\end{array}$

Your file Votre référence ISBN: 978-0-494-23334-4 Our file Notre référence ISBN: 978-0-494-23334-4

NOTICE:

The author has granted a nonexclusive license allowing Library and Archives Canada to reproduce, publish, archive, preserve, conserve, communicate to the public by telecommunication or on the Internet, loan, distribute and sell theses worldwide, for commercial or noncommercial purposes, in microform, paper, electronic and/or any other formats.

The author retains copyright ownership and moral rights in this thesis. Neither the thesis nor substantial extracts from it may be printed or otherwise reproduced without the author's permission.
AVIS:

L'auteur a accordé une licence non exclusive permettant à la Bibliothèque et Archives Canada de reproduire, publier, archiver, sauvegarder, conserver, transmettre au public par télécommunication ou par l'Internet, prêter, distribuer et vendre des thèses partout dans le monde, à des fins commerciales ou autres, sur support microforme, papier, électronique et/ou autres formats.

L'auteur conserve la propriété du droit d'auteur et des droits moraux qui protège cette thèse. $\mathrm{Ni}$ la thèse ni des extraits substantiels de celle-ci ne doivent être imprimés ou autrement reproduits sans son autorisation.
In compliance with the Canadian

Privacy Act some supporting forms may have been removed from this thesis.

While these forms may be included in the document page count, their removal does not represent any loss of content from the thesis.
Conformément à la loi canadienne sur la protection de la vie privée, quelques formulaires secondaires ont été enlevés de cette thèse.

Bien que ces formulaires aient inclus dans la pagination, il n'y aura aucun contenu manquant.

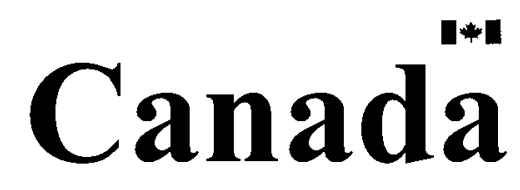




\begin{abstract}
A thermal analysis of the potential monolithic integration of AlGaN/GaN HEMTs with CMOS in silicon substrates is performed. ATAR, an in-house 3-D thermal modeling tool, is used to perform a thermal analysis on a $300 \mu \mathrm{m}$ wide $\mathrm{GaN}$ transistor in two different packages. Simulations ranging from $2 \mathrm{~W} / \mathrm{mm}$ to $8 \mathrm{~W} / \mathrm{mm}$ of dissipated power in the transistor suggest that the surrounding region experiences a slight thermal gradient, but will still be able to house CMOS circuitry with some careful design. Due to the highresistivity silicon substrate, the local heating of the GaN HEMT is substantial, which is undesirable. A novel back-trenching technique, which can lower the device maximum temperature by $100 \mathrm{~K}$ is proposed. The potential for modeling the thermal transient behavior using an RC network is also demonstrated.
\end{abstract}




\section{Acknowledgements}

Dr. Garry Tarr
Dr. Tom Smy
Dr. Jennifer Bardwell
Mom
Dad
Nonna
Livia
Zio
Irene
James
Kris
Albert
Graham
Adam
Faisal
Keith
Steve P.
Steve M.
Harpreet
Victor
Charles
Dritan
Gerrardo
Jack Bauer
Marcello Lippi

iii 


\section{Table of Contents}

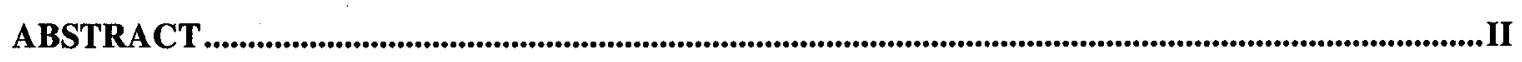

ACKNOWLEDGEMENTS............................................................................................................................. III

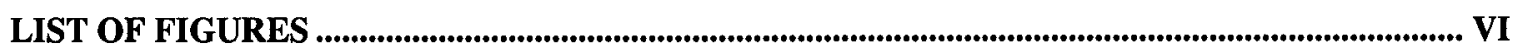

LIST OF ABBREVIATIONS AND SYMBOLS..............................................................................

CHAPTER 1: INTRODUCTION .........................................................................................................................

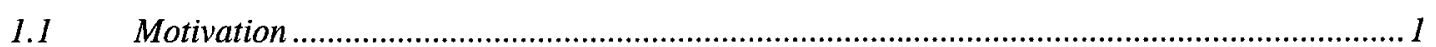

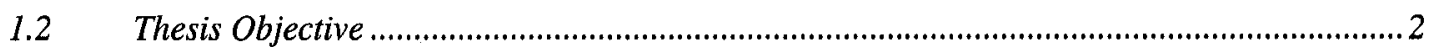

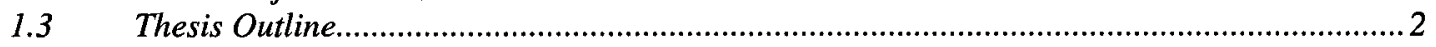

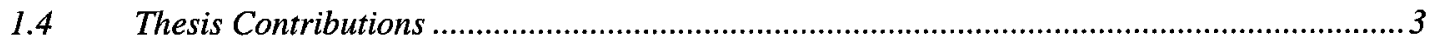

CHAPTER 2: GAN TECHNOLOGY AND THERMAL OVERVIEW ....................................................4

$2.1 \quad$ Gallium Nitride HEMT Basics .................................................................................. 4

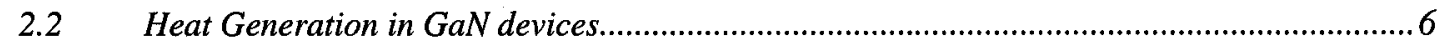

2.3 Heat Conduction in Semiconductors.............................................................................. 7

$2.4 \quad$ Implications of Thermal management on Semiconductor Devices.....................................9

CHAPTER 3: THERMAL SIMULATION ......................................................................................... 12

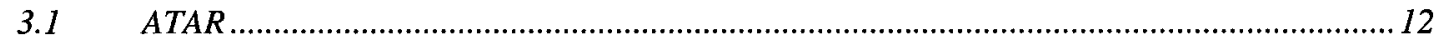

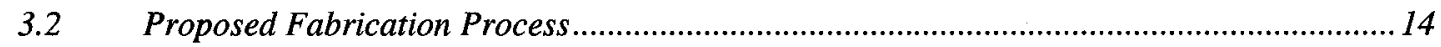

Simulation Models...................................................................................................... 17

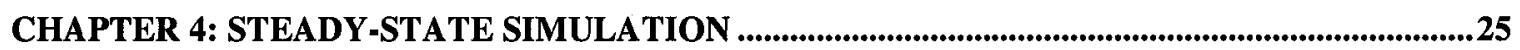

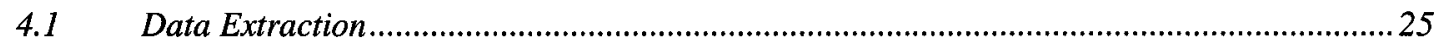

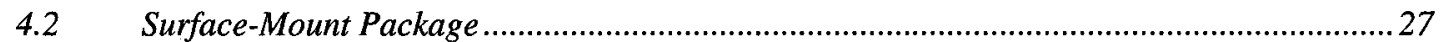

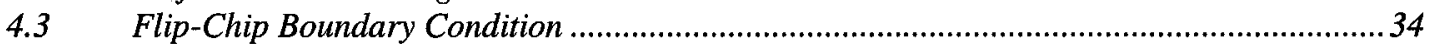

4.4 Internal thermal characteristics of GaN HEMT device ..................................................4

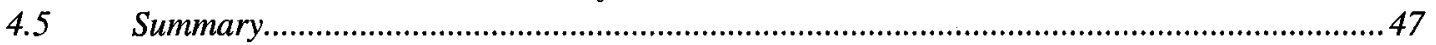




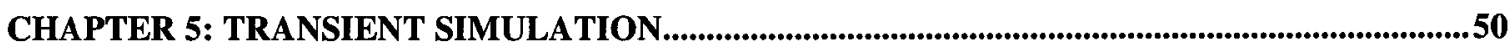

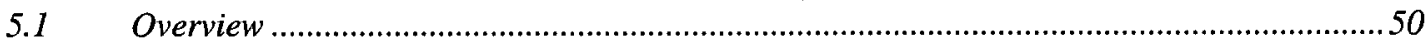

$5.2 \quad$ Thermal Modeling with an RC Network .........................................................................5

CHAPTER 6: IMPROVING THERMAL PERFORMANCE.......................................................................58

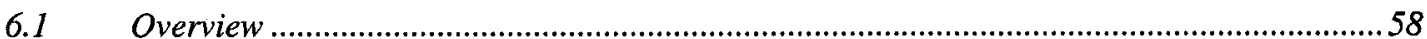

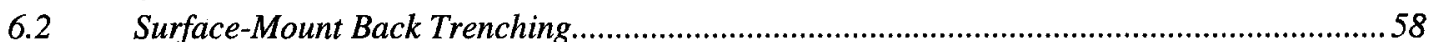

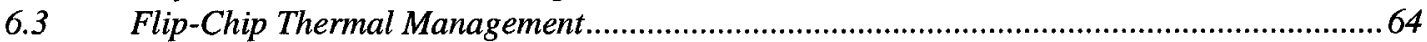

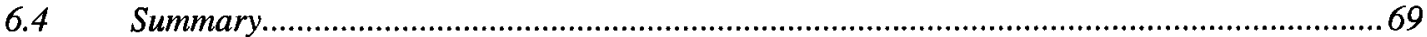

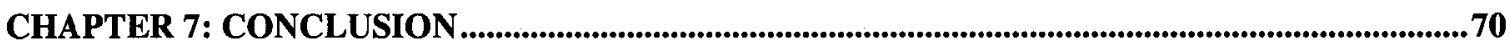

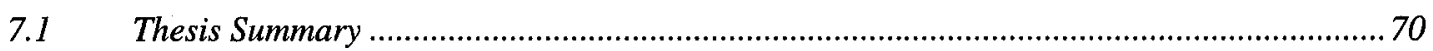

REFERENCES 


\section{List of Figures}

FIGURE 1: GAN HEMT LAYER STRUCTURE.

FIGURE 2: ALGAN/GAN DC CHARACTERISTICS WITH AND WITHOUT SELF-HEATING EFFECTS (NATIONAL

RESEARCH COUNCIL OF CANADA) .............................................................................................

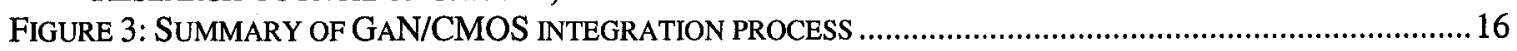

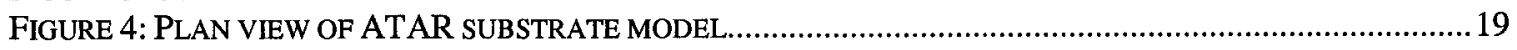

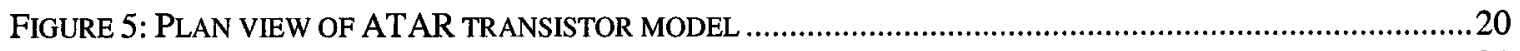

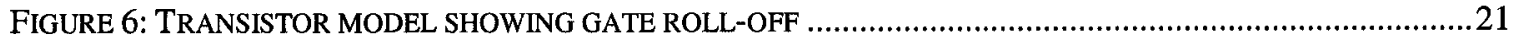

FIGURE 7: GOLD AIR-BRIDGE CONNECTING INNER SOURCE METALLIZATION …………................................2

FIGURE 8: HEAT SOURCE APPLICATION IN PINCH-OFF REGION OF THE DEVICE ...........................................2

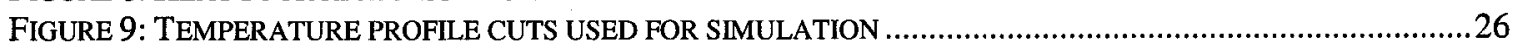

FIGURE 10: CONTOUR PLOT FOR SURFACE MOUNT PACKAGE AT SILICON SURFACE - 2.4 W POWER ................28

FIGURE 11: CROSS SECTION PLOT OF TEMPERATURE DISTRIBUTION WITH SURFACE-MOUNT BOUNDARY

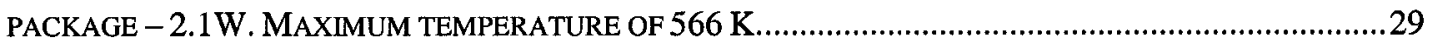

FIGURE 12: TEMPERATURE VS. POWER PLOT FOR VARIOUS POWERS, SURFACE MOUNT PACKAGE.....................30

FIGURE 13: MAXIMUM DEVICE TEMPERATURE VERSUS SUBSTRATE THICKNESS, FOR VARIOUS POWERS........ 31

FIGURE 14: ANALYTICALLY CALCULATED THERMAL RESISTANCE VERSUS SUBSTRATE THICKNESS ...............32

FIGURE 15: DECREASE IN TEMPERATURE AT SILICON/OXIDE INTERFACE FOR A $50 \mu \mathrm{M}$ THICK SUBSTRATES OVER THE BASELINE $256 \mu$ M THICK SUBSTRATE.................................................................................. 33

FIGURE 16: DECREASE IN TEMPERATURE VS. POSITION FOR VARIOUS SUBSTRATE THICKNESSES, FOR A FIXED

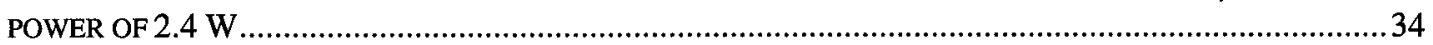

FIGURE 17: CONTOUR PLOT OF SILICON/OXIDE INTERFACE FOR FLIP-CHIP PACKAGE - $2.4 \mathrm{~W}$......................... 35

FIGURE 18: CROSS-SECTION CONTOUR PLOT OF COOLING PATTERN WITH FLIP-CHIP BOUNDARY CONDITION.

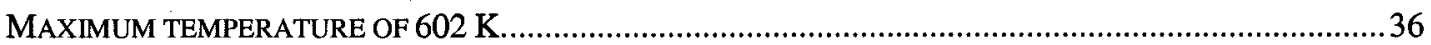

FIGURE 19: TEMPERATURE PROFILE AT SILICON/OXIDE INTERFACE FOR FLIP-CHIP PACKAGING .......................37

FIGURE 20: MAXIMUM TEMPERATURE VERSUS DISSIPATED POWER - BOTH PACKAGES ................................38

FIGURE 21: IMPACT OF INCREASED METAL THICKNESS ON MAXIMUM DEVICE TEMPERATURE - FLIP-CHIP

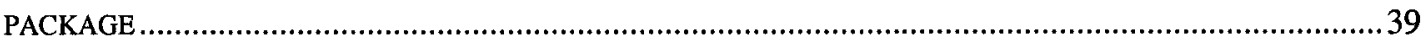

FIGURE 22: THERMAL IMPACT OF INCREASED METAL THICKNESS ON SILICON/OXIDE INTERFACE ..................40

FIGURE 23: TEMPERATURE DISTRIBUTION ACROSS GATE PERIPHERY FOR FLIP-CHIP PACKAGE …………….....42

FIGURE 24: TEMPERATURE DISTRIBUTION ACROSS GATE PERIPHERY FOR SURFACE-MOUNT PACKAGE ...........43

FIGURE 25: TRANSISTOR SURFACE CONTOUR PLOTS - 2.4 W ......................................................................4 44

FIGURE 26: TEMPERATURE DISTRIBUTION ALONG GATE LENGTH - SURFACE MOUNT PACKAGE .....................45

FIGURE 27: TEMPERATURE DISTRIBUTION ALONG GATE LENGTH - FLIP-CHIP PACKAGE..................................46

FIGURE 28: MAXIMUM TEMPERATURES FOR VARIOUS DEVICE PARAMETER CHANGES …............................48

FIGURE 29: FIVE KEY POINTS OF INTEREST FOR TRANSIENT SIMULATION.................................................51

FIGURE 30: TRANSIENT TEMPERATURE RESPONSE FOR INTEREST POINTS - FLIP-CHIP PACKAGE .....................51

FIGURE 31: THREE-RUNG RC NETWORK USED TO MODEL TRANSIENT BEHAVIOUR …..............................54

FIGURE 32: TRANSIENT FIT FOR GATE POINT USING A THREE-RUNG RC NETWORK ……...............................56

FIGURE 33: IMPROVEMENT IN MAXIMUM DEVICE TEMPERATURE USING BACKSIDE TRENCHES - SURFACEMOUNT PACKAGE

FIGURE 34: TEMPERATURE PROFILE ACROSS GATE PERIPHERY FOR VARIOUS TRENCH DIMENSIONS - $1.8 \mathrm{~W} . .61$

FIGURE 35: TEMPERATURE DISTRIBUTION ALONG OUTER GATE - SURFACE-MOUNT PACKAGE, $1.8 \mathrm{~W}$...........61

FIGURE 36: TEMPERATURE DISTRIBUTION ALONG INNER GATE - SURFACE-MOUNT PACKAGE, $1.8 \mathrm{~W}$............62

FIGURE 37: EFFECT OF A 32 X 32 MICRON BACKSIDE TRENCH ON THE SURFACE MOUNT PACKAGE ................63

FIGURE 38: ATAR MODEL CROSS-SECTION SHOWING THE SOURCE PAD VIAS AS WELL AS BACKSIDE TRENCH

FIGURE 39: EFFECTS OF DIFFERENT COOLING STRATEGIES FOR THE FLIP-CHIP PACKAGE

FIGURE 40: EFFECT OF SOURCE PAD VIAS AND BACKSIDE TRENCHES ON THE FLIP CHIP PACKAGE AT THE SILICON/OXIDE INTERFACE.

FIGURE 41: INTERFACE CONTOUR PLOT FOR FLIP-CHIP PACKAGE - $2.4 \mathrm{~W}$... 


\section{List of Abbreviations and Symbols}

$\begin{array}{ll}\text { GaN } & \text { Gallium Nitride } \\ \text { GaAs } & \text { Gallium Arsenide } \\ \text { HEMT } & \text { High Electron Mobility Transistor } \\ \text { AlGaN } & \text { Aluminum Gallium Nitride } \\ \text { MESFET } & \text { Metal-Semiconductor Field-Effect Transistor } \\ \text { 2-DEG } & \text { Two-Dimensional Electron Gas } \\ \text { MBE } & \text { Molecular Beam Epitaxy } \\ \text { MOCVD } & \text { Metal-Organic Chemical Vapour Deposition } \\ \text { CMOS } & \text { Complimentary Metal Oxide Semiconductor } \\ \text { TLM } & \text { Transmission Line Method } \\ \text { BPSG } & \text { Borophosphosilicate Glass } \\ \text { MMIC } & \text { Monolithic Microwave Integrated Circuit } \\ & \\ \text { T } & \text { Temperature }(\mathrm{K}) \\ \mathrm{H} & \text { Power Density }\left(\mathrm{W} / \mathrm{m}^{3}\right) \\ \mathrm{q} & \text { Heat Flux }\left(\mathrm{W} / \mathrm{m}^{2}\right) \\ \mathrm{k} & \text { Thermal Conductivity }(\mathrm{W} / \mathrm{cm} \cdot \mathrm{K}) \\ \mathrm{C} & \text { Heat Capacity }(\mathrm{J} / \mathrm{W}) \\ \mathrm{R}_{\mathrm{th}} & \text { Thermal Resistance }(\mathrm{K} / \mathrm{W}) \\ \tau & \text { Relaxation Time }(\mathrm{s}) \\ \alpha & \text { Diffusion Constant }\left(\mathrm{m}^{2} / \mathrm{s}\right) \\ \rho & \text { Density }\left(\mathrm{kg} / \mathrm{m}^{3}\right) \\ \mathrm{c}_{\mathrm{p}} & \text { Specific Heat }(\mathrm{J} / \mathrm{kg} \cdot \mathrm{K}) \\ & \end{array}$




\section{Chapter 1}

\section{Introduction}

\subsection{Motivation}

Gallium Nitride (GaN) High Electron Mobility Transistors (HEMTs) are a new technology, which are becoming the ideal choice for microwave power applications. This is due to the ability of $\mathrm{GaN}$ to withstand high voltages and operate at high frequencies, caused by the wide band-gap of this material $(3.4 \mathrm{eV})$, high thermal conductivity $(>1.5$ $\mathrm{W} / \mathrm{cm} \cdot \mathrm{K})$ and large breakdown field $(\sim 3 \mathrm{MV} / \mathrm{cm})$ [Eastman, 2002]. Traditionally, GaN transistors have been grown on silicon-carbide or sapphire substrates, but both of these materials have drawbacks. Sapphire is plagued with low thermal conductivity, whereas silicon-carbide is quite costly, making these devices financially restrictive.

Recent advances in Gallium Nitride epitaxy have allowed for the growth of HEMT layers on silicon $<111>$ oriented substrates. Silicon does not have quite as high a thermal conductivity as silicon-carbide, but this is offset by the huge economic advantage of using low-cost silicon substrates. The future of this technology lies in the use of silicon substrates, which can allow for the possible integration of GaN HEMT devices with conventional CMOS circuitry. A potential application of this technology is the inclusion of CMOS control and logic circuitry on the same chip as GaN power transistors for wireless power amplifiers. 
In order for this technology integration to be successful, the placement of the CMOS circuitry with respect to the GaN devices is of great importance. Due to the large quantity of heat generated by GaN power transistors, a complete thermal study is required in order to ensure proper thermal isolation of the CMOS devices. Excess heat decreases the lifetime of integrated circuits, as well as degrading their performance. This makes proper thermal design, including layout and packaging of this new technology paramount for this type of project.

\subsection{Thesis Objective}

The goal of this thesis is to examine the thermal implications of a high-power GaN transistor to a surrounding area capable of housing CMOS circuitry. ATAR, a numerical 3-D thermal simulation tool developed at Carleton University, is used to carry out this work. The first step of this thesis is to develop a simulation model that represents the proposed technology accurately. Once this has been completed, minor changes can then be made to this model in order to examine which properties have the largest impact on thermal behavior. The results of these simulations should help to determine where the CMOS circuitry should be placed, as well as how to optimize the thermal design of the proposed process.

\subsection{Thesis Outline}

Chapter 2 will begin with a brief description of typical GaN/AlGaN devices, including their thermal properties. Some background theory of how heat diffuses through 
Introduction

semiconductors is provided, and the manner in which heat affects the performance of semiconductor devices negatively is also discussed. A description of the simulation models is given in chapter 3 . This chapter also includes an explanation of the simulation tool ATAR. Next, chapter 4 presents the steady-state simulation results for both flip-chip and surface-mount packages. The effects of various model parameters are examined as well. Chapter 5 provides a quick demonstration of how transient simulations can provide useful information that can then be used to generate compact thermal models made from RC networks. Finally, Chapter 6 presents a cost-effective manner of dissipating the heat from the GaN transistor by using metal filled back-trenches and source vias. A summary of the results from this work is given in chapter 7.

\subsection{Thesis Contributions}

A thermal model which can examine the thermal implications of integrating CMOS circuitry with a GaN power transistor has been developed. Steady-state simulations are used to examine the temperature profile of areas capable of housing CMOS around a GaN power transistor. Both flip-chip and surface mount packages have been considered. In addition, a novel back-trenching technique as well as a source metal heat spreader is proposed to reduce GaN device temperatures. A compact thermal model consisting of a three-rung RC ladder has been developed using data from transient simulations. 


\section{Chapter 2}

\section{GaN Technology and Thermal Overview 2.1 Gallium Nitride HEMT Basics}

Gallium Nitride HEMTs are similar in structure and operation principles to GaAs MESFETs. GaN High Electron Mobility Transistors make use of a Schottky gate to control a device channel, formed by a vertical heterostructure of $\mathrm{GaN}$ layers. The device channel in this case is a 2-dimensional electron gas (2-DEG), which is formed at the interface of a $\mathrm{GaN}$ and $\mathrm{AlGaN}$ layer due to the polarization and band-gap difference between the two materials.

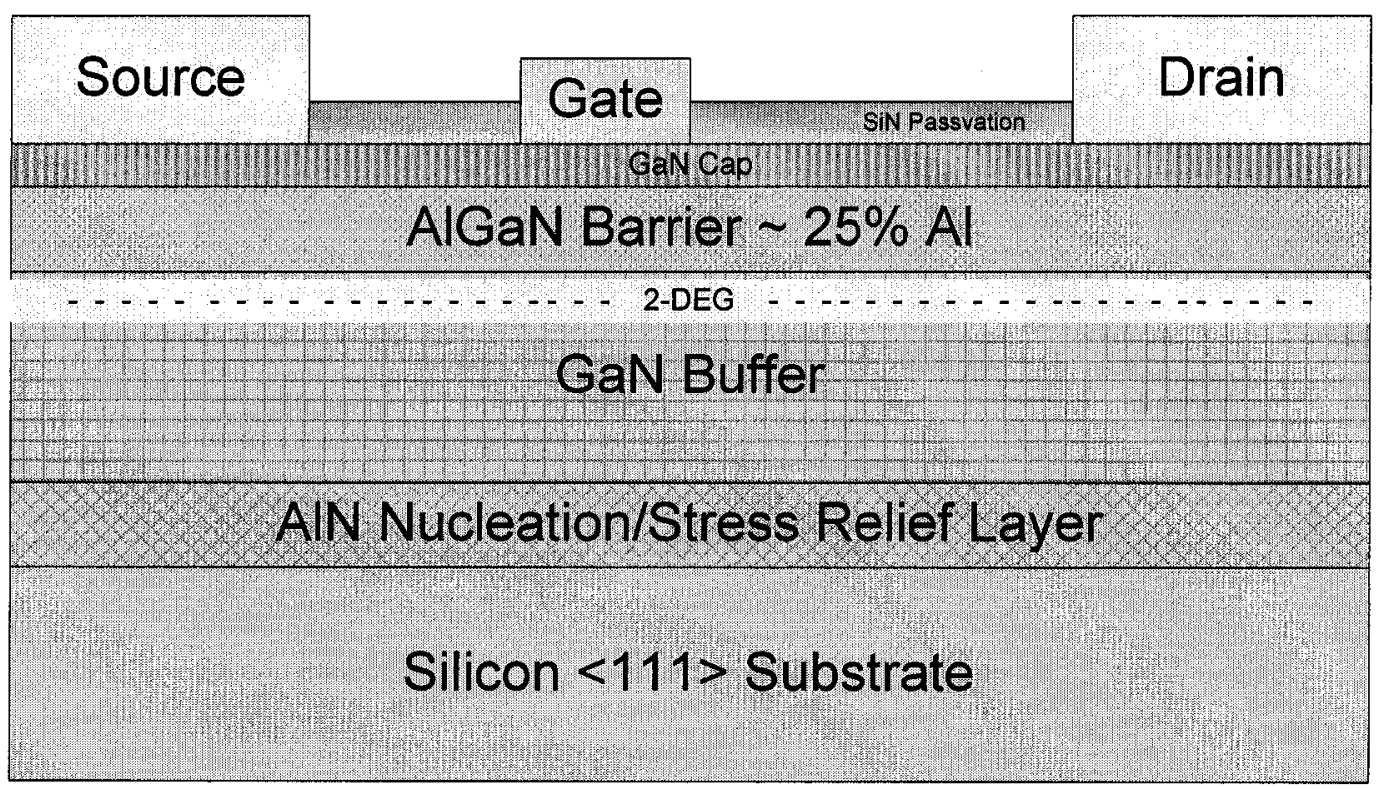

Figure 1: GaN HEMT Layer structure

Figure 1 shows a typical GaN HEMT layer stack, including the location of a 2-

DEG. MOCVD (Metal-Organic Chemical Vapour Deposition) or MBE (Molecular Beam Epitaxy) techniques are used to grow these layers on silicon $<111>$ substrates. Typically, 
a thin aluminum-nitride nucleation layer is used to promote crystal growth on the silicon substrate. This nucleation layer is also used for stress relief between the GaN stack and the silicon substrate. In order to improve stress relief, multiple AlN/GaN stacks are grown on top of each other before the final GaN buffer layer is grown. The GaN buffer layer is typically in the order of 1 to $2 \mu \mathrm{m}$ thick in order to minimize the number of dislocations at the crystal surface. A thin AlGaN barrier layer, typically in the order of $10-100 \mathrm{~nm}$, is then grown in order to produce an electron-confining heterojunction and form the 2-DEG. Extremely thin ( 10 $)$ GaN cap layers have also been deployed on the top of the structure in order to increase the Schottky barrier height of the gate contact [Yu, 1998]. In addition, the GaN cap layer improves reliability by preventing the oxidation of aluminum in the $\mathrm{AlGaN}$ barrier layer. A silicon-nitride passivation layer is used in order to increase device performance and reliability through the mitigation of surface traps caused by polarization effects of the AlGaN layer [Vetury, 2001].

Thin-film metal stacks are used to form ohmic contacts to the source and drain. Typical strategies include the use of $\mathrm{Ti} / \mathrm{Al} / \mathrm{Ti} / \mathrm{Au}$ or $\mathrm{Ti} / \mathrm{Al} / \mathrm{Ni} / \mathrm{Au}$ stacks, which are subsequently rapid thermal annealed at around $850^{\circ} \mathrm{C}$. Schottky gates are formed using Pt/Au or Ni/Au stacks. Unlike conventional silicon MOSFETs, the HEMT is in the "ON" state when no voltage is applied to the gate. If a potential is placed across the drain to the source, current will flow. Once a negative potential is placed on the gate, a depletion region is formed, which reduces the concentration of carriers in the 2-DEG. The negative potential, which fully turns off the channel, is known as the pinch-off voltage. The high mobility of the 2-DEG layer and large GaN band-gap allow for high-gain, high frequency 
GaN Technology and Thermal Overview

and large voltage operation. Current $\mathrm{GaN}$ device performance has exceeded the $7 \mathrm{~W} / \mathrm{mm}$ power level at $10 \mathrm{GHz}$ and $12 \mathrm{~W} / \mathrm{mm}$ at $2 \mathrm{GHz}$ [Dumka,2004][Johnson,2004].

\subsection{Heat Generation in GaN devices}

Three primary sources of heat in semiconductor devices are as follows: radiative heating, joule heating, and electron-hole recombination. Because of the lack of holes in HEMT devices, electron Joule heating caused by the motion of electrons in materials, is the primary source of heat. If we ignore the small gate current, the total heat generated is equal to $I_{d s} V_{d s}$, which is the power in the device. Due to the high voltages and currents generated in $\mathrm{GaN}$ devices, large quantities of heat are generated in the transistor. If one considers a $300 \mu \mathrm{m}$ wide $\mathrm{GaN}$ power transistor that can generate $8 \mathrm{~W} / \mathrm{mm}$ of power deployed in a power amplifier operating in Class A with a power added efficiency (PAE) of 50\%. A simple calculation shows that 2.4 Watts of power is dissipated as heat in the device, which produces an large heat flux in the transistor region.

The heat generation region is the site of the peak electric field. This area is the pinch-off region directly under the gate on the drain side, which was verified experimentally for AlGaN/GaN HEMTs by Kuball et al [Kuball, 2002]. For modeling purposes, the source of heat can be approximated as a flat rectangular region under the gate on the drain side as shown in chapter 3. 


\subsection{Heat Conduction in Semiconductors}

The manner in which heat spreads throughout a semiconductor device is through conductive heat flow, which is governed by the heat transfer equation also known as Fourier's law shown below:

$$
q(x, y, z)=-k \nabla T(x, y, z)
$$

where $q$ is the heat flux $\left(\mathrm{W} / \mathrm{m}^{2}\right)$, and $\mathrm{k}$ is the thermal conductivity of the medium $(\mathrm{W} / \mathrm{m} \cdot \mathrm{K})$ [Bejan, 2003]:. $T$ and $x, y, z$ denote temperature $(\mathrm{K})$ and position $(\mathrm{m})$.

This time-independent form of Fourier's law assumes an infinite speed of propagation of heat, making it only useful for steady-state problems. In order to account for finite carrier time, an extra term including the factor $\tau$ has been included in Fourier's law, where $\tau$ represents the relaxation time of the heat carrier:

$$
\tau \frac{\partial q(x, y, z, t)}{\partial t}+H(x, y, z, t)=-k \nabla T(x, y, z, t)
$$

where $H$ is the volumetric heat generation, or power density $\left(\mathrm{W} / \mathrm{m}^{3}\right)$ [Celo, 2001]. A short relaxation time reduces this equation to Fourier's law (2.1). It is also useful to define a thermal resistance for heat conduction, which is analogous to electrical resistance.

$$
R_{t h}=\frac{T_{1}-T_{2}}{H}=\frac{L}{k A} \quad[\mathrm{~K} / \mathrm{W}]
$$

In this case, $L$ is the path length between two points and $A$ is the cross-sectional area [Bejan, 2003]. This is useful from a modeling perspective as a system can be 
approximated with a series of thermal resistances. The relaxation time, $\tau$, is also related to thermal resistance in the following manner:

$$
\tau=R_{t h} C
$$

where $C$ is the heat capacity of the material $(\mathrm{J} / \mathrm{K})$ [Celo, 2001]. It can be noted that this is similar to the electrical time constant. Two other forms also exist for the time-dependent heat flow equation.

$$
\begin{aligned}
& \rho c_{p} \frac{\partial T(x, y, z, t)}{\partial t}=k \nabla^{2} T(x, y, z, t)+H(x, y, z, t) \\
& \frac{1}{\alpha} \frac{\partial T(x, y, z, t)}{\partial t}=\nabla^{2} T(x, y, z, t)+\frac{H(x, y, z, t)}{k}
\end{aligned}
$$

where $\rho$ is the density of the material and $\alpha$ is the diffusion constant of the material $\left(\mathrm{m}^{2} / \mathrm{s}\right)$ [Celo, 2001]. $c_{p}$ is the specific heat of the material $(\mathrm{J} / \mathrm{kg} \cdot \mathrm{K})$. The thermal conductivity $(k)$ is a material property that is not always constant, but rather a decreasing function as temperature rises for all semiconductor materials. Hence, the equation for timeindependent heat flow is as follows:

$$
q(x, y, z)=-k(T) \nabla T(x, y, z)
$$

and the time-dependant equation becomes [Smy, 2001]:

$$
\rho c_{p} \frac{\partial T(x, y, z)}{\partial t}+H(x, y, z, t)=\nabla(k(T) \nabla T(x, y, z))
$$

These partial differential equations, (2.6) and (2.7), are solved numerically using ATAR in order to model heat flow in semiconductor devices. The manner in which this is performed will be discussing in section 3.1. 


\subsection{Implications of Thermal management on Semiconductor Devices}

Heat is not desired in semiconductor devices. Self-heating in the transistor degrades electrical performance due to reduced electron mobility and electron saturation velocity, which are two properties that make $\mathrm{GaN}$ an attractive technology [McAlister, 2006]. Figure 2, an IV curve for an AlGaN/GaN HEMT demonstrates these effects.

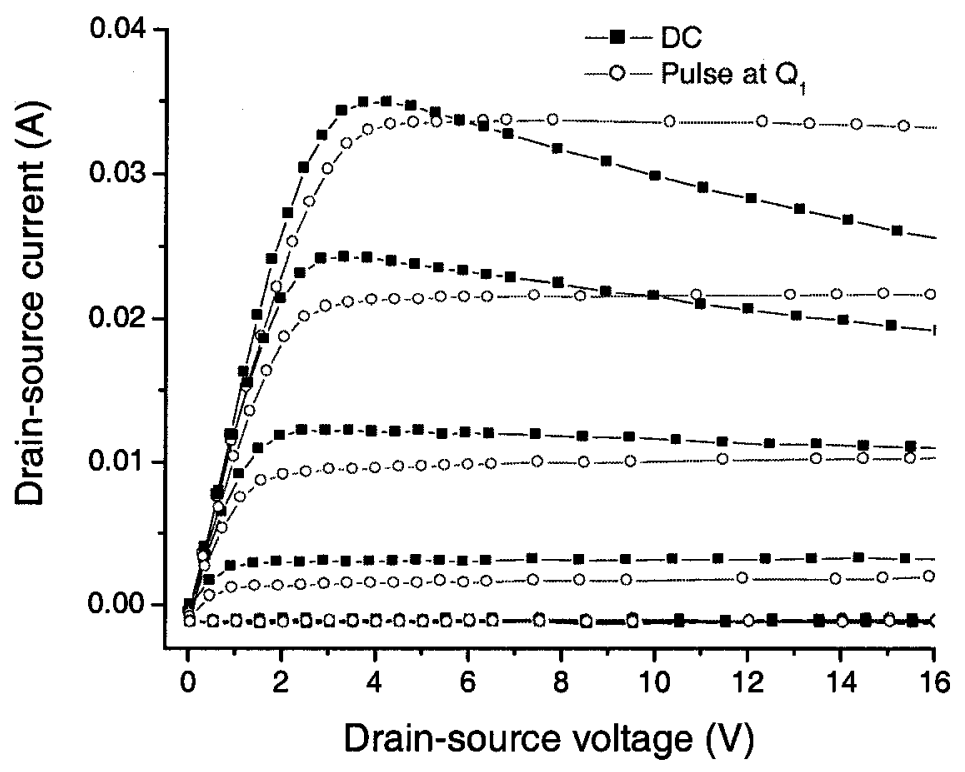

Figure 2: AlGaN/GaN DC characteristics with and without self-heating effects (National Research Council of Canada)

Notice that as the voltage increases, the current falls off, which is caused by a decrease in electron mobility in the $2 \mathrm{DEG}$ due to the device getting hotter. Tan et al have shown that the mobility of the channel falls off as $\mathrm{T}^{-0.5}$ for AlGaN/GaN 
short channel devices $(<1 \mu \mathrm{m})$ and $\mathrm{T}^{-1.5}$ for long channel devices $(>5 \mu \mathrm{m})[\mathrm{Tan}$, 2006]. Excessive heat can also lead to thermal breakdown. The mechanism that causes this is hot electron generation and impact ionization, which occurs when electrons in the HEMT channel obtain energies greater than the band-gap due to high voltages and rises in temperature [Borgarino, 2000].

$\mathrm{RF}$ performance is also hampered by self-heating, resulting in a reduction in transistor gain and a large increase in thermal noise. Noise generation is also a large issue in RF circuits, and increases as a function of temperature. Heat increases the resistivity of aluminum or copper interconnects, which increases the RC time constant of the lines and hence increases signal delay, limiting the operating frequency of the chip [Rose, 1999].

CMOS is also affected by self-heating in the same manner; however it cannot withstand the high temperatures that $\mathrm{GaN}$ can, making it more susceptible to reliability issues. This refers to the breakdown of device components due to excessive heat. The electro-migration process in interconnects is accelerated due to high heat, eventually causing chip failure due to broken connections. Mismatches in thermal expansion coefficients between two materials can lead to elevated stresses, resulting in the physical breakdown of semiconductor components.

Although a primary advantage of $\mathrm{GaN}$ is that it can operate at temperatures upwards of $300{ }^{\circ} \mathrm{C}$, the issue of performance degradation remains. Therefore, it is beneficial to reduce the operating temperature of the device at all times. The choice of substrate has a very large effect on the thermal performance. 
This is the reason that silicon-carbide substrates offer the greatest performance as they have a thermal conductivity of $4.5 \mathrm{~W} / \mathrm{cm} \cdot \mathrm{K}$ [Eastman, 2002]. The use of silicon substrates $(\mathrm{k}=1.5 \mathrm{~W} / \mathrm{cm} \cdot \mathrm{K})$ presents a thermal design challenge that must be overcome in order to take advantage of this technology, especially for power devices. A complete thermal study is necessary to ensure proper thermal isolation between the GaN power devices and CMOS circuitry in this proposed technology. 


\section{Chapter 3}

\section{Thermal Simulation}

\subsection{ATAR}

ATAR is a 3-D thermal modeling tool, which was developed at Carleton University by Dr. T.J. Smy [Smy, 2001]. This tool uses the finite difference method to solve the heat transfer equations (2.6) for steady-state or transient problems. The main advantage of ATAR is its ease of use and extremely fast simulation time. ATAR has the ability to generate an accurate model based on layout and technology information provided by the user. The remaining information required includes some simple data regarding the location and the intensity of the heat source. Using these data, ATAR can generate an accurate solution without having to consider any electrical effects, and hence reduce the problem to strictly thermal. This method offers a large advantage over commercial software, which requires detailed model information and long simulation times to solve a complete electro-thermal problem. A commercial simulator, Femlab, was used at the beginning of this research, but was quickly abandoned due to the large computer resources and simulation time required to generate a solution.

Once a structure has been defined by the user, ATAR transforms it into a 3-D quad-tree mesh of different sized rectangles, representing a network of thermal resistances and capacitances. The thermal resistance between blocks is calculated as per equation 2.3. Different sized blocks are used to represent regions of different thermal importance. 
A high-density mesh of blocks is used where the heat source is placed in order to generate an accurate solution. An algorithm is used that allows a block to have a maximum connection of two blocks on any vertical side and four blocks on the top or bottom. The result of this meshing is that as the distance from the heat source increases, the block size becomes larger because the temperature distribution has a much smaller gradient. This method substantially reduces simulation times while still generating an accurate solution.

Another advantage of ATAR is that it allows for small changes to be made in the model in a simple fashion because the technology has already been established. This enables the user to investigate the result of changes quickly, whether they are geometrical or structural, by generating multiple models easily. This functionality is extremely useful, as it allows the user to determine which aspects of the model have the greatest thermal impact in a timely manner. Model linkage is also available, which is quite useful when working with multiple devices on one substrate. Keeping the substrate and device as separate models allows for different locations of the device to be examined as well as the orientation of multiple devices to be examined without having to generate multiple models. This added flexibility is especially useful when conducting large-scale projects that include many devices.

Boundary conditions are typically set by specifying a constant temperature somewhere in the structure, typically at the bottom of the substrate. The sides of the model are generally set to an adiabatic boundary condition. This produces an accurate solution for a sufficiently large model. This zero-flow condition can also be used as a 
thermal mirror. Using this condition, it is possible to take advantage of symmetry and only have to model a fraction of the structure in order to find a solution.

Two simulation modes are available in ATAR: steady-state and transient. The steady-state simulation solves a large matrix of the time-independent heat equations using a direct solver for problems with a temperature independent thermal conductivity. An iterative approach using successive over-relaxation is used for temperature-dependent thermal conductivities, which simply uses the direct solver multiple times as the thermal conductivity is adjusted with temperature. For transient problems, the time-dependent heat equation is solved (2.6) using the transmission line method (TLM). TLM represents the model as a matrix of transmission lines with voltage pulses traveling through them, which is analogous to the flow of heat through the semiconductor.

\subsection{Proposed Fabrication Process}

An overview of the proposed integration process is needed in order to understand the thermal simulation models that are used in this work. This process starts with a silicon $<111>$ wafer with pre-grown GaN HEMT layers. An outline of the major processing steps is given in Figure 3. 
Thermal Simulation

1. Starting Materials

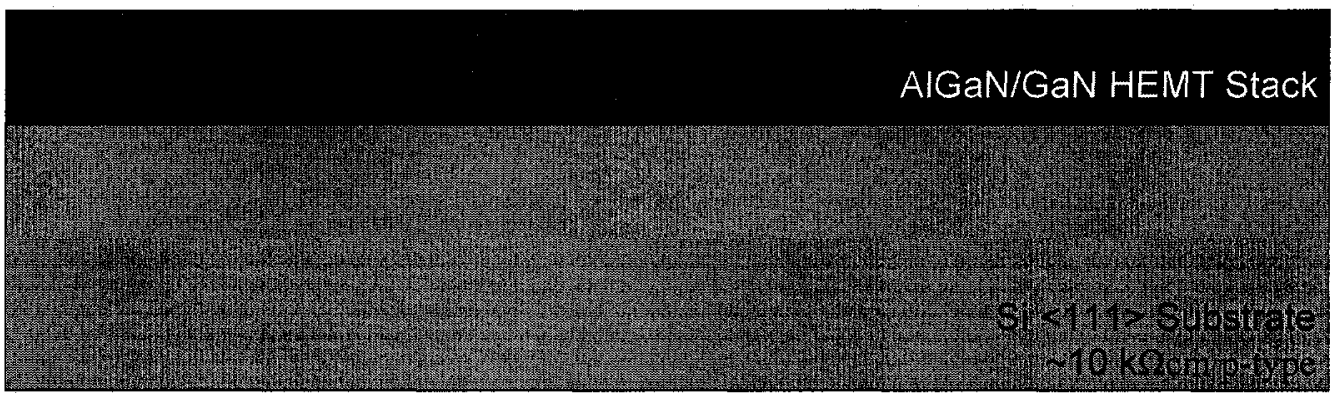

\section{AIGaN/GaN Stack Etch} and Wafer Smoothing
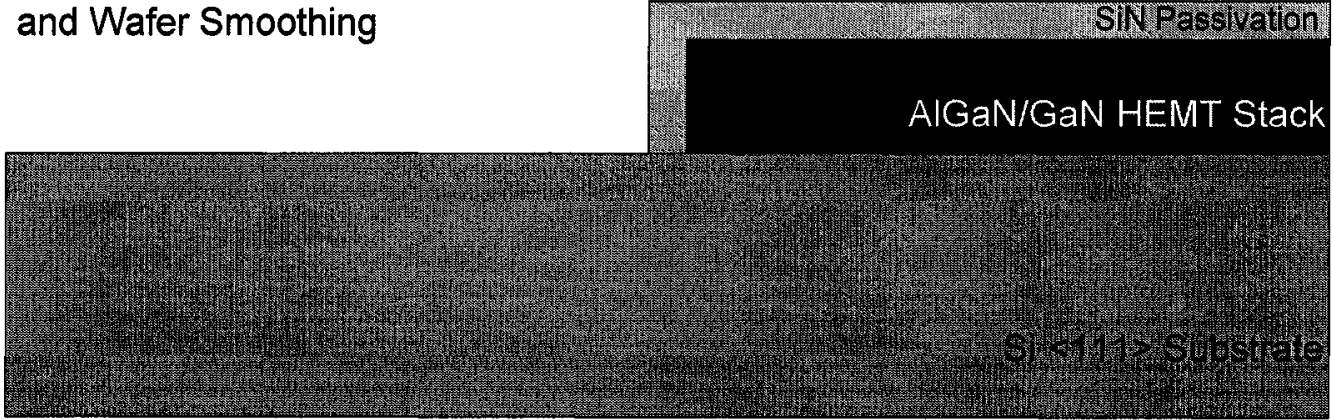

\section{NMOS Processing}

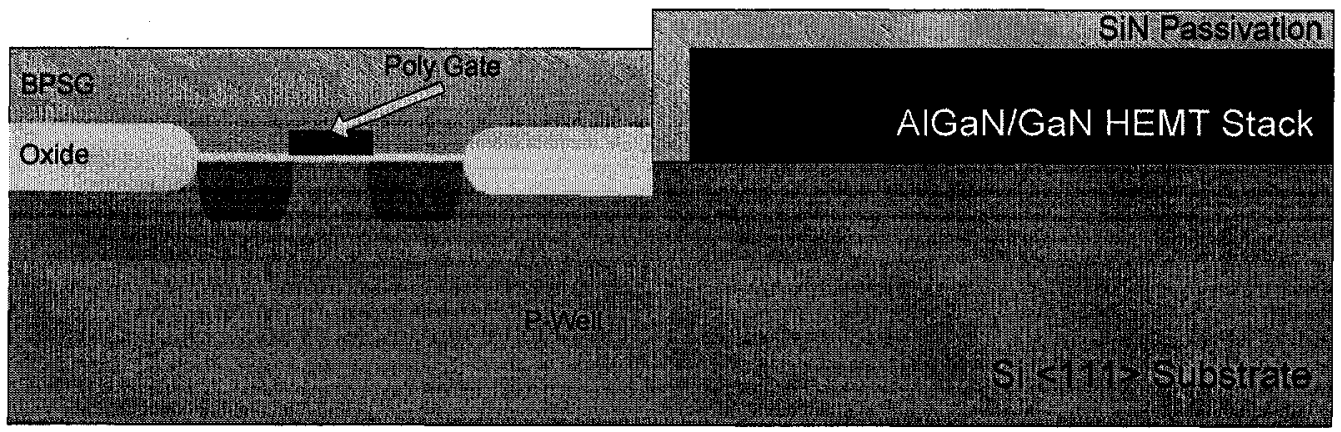




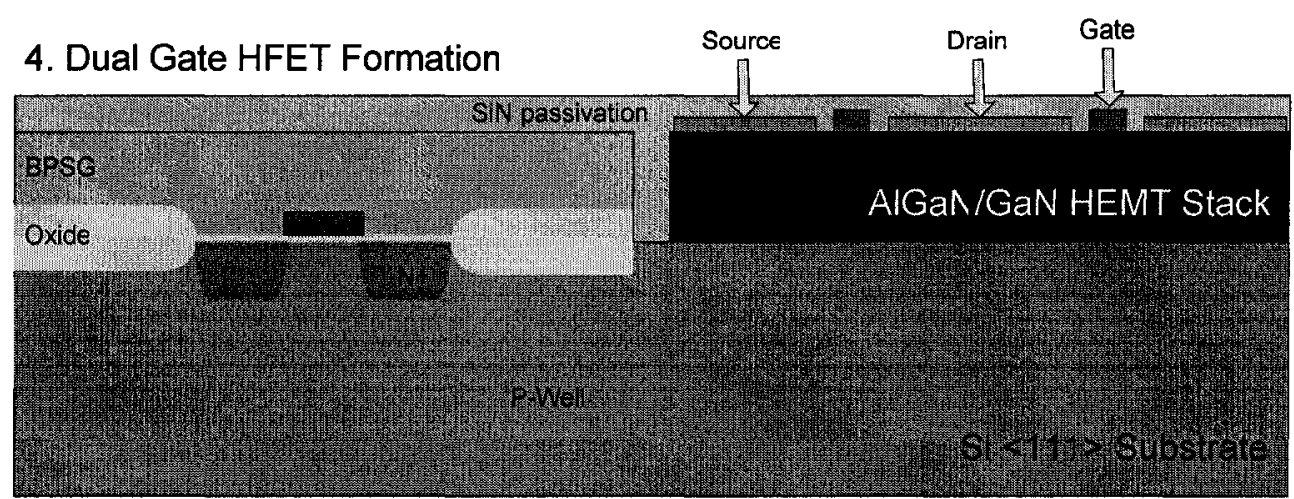

\section{Metallization and CPW formation}

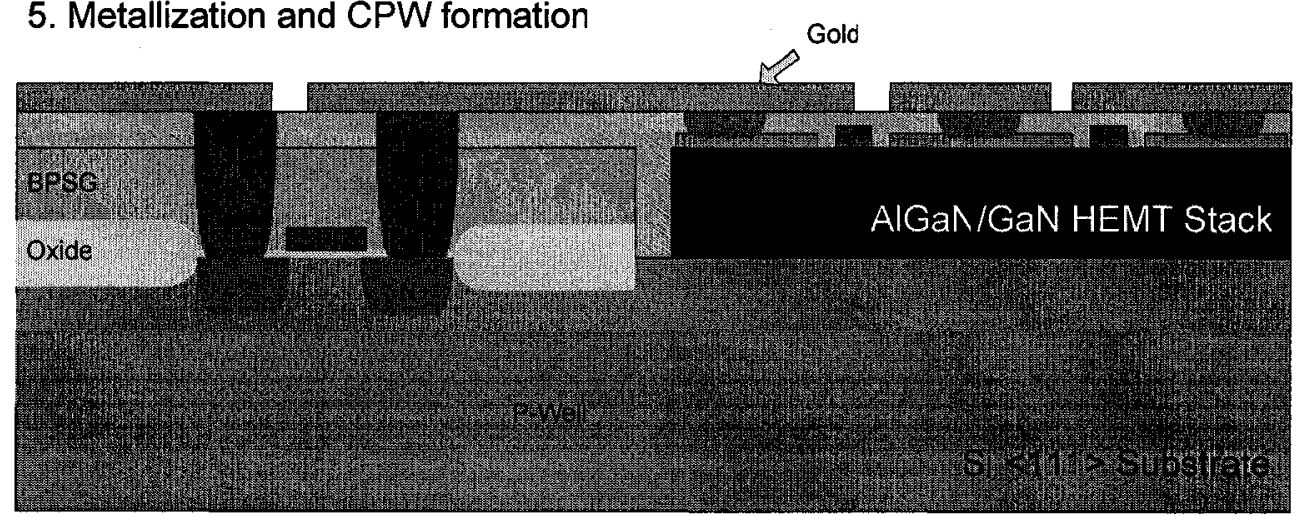

\section{Figure 3: Summary of GaN/CMOS integration process}

The process revolves around isolating the $\mathrm{GaN}$ layers into islands on which the high-power HEMTs can be fabricated. This leaves the rest of the surface for CMOS and passive components. Using silicon as a substrate for the passives rather than the $\mathrm{GaN}$ stack is advantageous in this case, as the high-resistivity silicon allows for lower substrate loss, and therefore, higher $\mathrm{Q}$ components. While there are other ways to approach this problem, this is the most logical approach at this point as selective GaN growth wafers are not widely available at this time.

The first major step in the process is to isolate the GaN islands for HEMT processing using a GaN etch followed by smoothing to prepare the silicon surface for 
CMOS processing. The typical thickness of a GaN HEMT stack is between 1.75 to $2 \mu \mathrm{m}$.

The GaN islands are then passivated with a nitride layer in order to protect the surface during the CMOS processing. The high-temperature oxidation steps required for the CMOS processing require it to occur prior to the HEMT fabrication. Otherwise this would be detrimental to the HEMT devices as the high temperatures will impact the contacts and Schottky gate as well as possibly cause cracking due to the elevated stress in the GaN/silicon interface. Once the CMOS processing is complete, the HEMT devices are fabricated while the CMOS is covered with a BPSG (borophosphosilicate glass) insulating layer. Once all the devices have been formed, metallization connects all devices together and forms the passive components in order to complete the processing. A simple 3-D model, which accurately represents this proposed approach is necessary in order to properly examine the thermal behaviour.

\subsection{Simulation Models}

The model structure used in this work is divided into two components, the substrate and the transistor models, which are linked together during the simulation using a continuous boundary condition at all interfaces. This method has the advantage of allowing for different transistor topologies to be used, without having to regenerate a substrate model. Simulation time is also saved by not having to reconstruct the same substrate model each time a simulation is performed. 


\subsubsection{Substrate Model}

The substrate model provides the link between the HEMT device and the chip package, which is realized by applying boundary conditions to either the topside or backside of the chip. Two different packages are examined, a flip-chip package as well a surface mount configuration. For a flip-chip package, a $300 \mathrm{~K}$ boundary condition is imposed at the surface of four $20 \mu \mathrm{m}$ high gold bumps placed symmetrically around the transistor. The thickness of $20 \mu \mathrm{m}$ is the minimum thickness needed to ensure that CPW performance is not affected by the package [Kusamitsu, 1999]. A surface mount package is simply simulated by applying a boundary condition of $300 \mathrm{~K}$ to the bottom of the silicon substrate.

As shown in Figure 4, the substrate model consists of a silicon slab, on which there is a centre gap for the GaN transistor model. Around this gap, there is a $1.8 \mu \mathrm{m}$ thick insulating layer, which represents the BPSG layer used in CMOS processing. This layer is set to have a thermal conductivity of $1.2 \mathrm{~W} / \mathrm{cm} \cdot \mathrm{K}$, which is the thermal conductivity of silicon dioxide. A metallization structure consisting of a $0.2 \mu \mathrm{m}$ thick gold layer is used to approximate a CPW structure providing electrical connection to the GaN transistor. There are two CPW lines, one for the gate and one for the drain, as well as two large ground planes for the source. An epoxy fill, which is typically used for flipchip mounting, is not included in this model. 


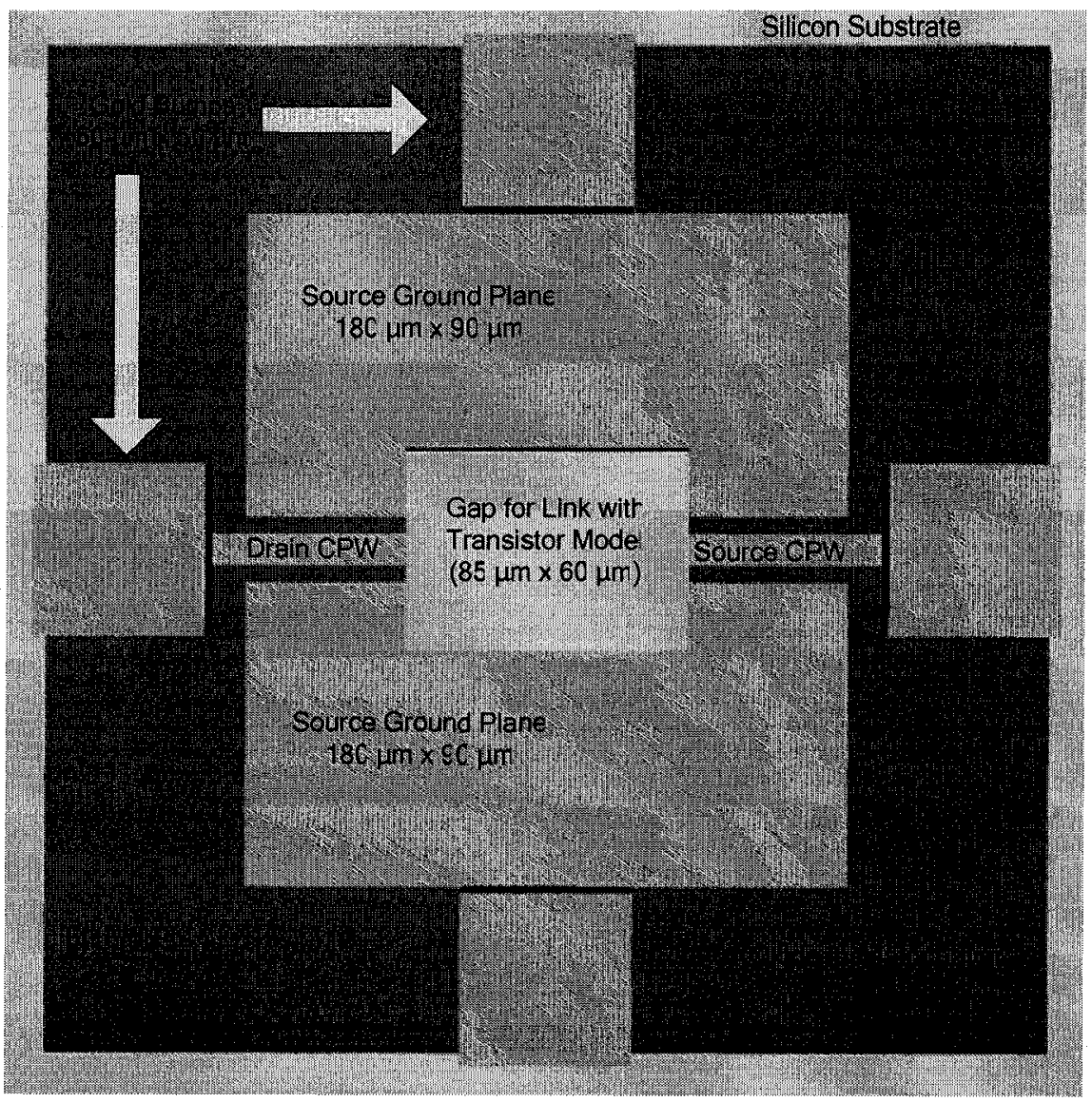

Figure 4: Plan view of ATAR substrate model

A thermal conductivity of $145 \mathrm{~W} / \mathrm{m} \cdot \mathrm{K}$ is used for silicon, and a value of 318 $\mathrm{W} / \mathrm{m} \cdot \mathrm{K}$ is used for the gold layer. A continuous boundary setting is given to the gap for the transistor model such that heat can flow both down and sideways into the substrate model.

\subsubsection{Transistor Models}

A six-fingered, $300 \mu \mathrm{m}$ wide high-power device is used for simulations in this work. In order to examine a challenging thermal scenario, the transistor is designed to be quite compact, which will result in a high thermal flux between the transistor and the 


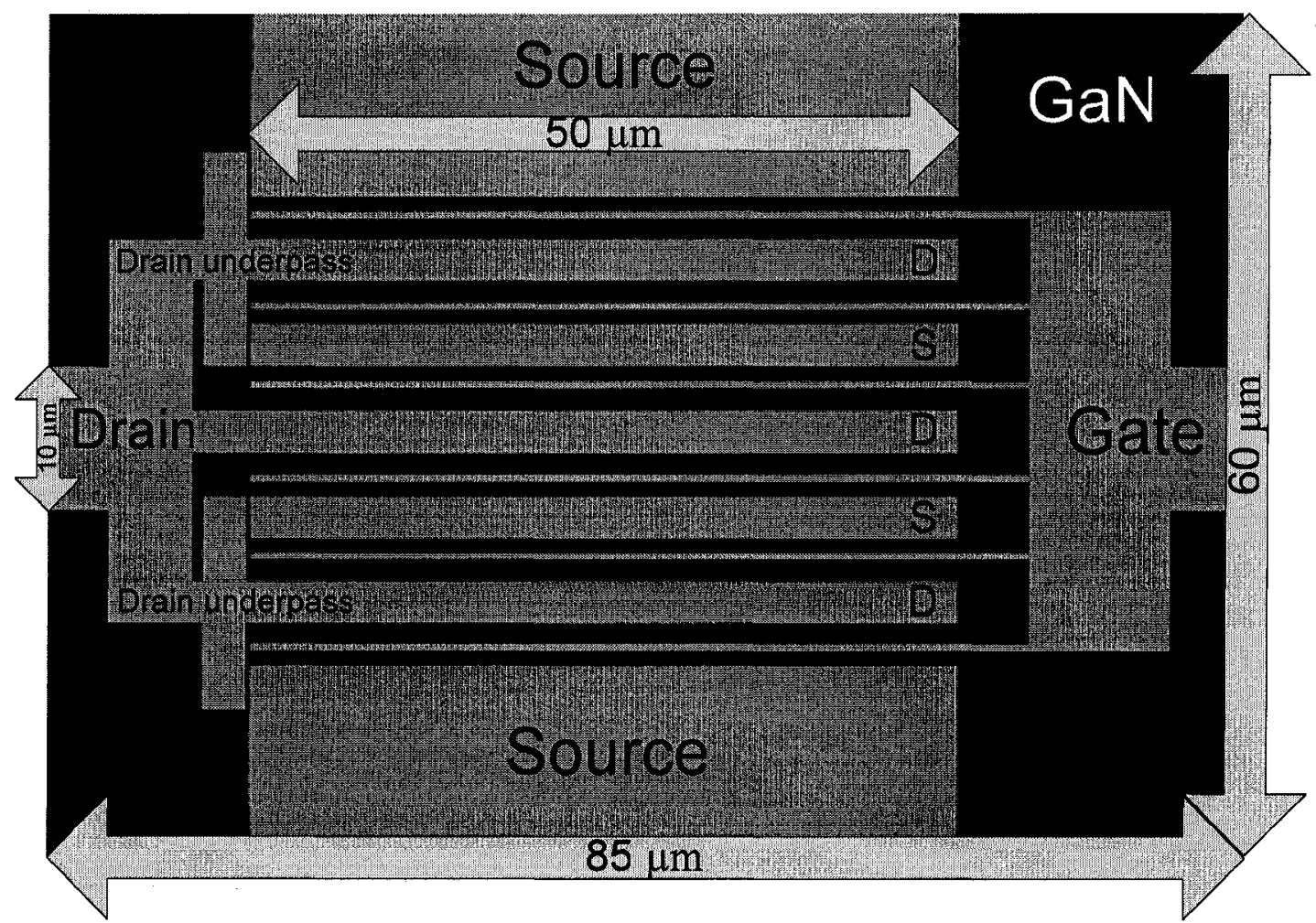

Figure 5: Plan view of ATAR transistor model

The inner source metal is connected using two air bridge structures, an approach common in multi-fingered transistors. The source, gate and drain metallization connect with the substrate model previously presented. The structure consists of a $1.8 \mu \mathrm{m}$ thick $\mathrm{GaN}$ island with a $0.2 \mu \mathrm{m}$ thick mesa on which the active area of the device is formed. The metallization is uniformly $0.2 \mu \mathrm{m}$ thick except for the Schottky gate and ohmic contacts, which are $0.25 \mu \mathrm{m}$ thick. The gate length is $0.5 \mu \mathrm{m}$ and the gate to gate spacing is set at $6 \mu \mathrm{m}$. The gates roll-off the edge of the mesa and connect to the gate metallization is shown in Figure 6. 


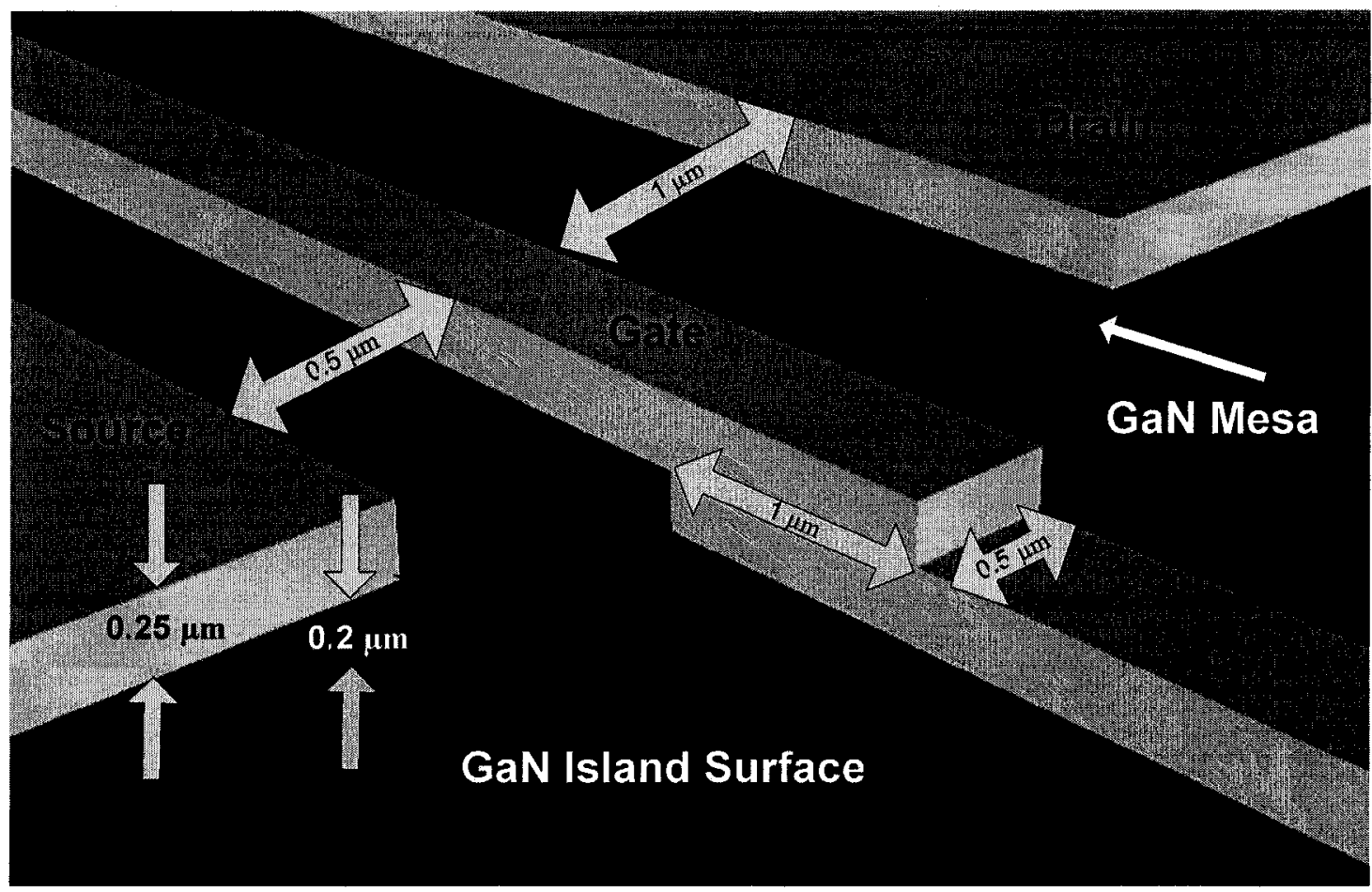

Figure 6: Transistor model showing gate roll-off

This figure also illustrates the asymmetric placement of the gate on the source side of the transistor. For simplicity, the Schottky gates and ohmic contacts have been approximated with gold rather than using multi-layer thin-film stacks. This approximation is valid as gold is the thickest layer on these stacks, and dominates the flow of heat due to its high thermal conductivity $(318 \mathrm{~W} / \mathrm{m} \cdot \mathrm{K})$ compared to that of platinum $(71.6 \mathrm{~W} / \mathrm{m} \cdot \mathrm{K})$, nickel $(90.7 \mathrm{~W} / \mathrm{m} \cdot \mathrm{K})$ and titanium $(21.9 \mathrm{~W} / \mathrm{m} \cdot \mathrm{K})$. The chip metallization is also gold, which is common in MMIC technology. It should be noted that aluminum and copper are both alternatives that can be used in this case, as they have similar electro-thermal properties. 
The thermal conductivity of $\mathrm{GaN}$ has a strong temperature variation and is therefore treated as the following second-order polynomial as per Kawamura et. al. [ Kawamura, 2005].

$$
k(T)=T_{0}\left(1+k_{T C 1} T+k_{T C 2} T^{2}\right)
$$

Where $T_{o}$ is $367.35, k_{T C l}$ is $-1.76 \times 10^{-3}$ and $k_{T C 2}$ is $8.17 \times 10^{-7}$. The thin aluminumnitride nucleation layer as well as the AlGaN buffer layer found in HEMT stacks are treated as bulk $\mathrm{GaN}$ for simplicity. This can be deemed an acceptable approximation as these layers are typically quite thin with respect to the rest of the GaN stack.

Two air bridges are formed with gold in order to connect the inner source ohmic contacts to the outer contacts.

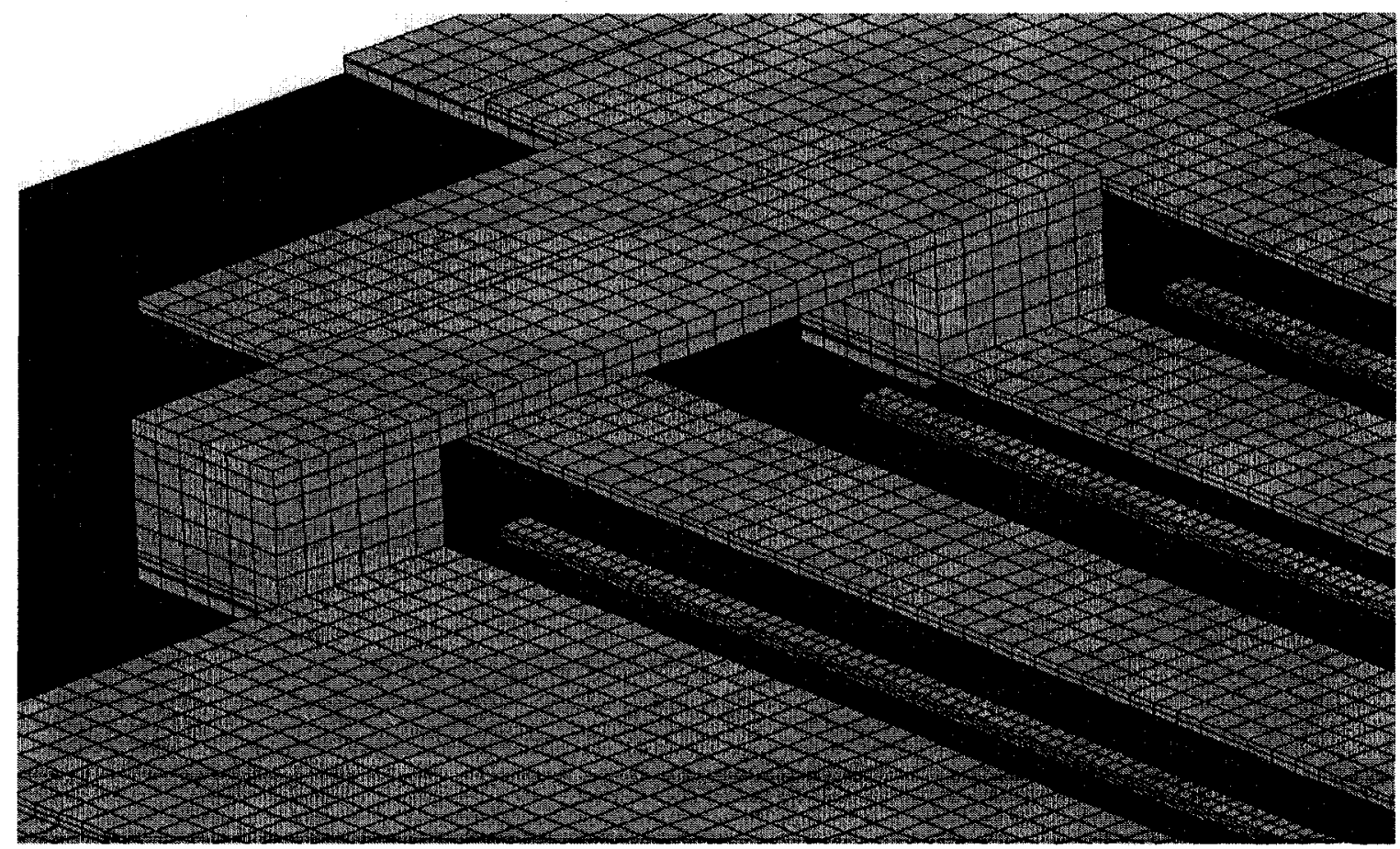

Figure 7: Gold air-bridge connecting inner source metallization 
The drain ohmic contact runs underneath the $2.5 \mu \mathrm{m}$ tall air bridge in order to properly connect to the drain pad. Figure 7 also illustrates the simulation grid, which shows a more concentrated region near the gates and larger blocks as one moves further away.

The final model property that is important to illustrate is the application of the heat source. As discussed in chapter 2, heat is generated on the drain side of the gate, which is the pinch-off region of the device. As illustrated in Figure 8, a thin rectangular region approximating the height of the 2-DEG is used as a heat source in each gate.

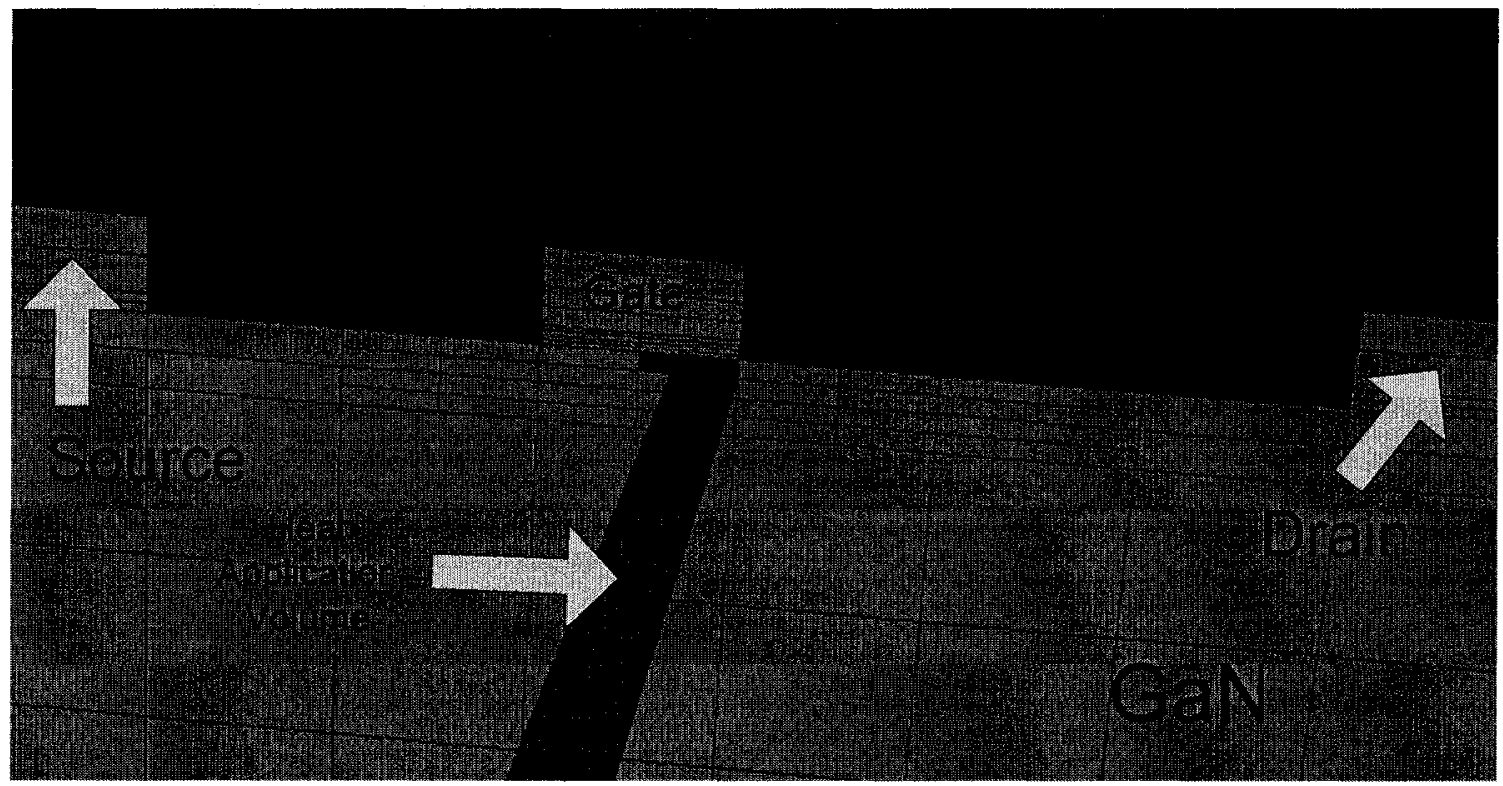

Figure 8: Heat source application in pinch-off region of the device

Figure 8 illustrates the higher grid refinement around the heat source region. ATAR allows for each heat source to dissipate a predetermined amount of power in order to simulate the device's thermal characteristics. 
Thermal Simulation 24

The model presented in this chapter is the basic model used for this work. By investigating the thermal consequences of changing the parameters and structure of this general model, conclusions can be drawn as to what a good thermal design for the integration of CMOS and GaN would include. 


\section{Chapter 4}

\section{Steady-State Simulation}

\subsection{Data Extraction}

This chapter examines the temperature distribution around the model for steadystate operation of the $\mathrm{GaN}$ transistor. Simulations are performed under both packages explained in chapter 3. The heating and cooling behavior of the structure will be examined in the following chapter. As the majority of operation is steady-state, these simulations are the most important to predicting the thermal behavior of the structure.

The area of interest in the simulation model is the interface between the BPSG oxide layer and the silicon substrate outside of the transistor region, as this is the location in which CMOS circuitry would most likely be placed. The temperature in the GaN gate periphery and overall maximum temperature are also recorded as these values give an indication of the heat dissipating properties of the structure. Figure 9 demonstrates the four main areas from which data were extracted. The majority of these cuts are located at the silicon surface of the model. 


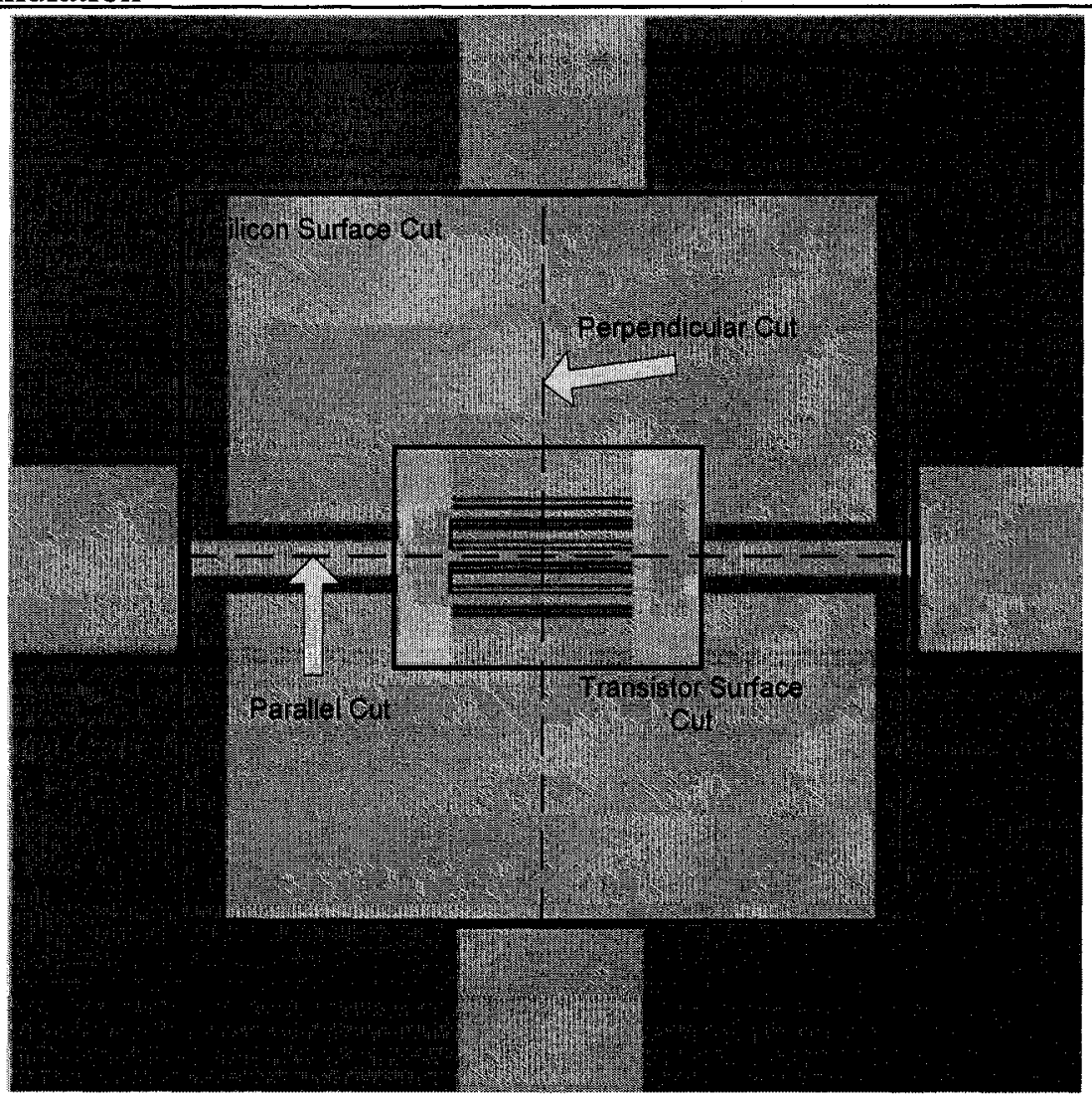

Figure 9: Temperature profile cuts used for simulation

The perpendicular cut is most commonly used in the results as it shows the temperature closest to the $\mathrm{AlGaN} / \mathrm{GaN}$ transistor. Because of the drain and gate pads, the parallel cut typically has a lower temperature profile due to the larger distance from the heat generation region of the HEMT device. Therefore, placing the CMOS circuitry directly along the perpendicular cut of the HEMT should represent the worst-case thermal scenario. A 1-D line extraction has far greater accuracy over a surface cut, which is 2-D. This is because more data points can be extracted without generating cumbersome data files.

The purpose of the 2-D surface cuts is to generate contour plots. These plots allow one to draw qualitative data as to how the heat is flowing in and around the device. The 
silicon surface cut is taken at the silicon/oxide interface, whereas the transistor surface plot is extracted right under the GaN Mesa, as this is the highest continuous layer in the transistor. The heat is generated only $0.2 \mu \mathrm{m}$ higher than this level, to provide a good indication of how the heat is distributed inside the transistor.

Power levels ranging from 0.6 to $2.4 \mathrm{~W}$ are used, meaning that each gate dissipates between 0.1 and $0.4 \mathrm{~W}$, hence, the power density ranges from 2 to $8 \mathrm{~W} / \mathrm{mm}$. Considering that the highest power density in $\mathrm{GaN}$ devices is around $10 \mathrm{~W} / \mathrm{mm}$, this power range is quite reasonable, especially for a small gate length of $0.5 \mu \mathrm{m}$. The maximum device temperature will also be presented as it gives a strong indication of the thermal performance of a chosen structure. Comparing this value between simulations will allow us to see which structural parameters have the greatest impact on thermal performance.

\subsection{Surface-Mount Package}

The following section reports on results for simulations with a backside boundary condition of $300 \mathrm{~K}$. The standard silicon substrate thickness for the model is $256 \mu \mathrm{m}$, however the substrate thickness has been varied for a set of simulations to examine its effect. Figure 10 shows the temperature distribution at the silicon surface for a power dissipation of $2.4 \mathrm{~W}$. 


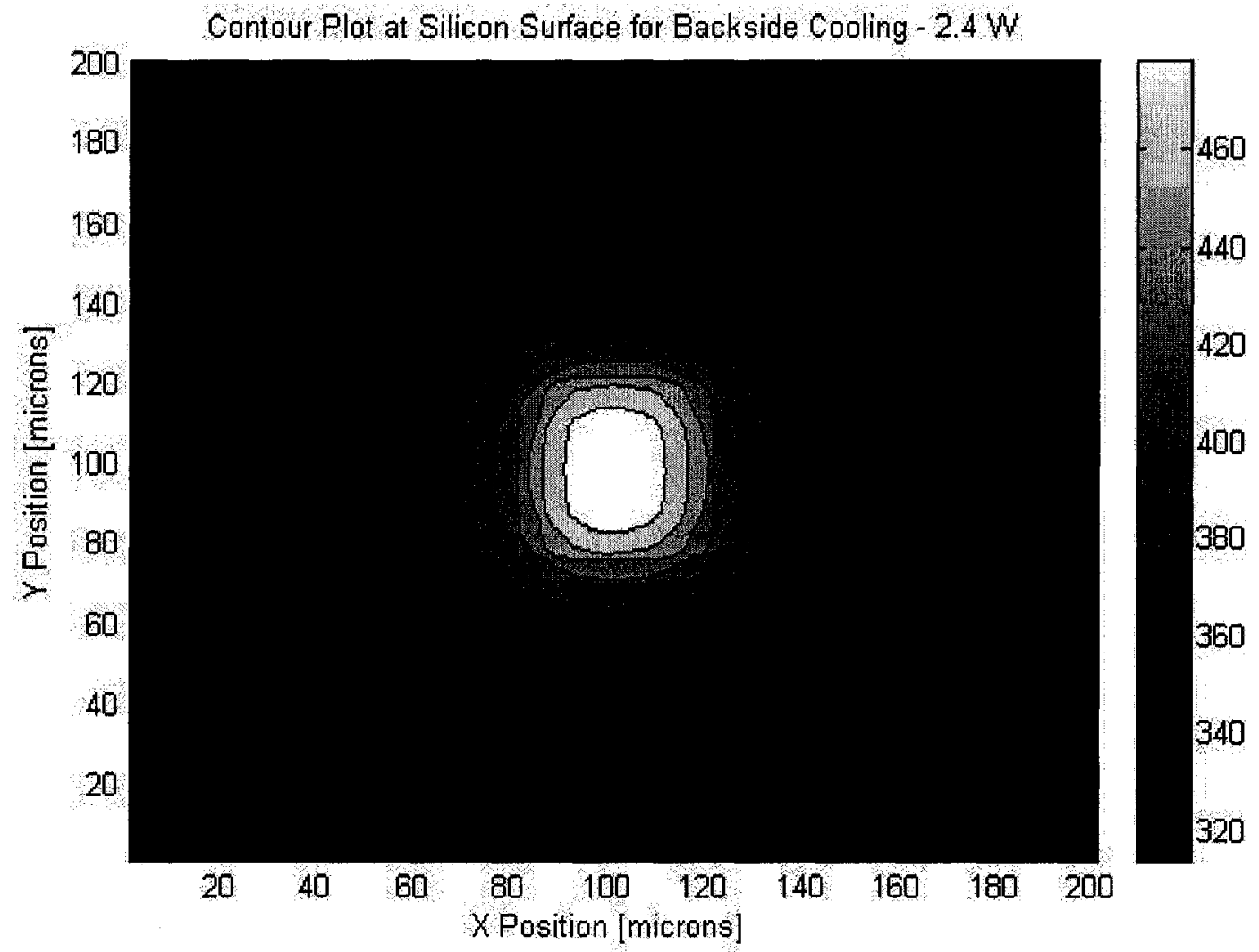

Figure 10: Contour Plot for surface mount package at silicon surface $-2.4 \mathrm{~W}$ power

This plot shows a well defined hot-spot at the centre of the device with temperature falling off quite rapidly at the edges of the GaN stack. As expected, a circular pattern is formed due to the uniform nature of the cooling. This is also quite apparent in Figure 11, which shows a 3-D cross-section plot through the device. 


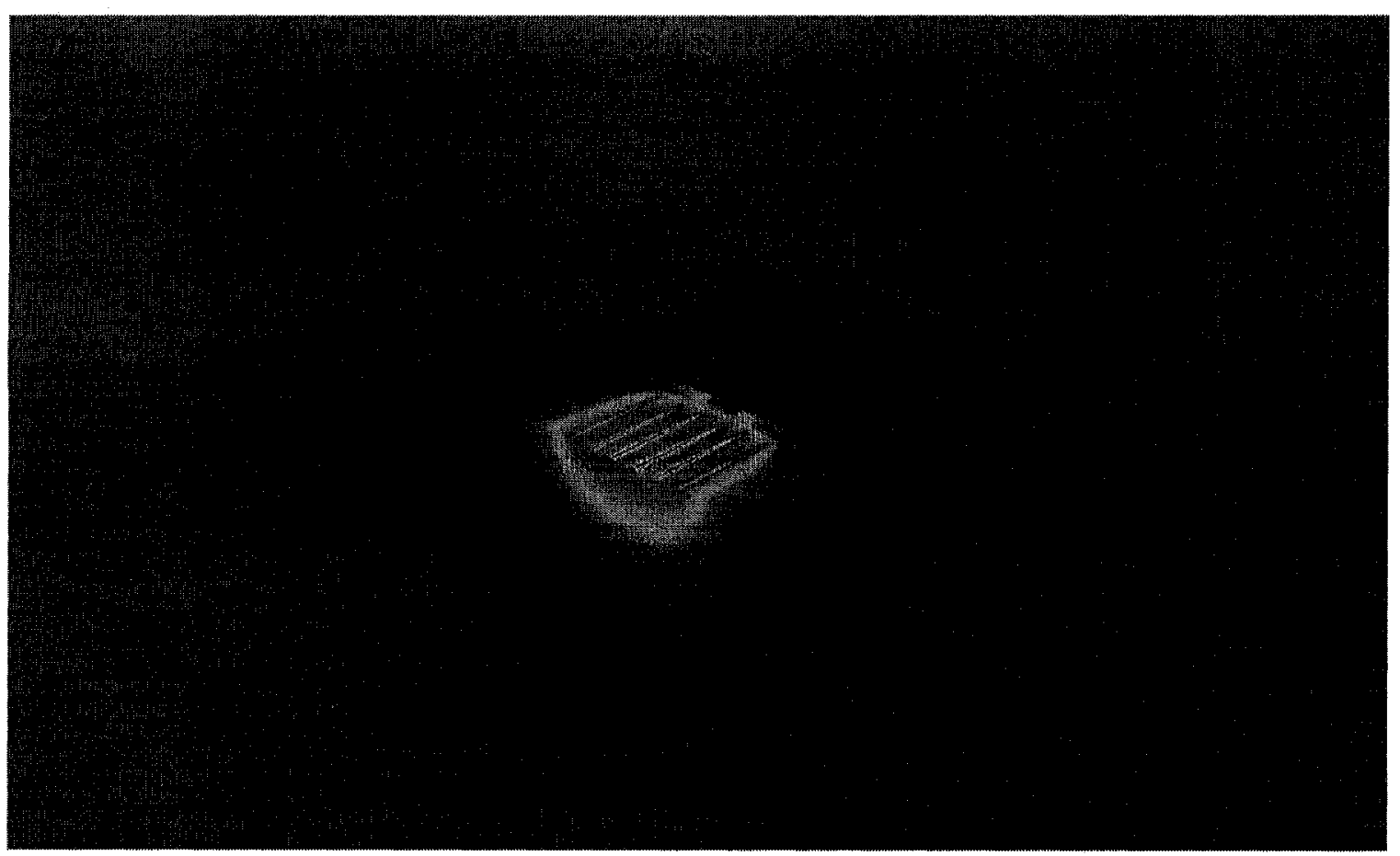

Figure 11: Cross section plot of temperature distribution with surface-mount boundary package 2.1W. Maximum temperature of $566 \mathrm{~K}$.

Plotting temperature versus power along the perpendicular cut at the silicon-oxide interface in the area outside the transistor shows a constant slope as one moves $20 \mu \mathrm{m}$ away from the $\mathrm{GaN}$ stack. 


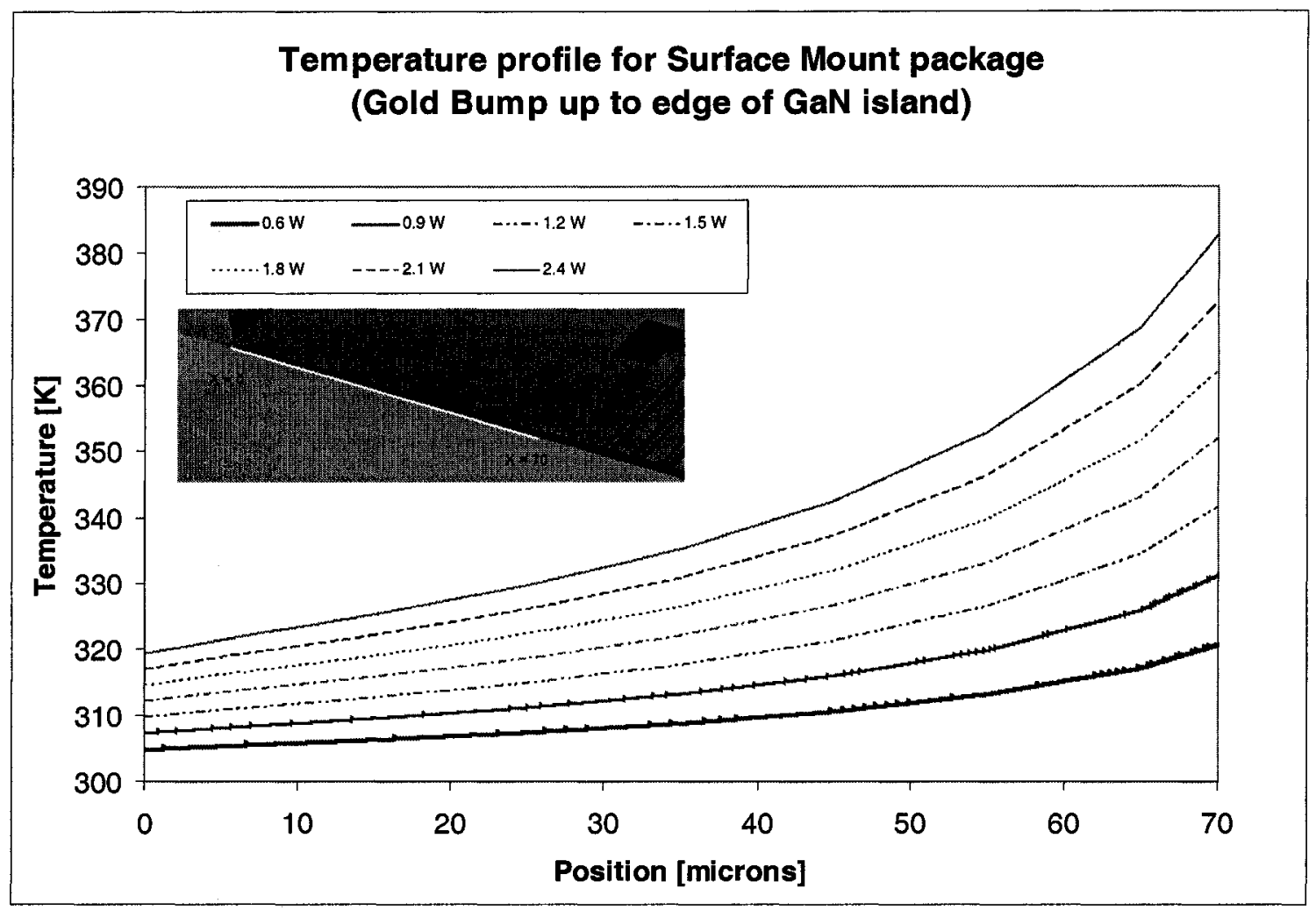

Figure 12: Temperature vs. Power plot for various powers, surface mount package

A linear dependence of temperature on power can be observed from the even spacing of the lines. In this case, the temperature values are quite low, which suggest that CMOS compatibility is achievable for surface-mount cooling. The majority of the temperature rise is therefore local to the transistor.

\subsubsection{Effects of Substrate Thickness}

The main factor that impacts the cooling from the substrate is its thickness. Thinning the substrate is a common technique to improve the thermal performance. A full 
set of simulations were performed with a varied substrate thickness from $50 \mu \mathrm{m}$ to 500 $\mu \mathrm{m}$. Once again, the silicon/oxide interface experiences moderate heating, but in this case the internal device temperatures show a substantial improvement.

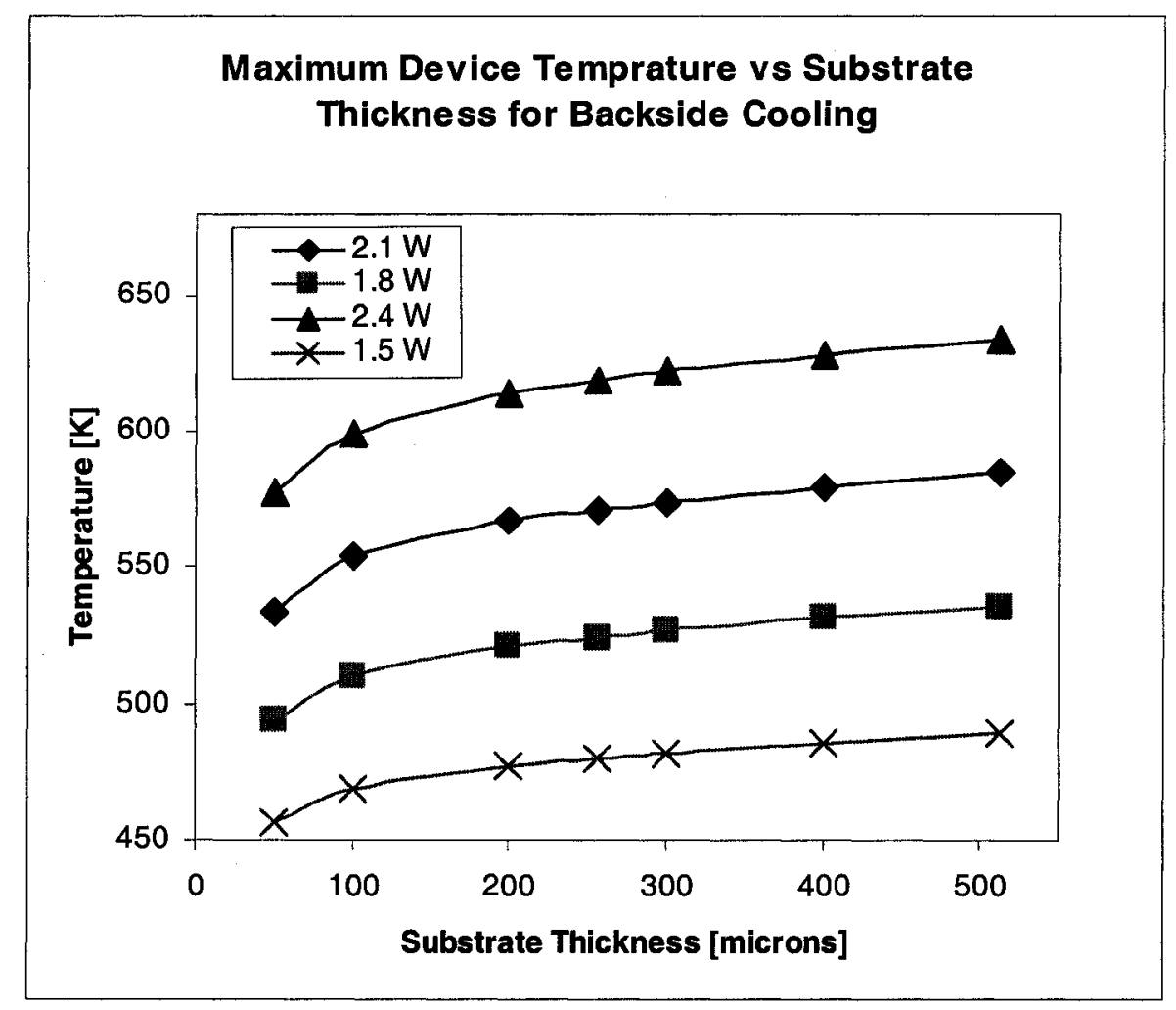

Figure 13: Maximum Device Temperature versus substrate thickness, for various powers

Plotting maximum temperature, located on the drain side of the inner gates at the pinch-off region, versus the substrate thickness for a range of power levels generates a family of almost identically shaped curves (Figure 13). Large improvements in temperature are visible as the thickness is reduced to values lower than $100 \mu \mathrm{m}$. One concern about thinning the wafer is that the smoothing process may add stress to the GaN/silicon interface, which can result in physical damage such as cracking.

These curves can also be compared to the thermal resistance of the devices, which can be calculated analytically using the formalism of Darwish et. al., using the device 

parameters of the transistor such as gate length, gate width, gate pitch, layer thickness, and thermal conductivity [Darwish, 2004]. Figure 14 plots the thermal resistance versus the substrate thickness generating a curve similar to that of Figure 13.

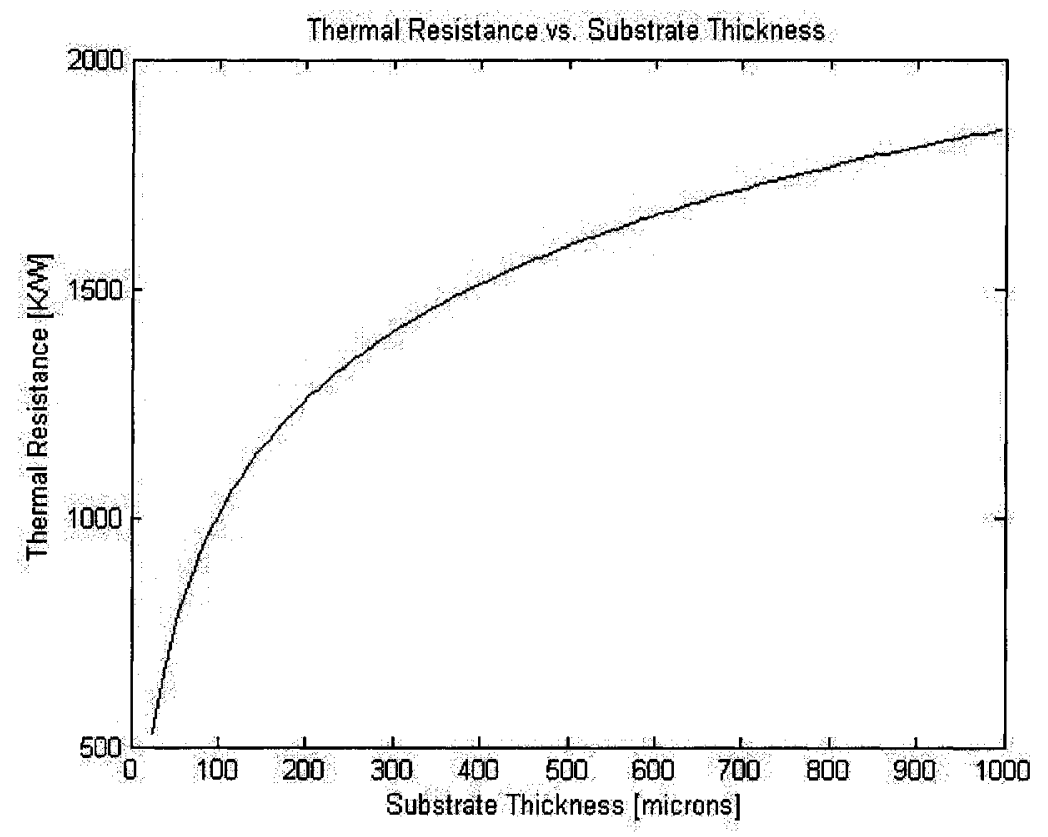

Figure 14: Analytically calculated thermal resistance versus substrate thickness

Some differences between the simulated and analytic curves are that the simulated temperature has a much shallower slope after the "corner" of the curve whereas the analysis shows a steady increase in thermal resistance. The corner of the curve is also at a lower value of substrate thickness in the simulated results. However, these calculations do show that the substrate thickness starts to play a major role in cooling as it approaches values under $100 \mu \mathrm{m}$. A comparison in temperature between the analytic formulation and simulation cannot be made due to the linear thermal conductivity and adiabatic boundaries used in these calculations, which are not reflected in the simulation model. 
The silicon/oxide interface region outside of the GaN device shows moderate improvement in temperature as the wafer is thinned. Figure 15 shows the improvement in temperature when the substrate thickness is changed from 256 to 50 microns.

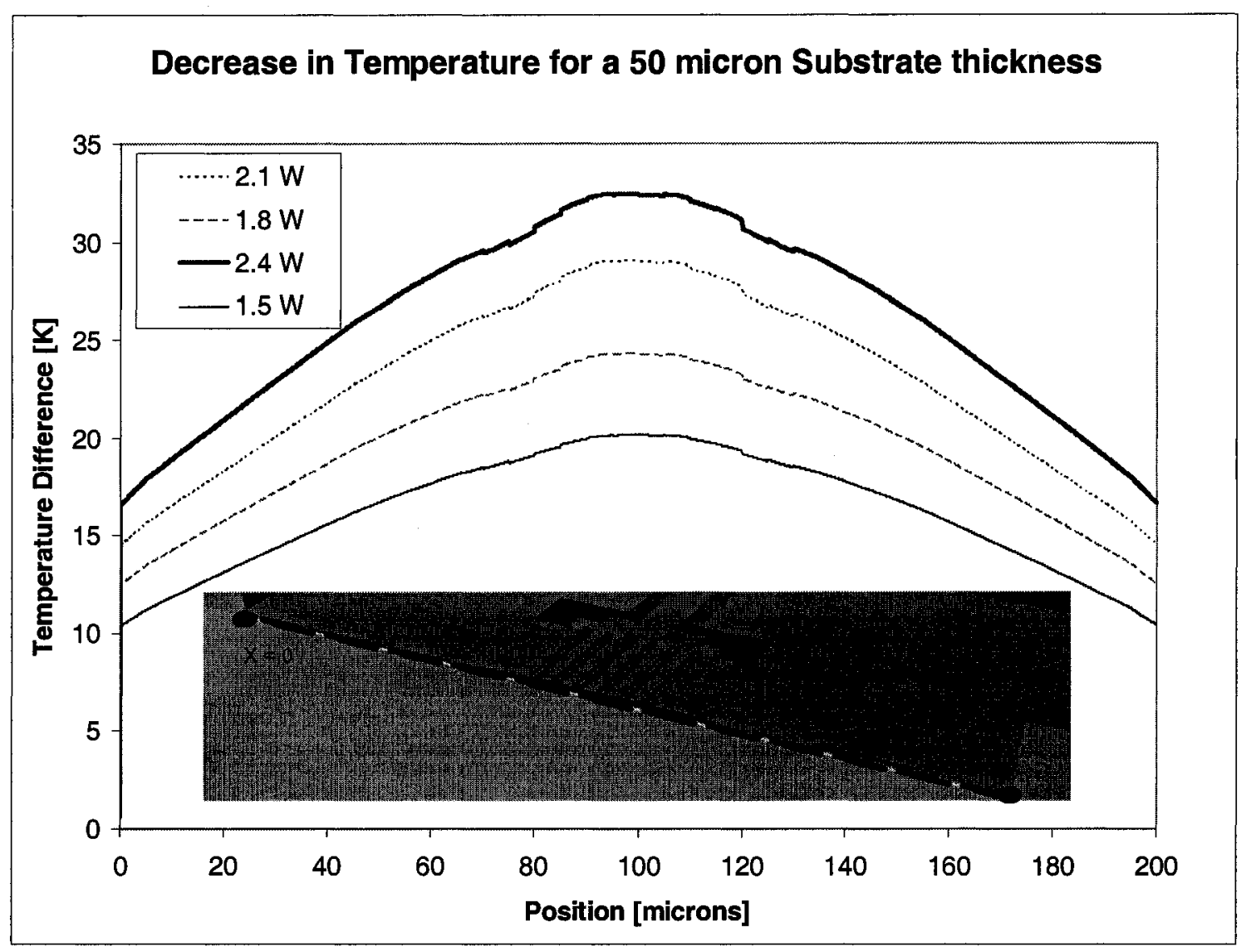

Figure 15: Decrease in temperature at silicon/oxide interface for a $50 \mu \mathrm{m}$ thick substrates over the baseline $256 \mu \mathrm{m}$ thick substrate.

This plot demonstrates that as we move away from the centre of the device, the temperature difference falls off in a linear fashion. The slope of the temperature decrease at the silicon/oxide interface changes based on the thickness of the substrate as well as the power dissipated as one would expect. This is illustrated in Figure 16, which shows the temperature improvement versus position for different thicknesses. The power is now fixed at $2.4 \mathrm{~W}$. The 50 and $100 \mu \mathrm{m}$ thicknesses show the greatest increase in slope, 
reinforcing the fact that the substrate thickness begins to have a large impact at these values.

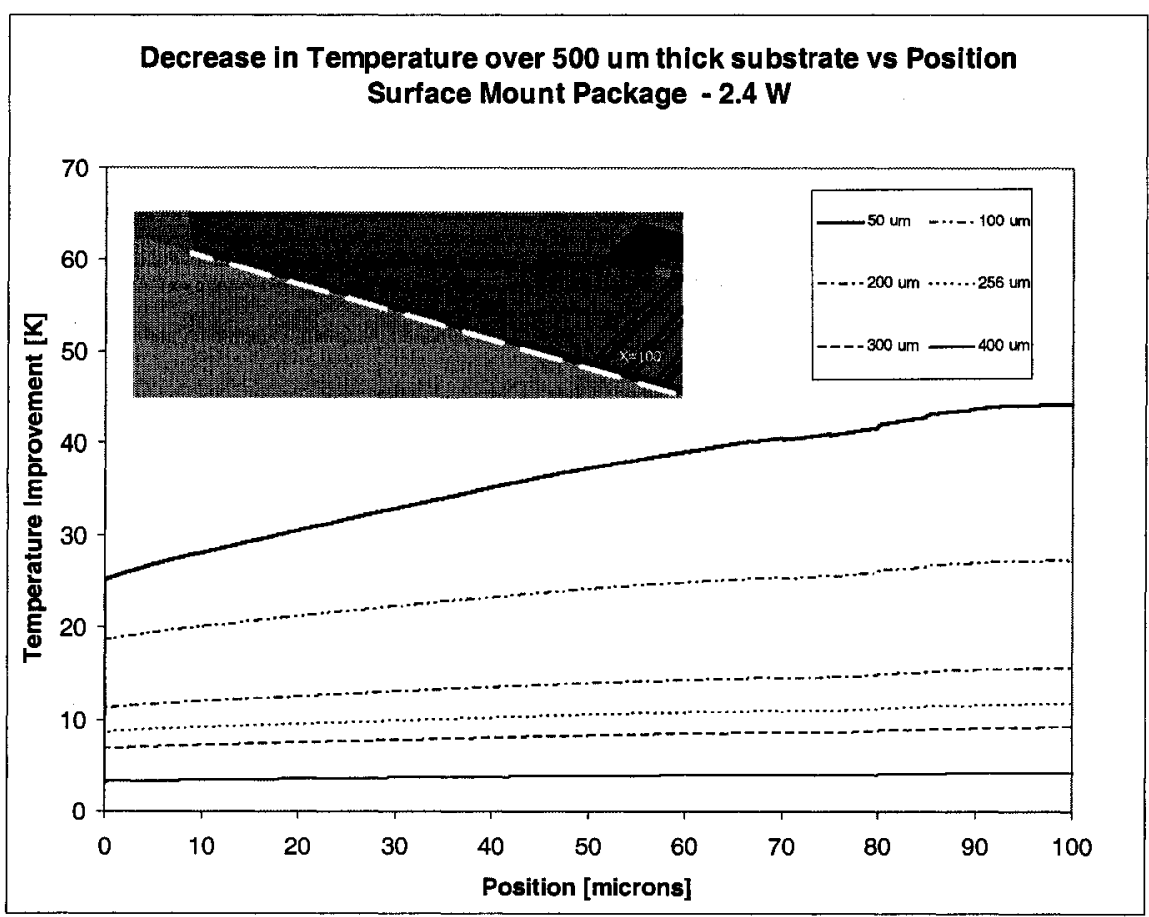

Figure 16: Decrease in temperature vs. position for various substrate thicknesses, for a fixed power of $2.4 \mathrm{~W}$

The surface mount boundary condition simulations show that the surrounding interface area does not experience significant heating. Significant improvement in device temperatures are observed as the substrate thickness is reduced below $100 \mu \mathrm{m}$. The cooling patterns are spherical around the heat source as expected.

\subsection{Flip-Chip Boundary Condition}

Flip chip mounting is becoming a more common packaging technique as it does not require delicate, high-inductance wire bonds to be formed, allowing for higher 
frequency operation as well as improved reliability. This technique employs large conductive bumps placed on the chip periphery such that it can be mounted upside down on a circuit board. The area between the bumps and the chip is typically filled with an insulating epoxy in order for the chip to be sealed. As discussed in section 3.3.3, this model uses four gold bumps placed symmetrically around the device. A $300 \mathrm{~K}$ boundary condition is applied to the top of these bumps for all flip-chip simulations.

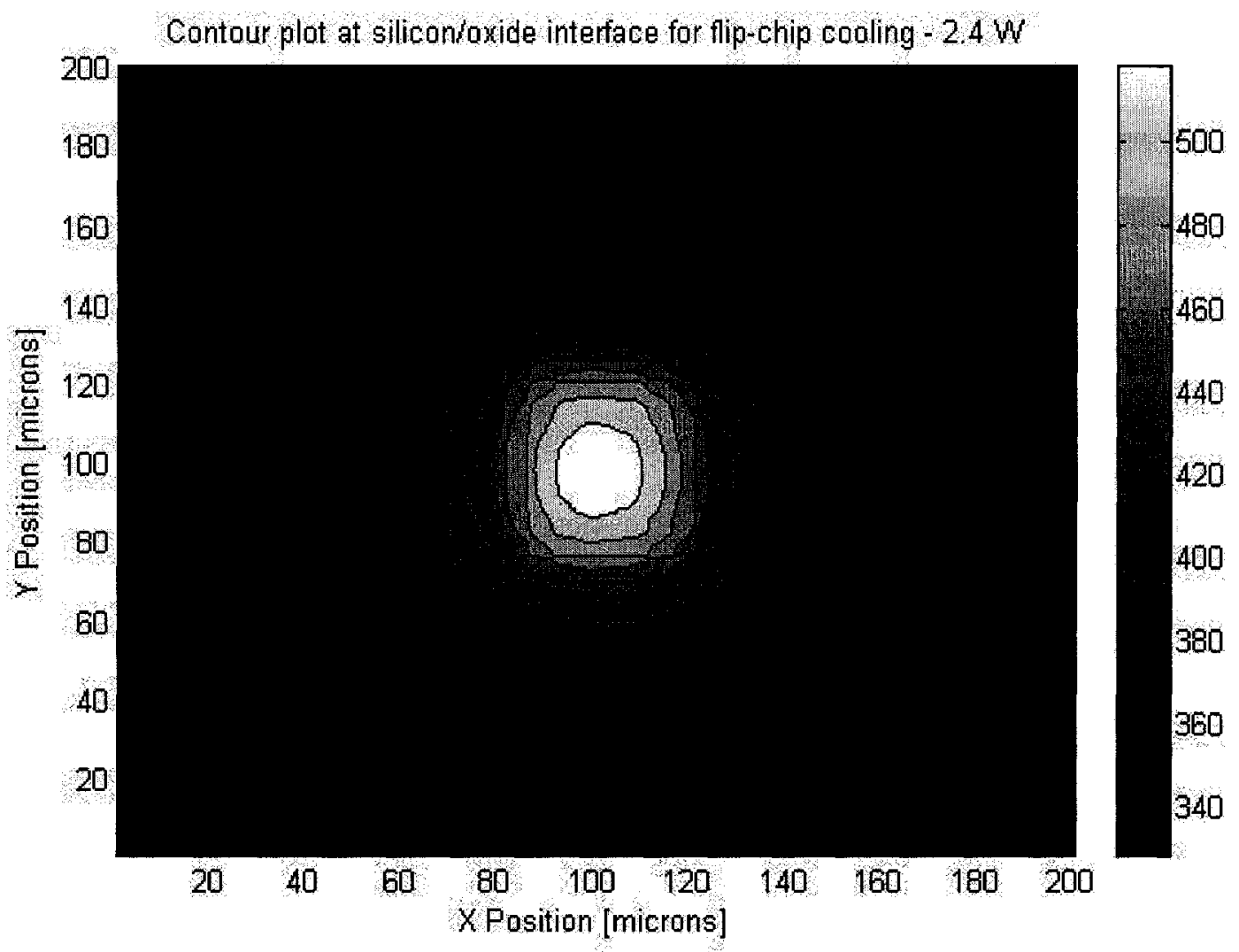

Figure 17: Contour plot of silicon/oxide interface for flip-chip package $-2.4 \mathrm{~W}$

The contour plot of the silicon/oxide interface shows a different temperature distribution than the surface-mount boundary condition (Figure 17). The cooling pattern 
is simply a function of the location of the gold bumps. The lateral nature of the heat flow is visible from the 3-D plot of Figure 18.

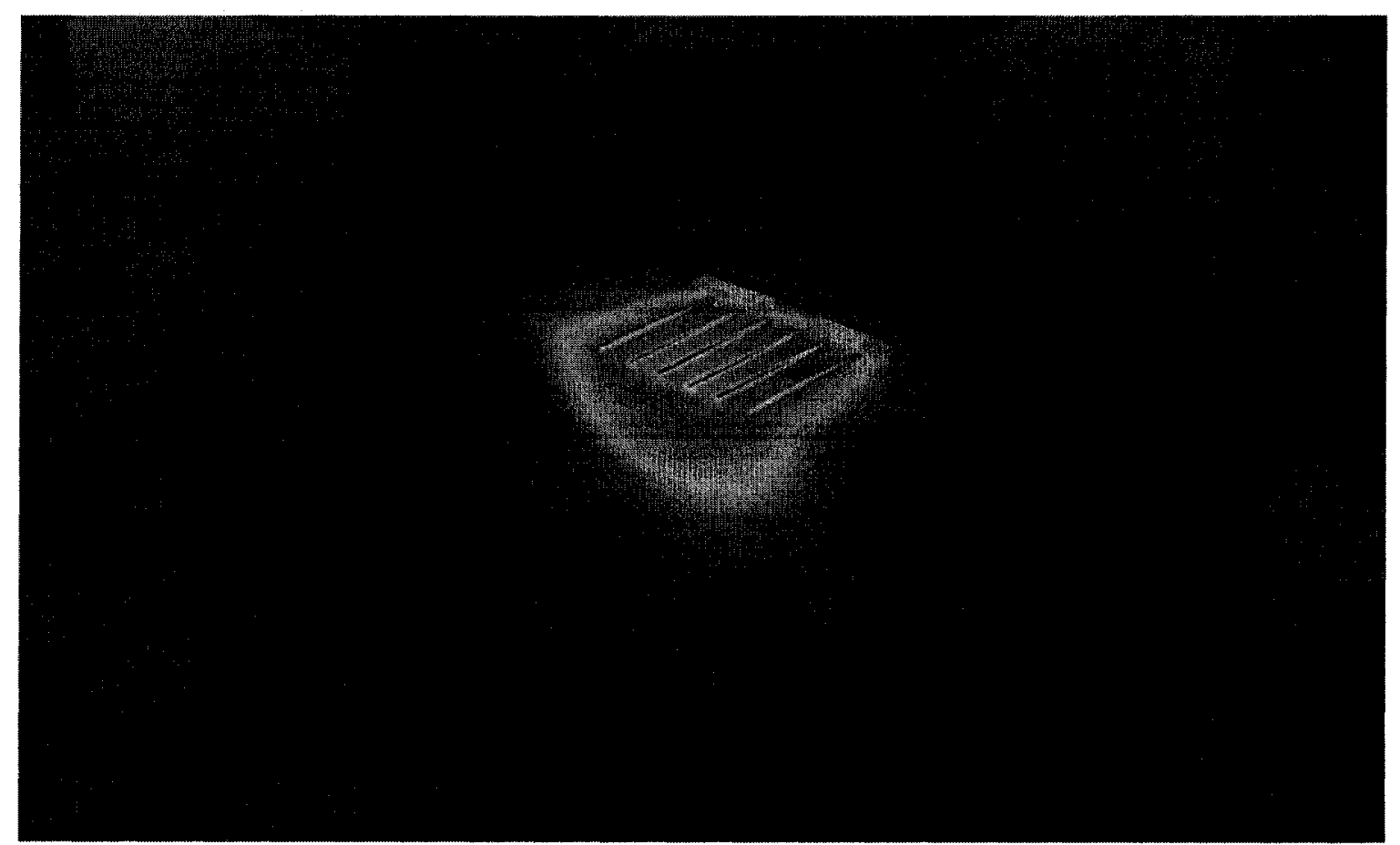

Figure 18: Cross-section contour plot of cooling pattern with flip-chip boundary condition. Maximum temperature of $602 \mathrm{~K}$.

Both contour plots illustrate that the hot-spot in the transistor region. This can be attributed to the $\mathrm{GaN}$ island being insulated by oxide and silicon, both of which have relatively poor thermal conductivity. Figure 19 shows the interface temperatures at the silicon/oxide interface for different power levels. 


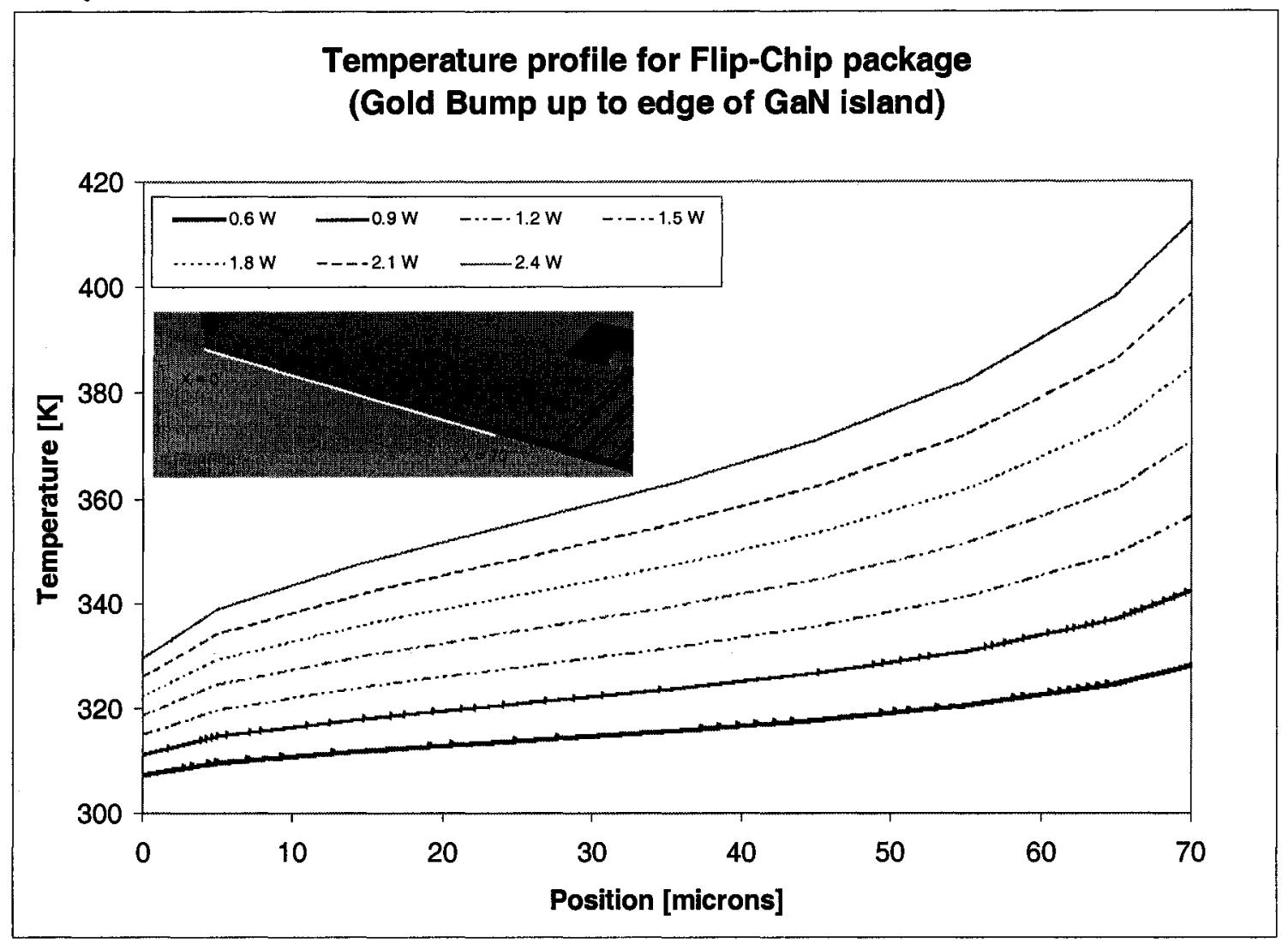

Figure 19: Temperature profile at silicon/oxide interface for flip-chip packaging

The surrounding region shows a greater temperature gradient than the surfacemount package because the heat is now flowing laterally rather than vertically. Once again, the gradient is pseudo-linear except for the region very close to the GaN or gold bump boundaries. The equal spacing between the plots suggests a linear relationship between the temperature and power applied. However, the higher temperatures in this case compared to the surface-mount package may begin to affect adjacent CMOS circuitry.

Comparing the maximum temperatures for both packages (Figure 20) demonstrates that the lateral nature of the flip-chip cooling may have serious thermal 
implications to CMOS circuitry. The position of the gold bumps should be placed in a manner that can allow for more efficient cooling of the GaN device as well as greater thermal insulation of the CMOS circuitry.

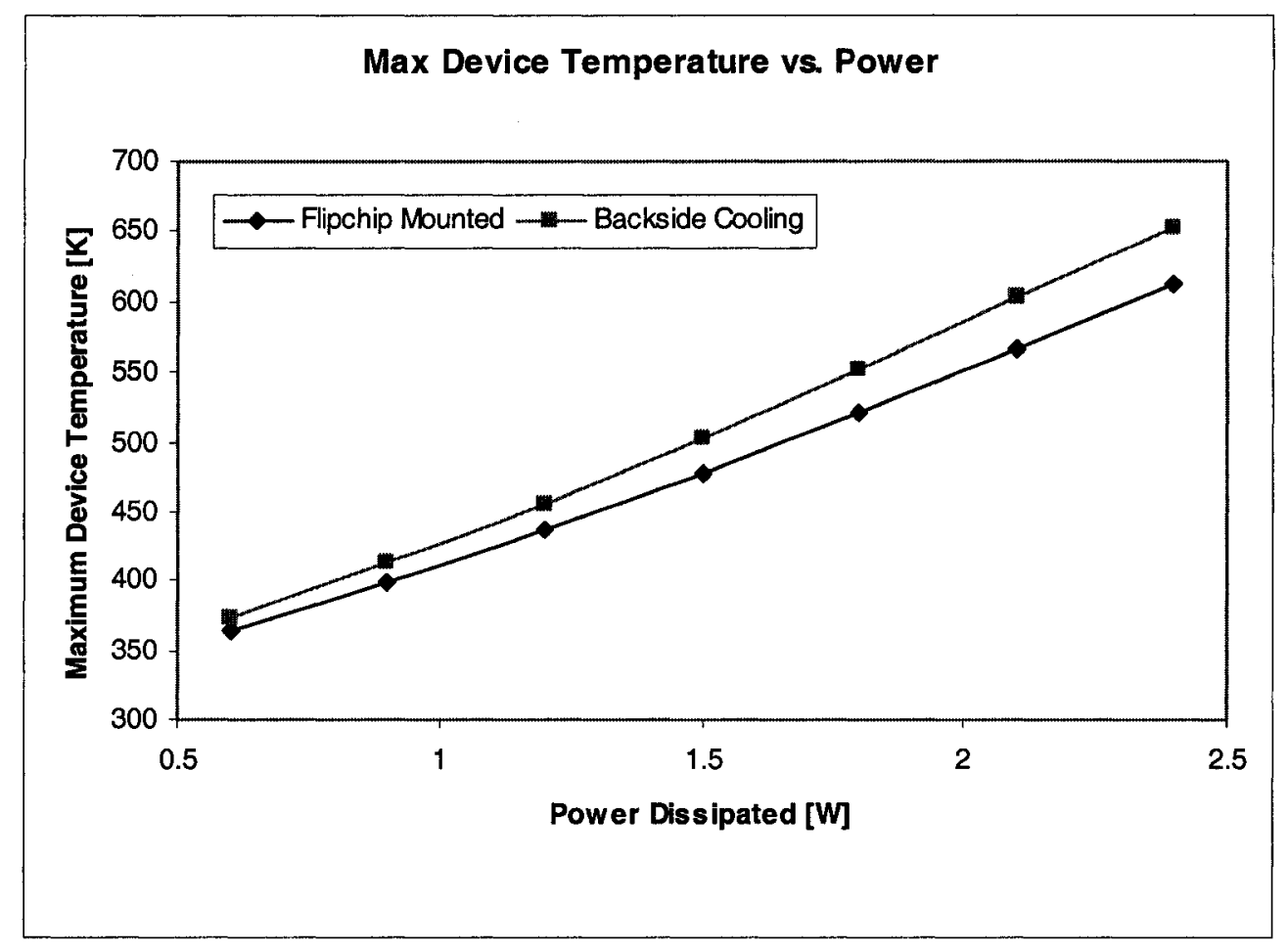

Figure 20: Maximum Temperature versus dissipated power - both packages

\subsubsection{Impact of Metal Thickness}

In order to improve the lateral heat flow, the impact of a thicker metallization has been examined. In theory, this should improve the effective thermal resistance between the GaN transistor and the top of the gold bumps. The thickness of the gate and source metallization, as well as the outer structure was increased from $0.2 \mu \mathrm{m}$ to $2.5 \mu \mathrm{m}$. 


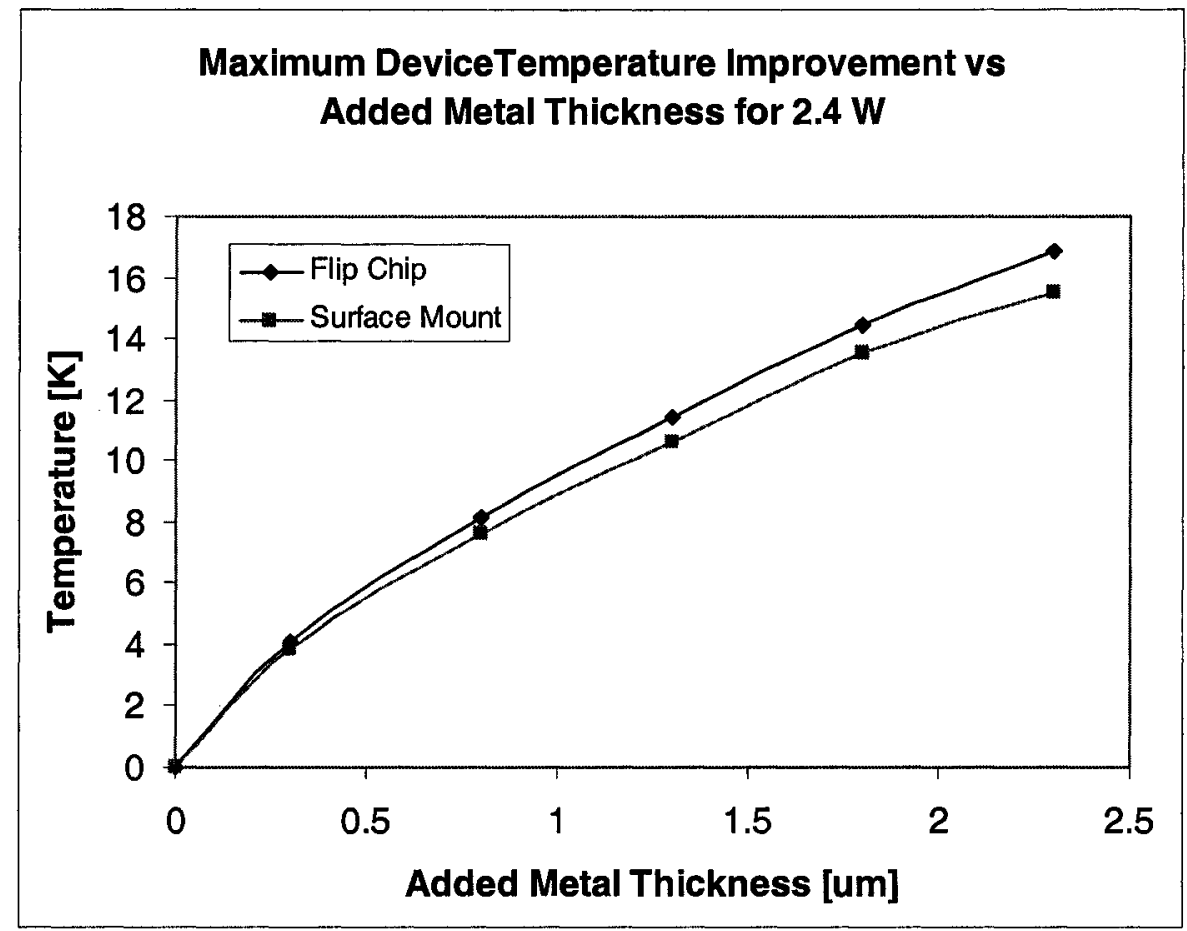

Figure 21: Impact of increased metal thickness on maximum device temperature - flip-chip package

Figure 21 shows that the impact of increased metal thickness on the maximum device temperature is moderate. Only a $17 \mathrm{~K}$ improvement results from increasing the metal thickness to $2.5 \mu \mathrm{m}$ in the worst case scenario, which is the flip-chip condition for a power of $2.4 \mathrm{~W}$. It is also interesting to note that the improvement in the flip-chip package is almost matched by the surface-mount package. Although the heat flow should be vertical in the surface-mount package, the increased thermal mass of the metal at steady-state still allows for heat to spread evenly across the device periphery, lowering the maximum temperature.

When the outer silicon/oxide interface region is considered, simulations show that the surface-mount boundary condition provides no improvement in temperature. The flipchip package also demonstrates modest cooling as shown in Figure 22. 


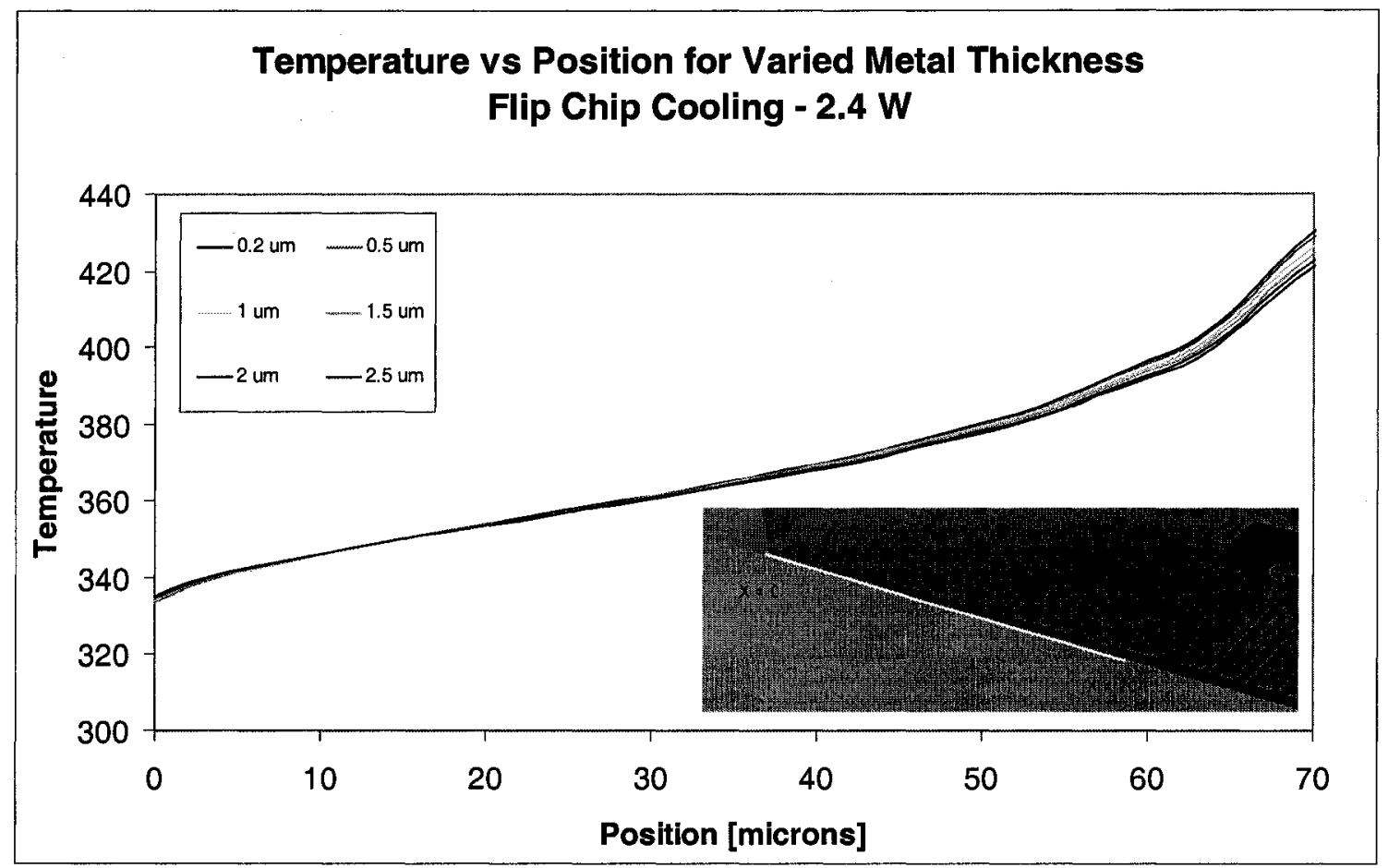

Figure 22: Thermal impact of increased metal thickness on silicon/oxide interface

The reason why there is no improvement in cooling at the silicon/oxide interface is twofold. Although the thicker metal does remove some heat from the device interior, the oxide layer between the silicon and the metal still stops this interface from being cooled effectively. Secondly, a thickness of $2.5 \mu \mathrm{m}$ is still relatively thin compared to the thick silicon substrate; therefore the effective thermal resistance between the gold bumps and the $\mathrm{GaN}$ is relatively unchanged. 


\subsection{Internal thermal characteristics of GaN}

\section{HEMT device}

It is important to investigate the thermal behaviour of the GaN device, especially in the gate region. Although $\mathrm{GaN}$ can operate at higher temperatures, heat is still unwanted as device performance suffers. The primary effect of excess heat is that the channel suffers a decrease in carrier velocity due to the decreased electron mobility. This section will examine the temperature distribution along the surface of the $\mathrm{GaN}$ transistor as well as the gates.

In this case, the data is extracted at the surface of the GaN mesa, which will give the approximate channel temperature of the device. The 1-D plots of Figure 23 and 24 show a cut perpendicular to the gates, at the centre of the transistor model. 


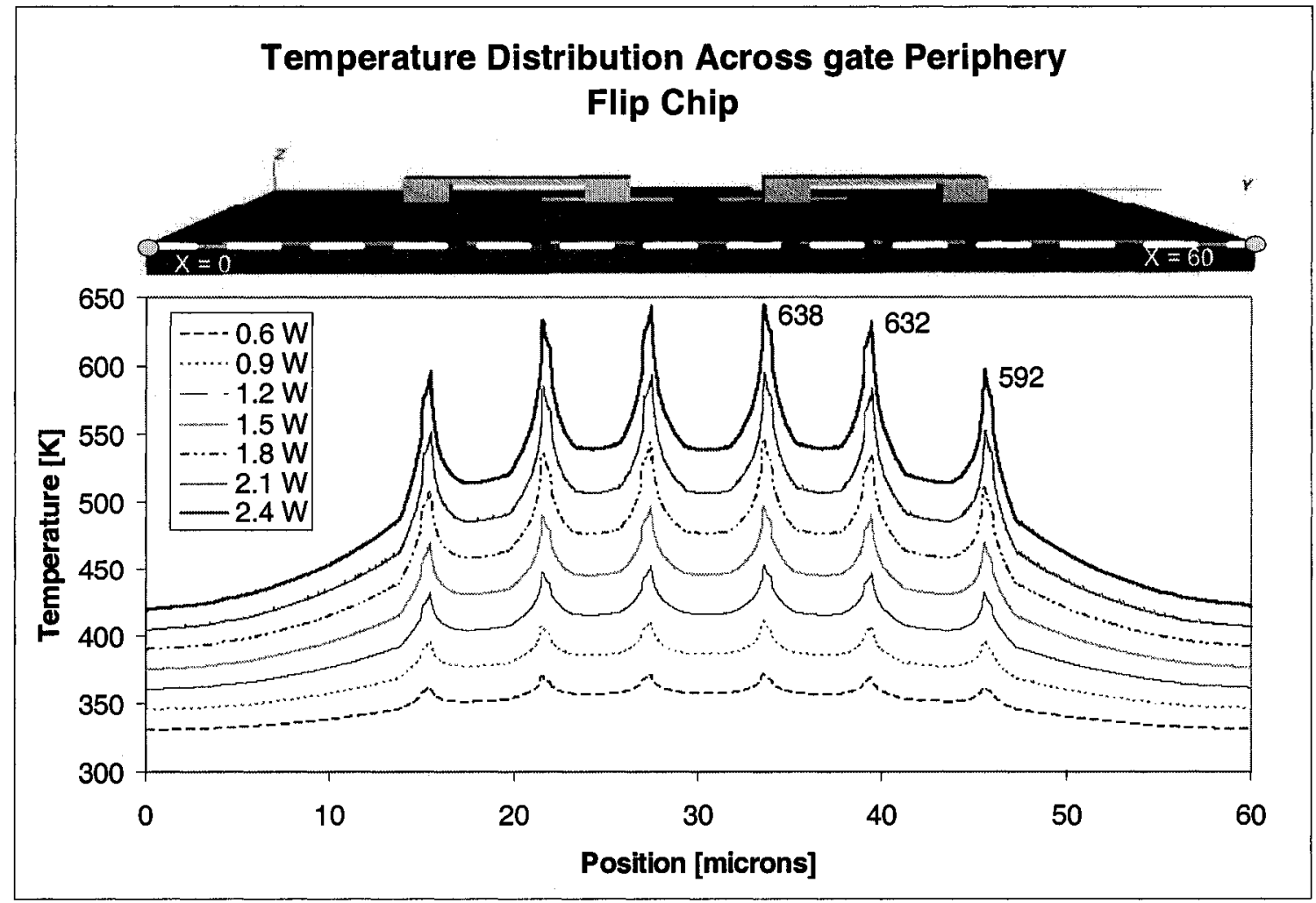

Figure 23: Temperature distribution across gate periphery for flip-chip package

Both plots demonstrate greatly elevated temperatures in the gate periphery of the device. The temperature distribution across the gates appears to be linear with applied power as the spacing between the lines is consistent. The peak temperature of the outer gate is much lower than that of the inner four gates. As expected, this difference is lower for the flip-chip condition as there is greater lateral heat flow. At high frequencies, this temperature difference may impact performance because the temperature difference between the gates changes their impedance with respect to each other, causing a phase difference in the input signal between the two gates. Considering the $\mathrm{T}^{-0.5}$ dependence of mobility on temperature, the inner and outer gates will also have dissimilar performance characteristics. 


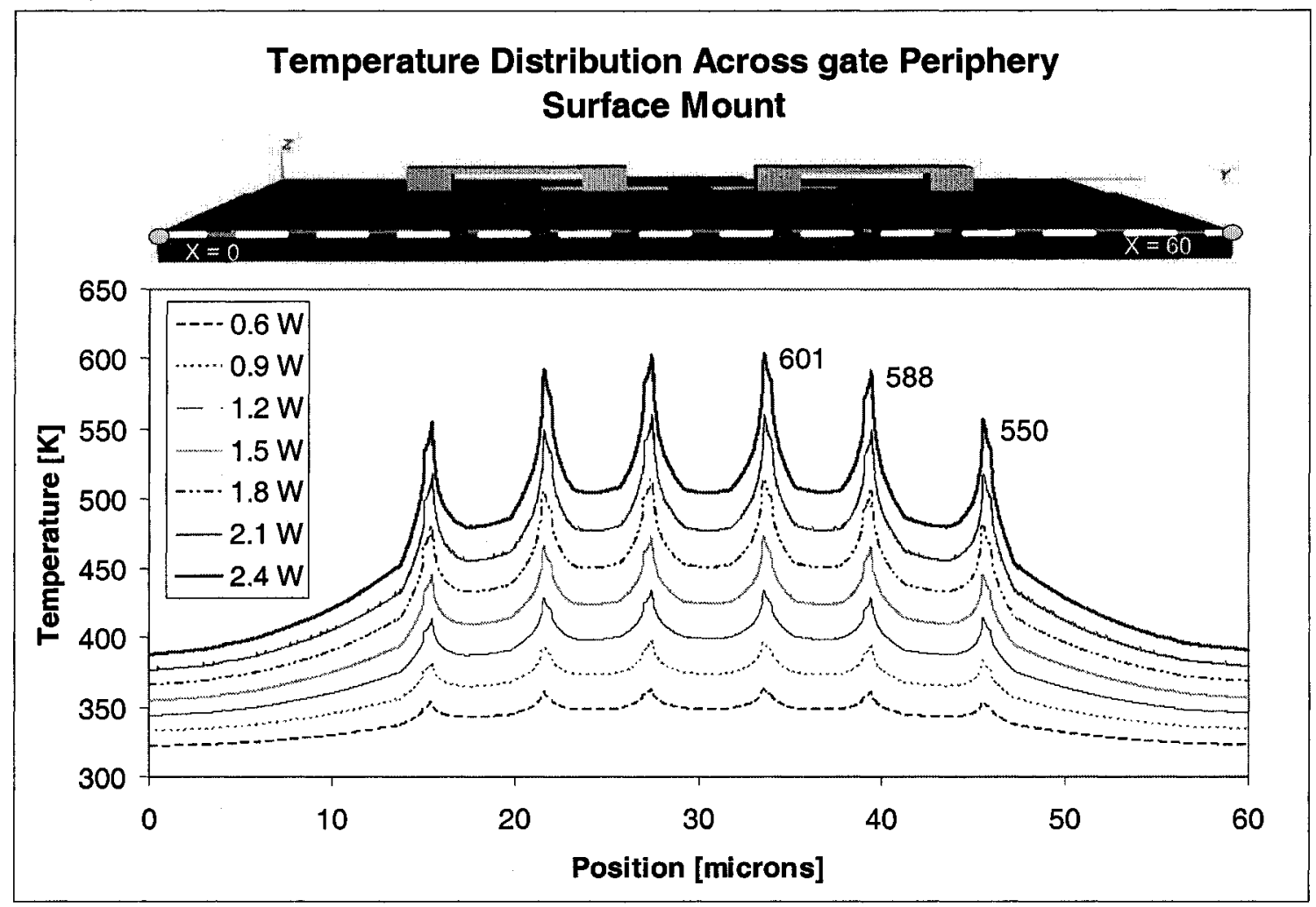

Figure 24: Temperature distribution across gate periphery for surface-mount package

Figure 25 shows contour plots for a plane directly under the GaN mesa, at a height of $1.8 \mu \mathrm{m}$ from the silicon surface. It is apparent that there is already a large drop in temperature compared to the gate values, at only of $0.2 \mu \mathrm{m}$ deeper. The tight spacing between the contours around the gate periphery is another indication of a hot-spot in the transistor centre. Because of this hot-spot, a possible solution is to increase the gate to gate spacing of the device. However, as this spacing is increased, the number of devices that can be put on a wafer decreases, which increases the cost of each device or chip. 


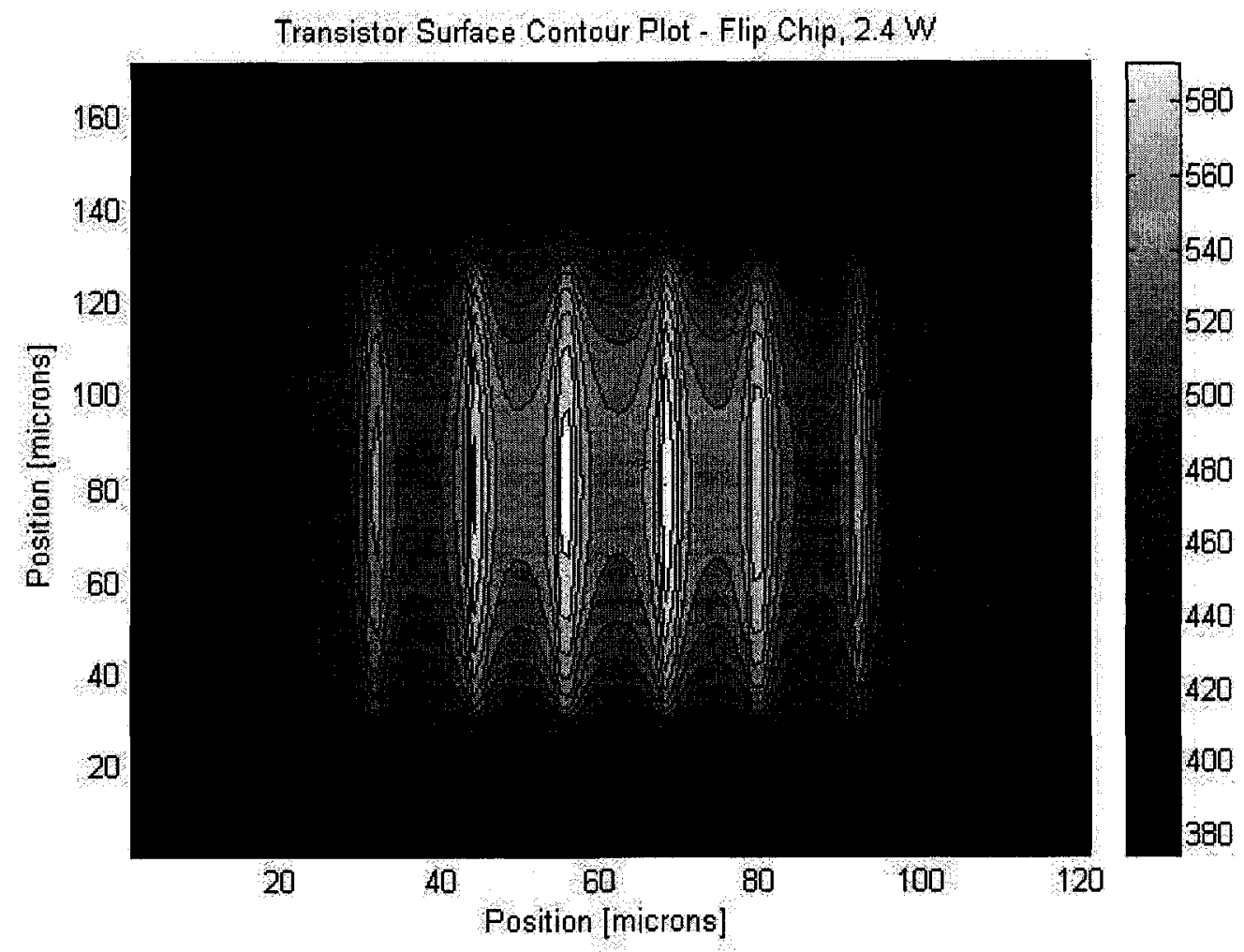

Transistor Surface Contour Plot - Surface Mount, 2.4 W

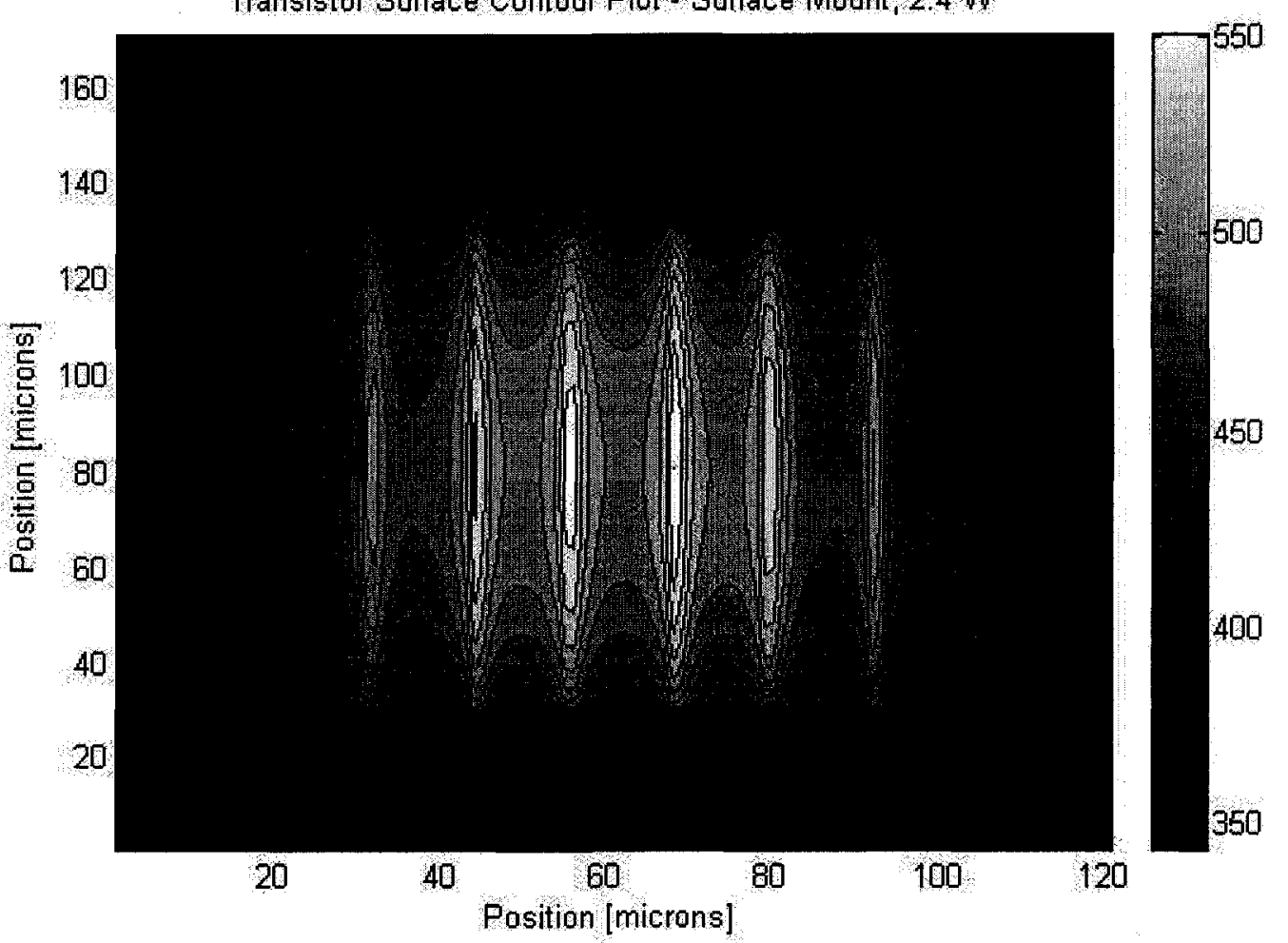

Figure 25: Transistor surface contour plots $-2.4 \mathrm{~W}$ 
Plotting the temperature along the gate (Figures 26 and 27) also reveals a wide temperature distribution. The distribution peaks at the centre as expected, and drops off quite rapidly. The distribution is slightly skewed due to the gate metal connection carrying heat away. Both the surface-mount and flip-chip package orientations show the same distribution of heat. The difference between the unconnected end of the gate and the middle can be as high as $90 \mathrm{~K}$ for the flip-chip condition.

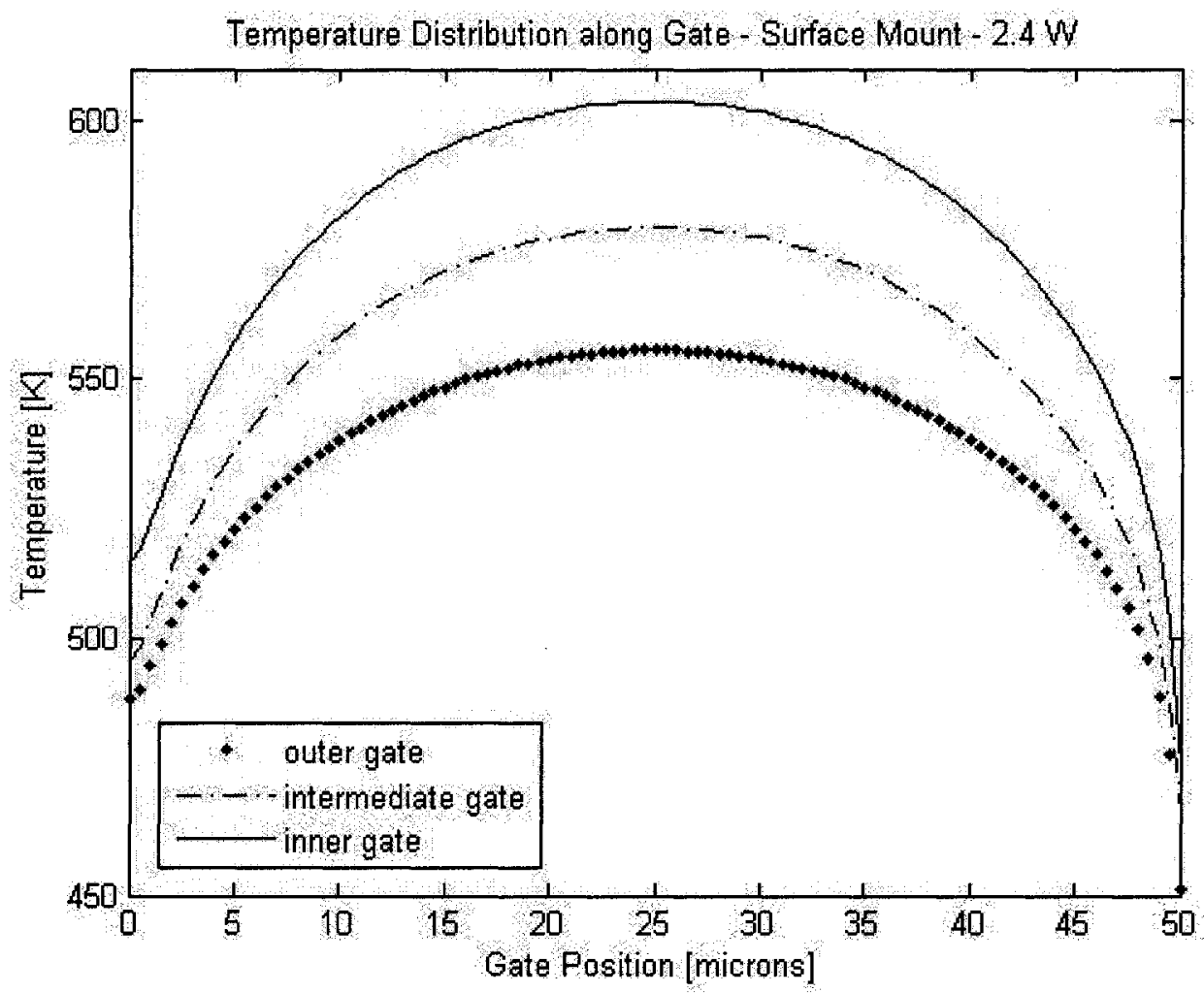

Figure 26: Temperature distribution along gate length - surface mount package 


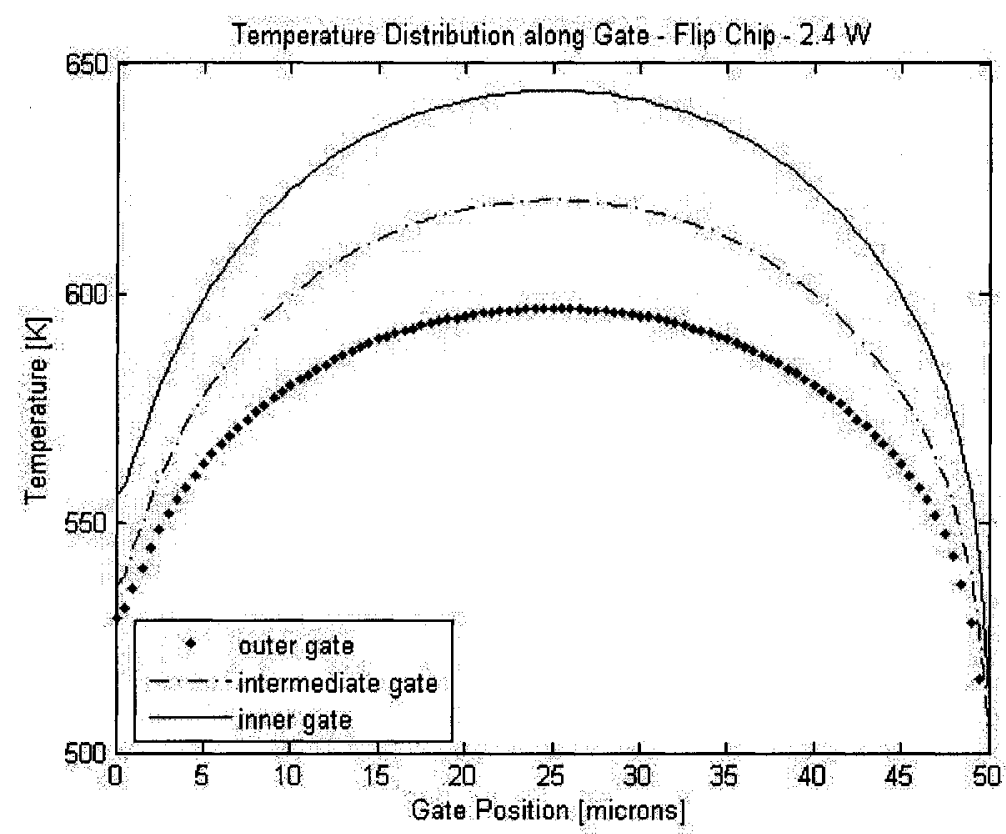

Figure 27: Temperature Distribution along gate length - flip-chip package

The large temperature difference between the gates is also a result of the simulation method used. Because a constant power is being applied to the gate, there is an evident hot-spot exactly in the centre of the gate periphery, resulting in large differences in temperature between the gates. As the $\mathrm{T}^{-0.5}$ dependence of current on temperature imposes itself, the heat will naturally be redistributed along around the transistor region as more heat will be generated in the cooler regions due to the higher current.

\subsubsection{Thermal Impact of Air Bridge}

The air bridge allows for connectivity between the inner and outer source contacts. From a thermal standpoint it has almost no effect, which is due to the thin nature of the metal bridge. The simulations showed no change in maximum temperature and very little change in the temperature contours when the air bridge was eliminated. 


\subsection{Summary}

Steady-state simulations have shown that the majority of the temperature rise is local to the GaN transistor. Hence the outer region in which CMOS circuitry could be located is adequately thermally insulated. Techniques such as common-centroid layout can be used to overcome the device mismatch in thermal gradient generated by the GaN device.

A good design however, will attempt to reduce the heat in the GaN device as well, as the $\mathrm{T}^{-0.5}$ dependency of mobility on temperature will affect device performance. Examining the maximum temperature of the device allows for the comparison of different structures as well as the thermal impact of different model parameters. Figure 28 shows the maximum temperature for simulations of both packages, dissipating $1.8 \mathrm{~W}$ of power. 

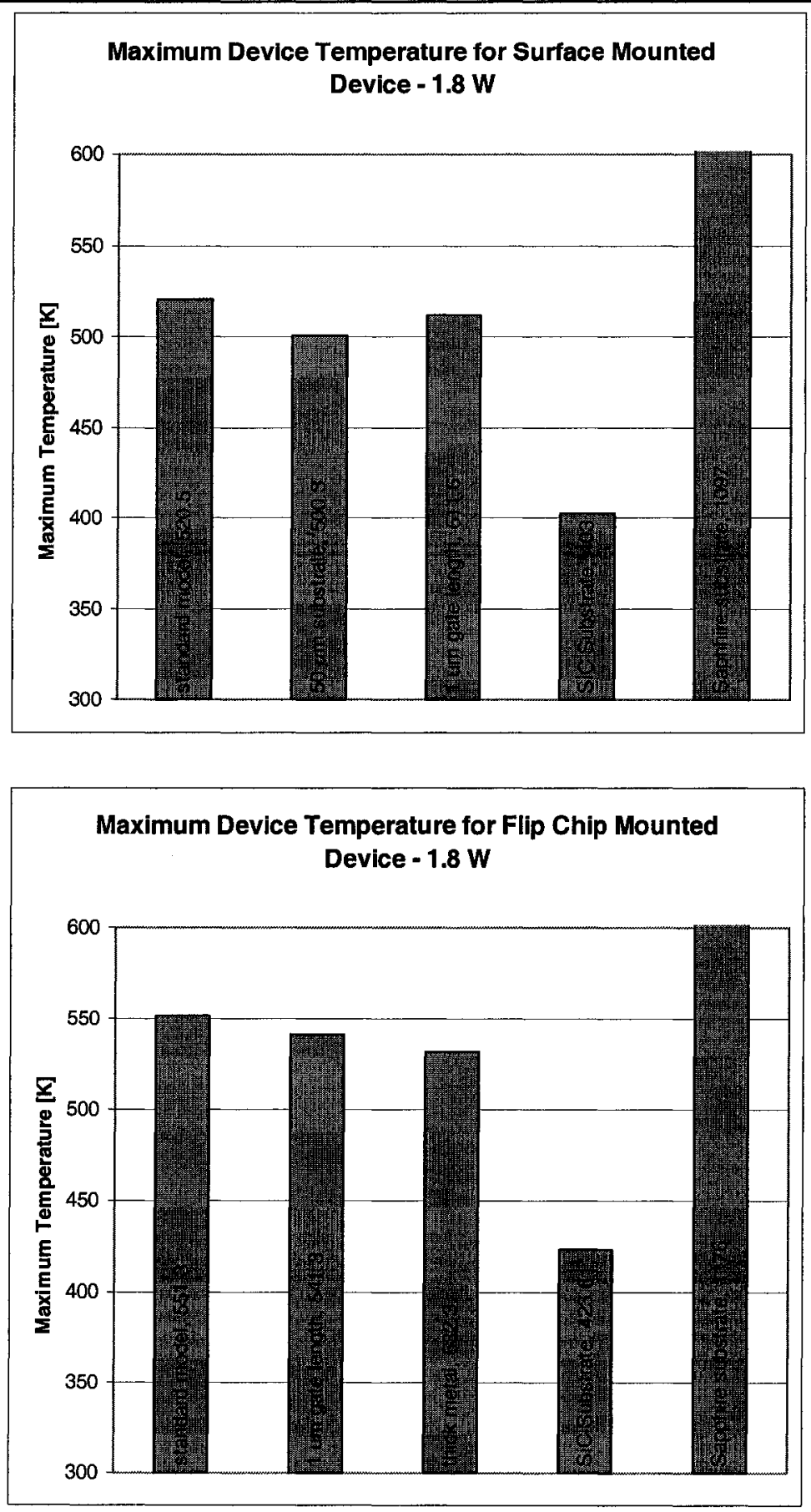

Figure 28: Maximum temperatures for various device parameter changes

Included in these plots is the maximum temperature of devices with siliconcarbide and sapphire substrates, the two other primary substrates for GaN epitaxy. Based on these plots it is evident that the thermal performance is most strongly affected by the 
choice of substrate, suggesting that even a well-designed transistor from a thermal standpoint is limited in performance by the substrate's thermal conductivity.

The integration of CMOS on the silicon substrate appears to be quite feasible from a thermal standpoint, as the temperature rise generated by the $\mathrm{GaN}$ transistor stays local. Simulations suggest that spacing of $20 \mu \mathrm{m}$ between the $\mathrm{GaN}$ island and the CMOS will provide adequate thermal isolation. The greatest thermal challenge is instead to develop a method in which heat can be dissipated effectively from the GaN transistor. Chapter 6 will discuss some possible methods of improving the thermal performance of the chip, such that the heat can spread from the transistor to other areas of the chip. 


\section{Chapter 5}

\section{Transient Simulations}

\subsection{Overview}

Transient Simulations allow us to track the thermal behavior of specific points in a device over a period of time. This is useful in order to determine the speed at which a point will get hot or cool down. This data can subsequently be used to model the thermal behavior of a device with an RC network. This allows for a compact thermal model to be created, with the resistances corresponding to the thermal resistance of the materials and the capacitors corresponding to the heat capacity. The advantage of a compact thermal model is that it can be used in circuit simulators in order to quickly estimate device temperatures such that the electrical characteristics can be adjusted accordingly.

In order to study the transient thermal characteristics of the model, five specific points of interest are chosen. Two of these points are on the gates and the remaining points are placed at the silicon/oxide interface at the gate, source and drain contacts, $5 \mu \mathrm{m}$ outside the GaN transistor as shown in the Figure 29. A $2.4 \mathrm{~W}$ transient simulation using a topside boundary condition is performed. It should be noted that the air bridge structure has been eliminated in this case for faster simulation. 


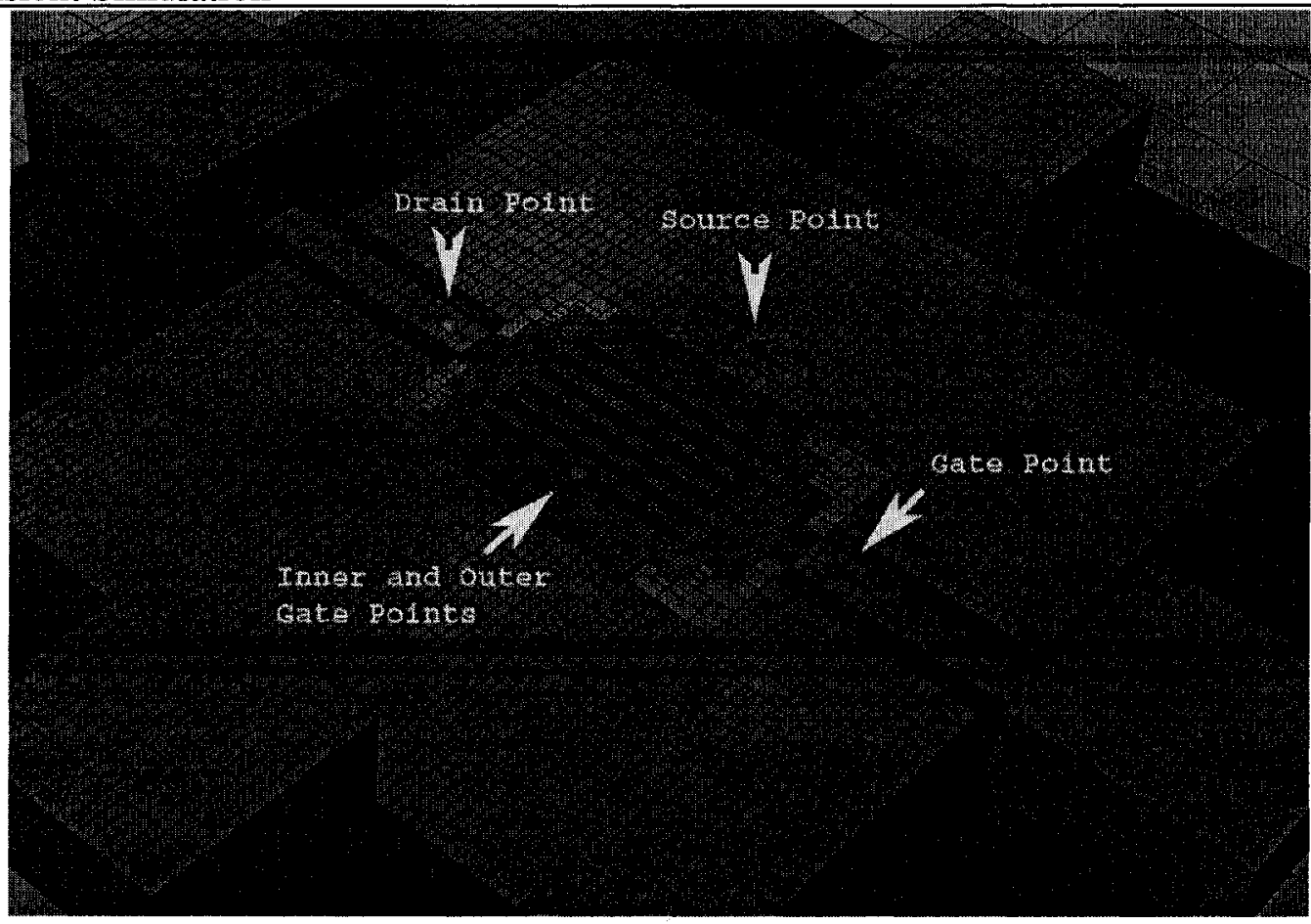

Figure 29: Five key points of interest for transient simulation

The transient temperature response at these points is shown in Figure 30.

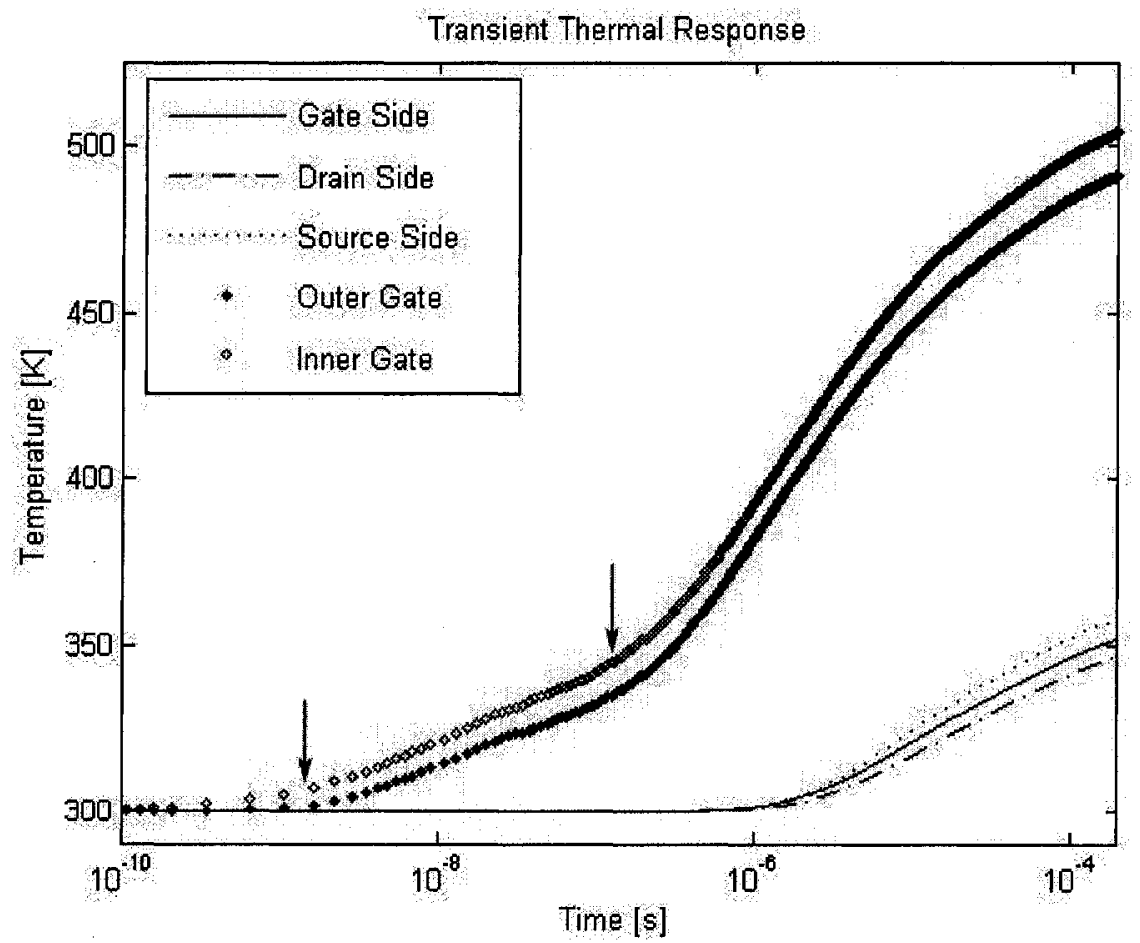

Figure 30: Transient temperature response for interest points - flip-chip package 
As expected, the two gate points show a much faster transient response than the interface points on the outside of the $\mathrm{GaN}$ transistor. Three thermal time constants are clearly identifiable in the gate response. The corner times and corresponding frequencies for the three outer points are as follows:

Table 1: Transient simulation corner times

\begin{tabular}{|c|c|c|}
\hline Point Location & Corner Time $(\boldsymbol{\mu}$ ) & Frequency $(\mathbf{K H z})$ \\
\hline Gate Side & 1.12 & 892 \\
\hline Drain Side & 1.54 & 649 \\
\hline Source Side & 1.10 & 908 \\
\hline
\end{tabular}

These values were determined by finding the time at which the second derivative of the curves was at a maximum. The frequency is simply the inverse of these times. This data suggests that the outer regions of the transistor experience steady-state heating for operation above $1 \mathrm{MHz}$. As expected, the source point reacts first to the transistor heating up due to its proximity to the gate periphery. The gate metallization provides lower thermal resistance to the gate side rather than to the drain side, which is why the gate experiences the heat $0.42 \mu$ s before the drain.

\subsection{Thermal Modeling with an RC Network}

A compact thermal model consisting of an $\mathrm{RC}$ network provides a quick estimate of the thermal behavior of a chip. By modeling the resistors and capacitors of this network with the physical properties of the materials used, a simple circuit can be formed, which can predict the heat transfer characteristics of a chip and package. This 
section will demonstrate that it is possible for transient simulation data to be converted into a network of resistors and capacitors in order to model the temperature response.

The first step to modeling the transient behavior is to extract the time constants from the plots. Three time constants are identifiable from the points in the gate, and two are identifiable from the points outside of the GaN regions. In this case, let us simply consider the inner gate point, and the point on the gate side of the transistor. The temperature rise of points on the chip can be approximated by a sum of damped exponentials:

$$
T=C_{1}\left(1-e^{-t / \tau_{1}}\right)+C_{2}\left(1-e^{-t / \tau_{2}}\right)+\ldots . .+C_{n}\left(1-e^{-t / \tau_{n}}\right)
$$

Where there are $n$, time constants $(\tau)$ in the transient. A three-rung series RC ladder can be used to approximate the temperature response of the current model. By subtracting away the steady-state value, the temperature can be turned into a sum of simple decaying exponentials, which corresponds to a cooling behavior rather than heating. The form is as follows:

$$
T=C_{1} e^{-t / \tau_{1}}+C_{2} e^{-t / \tau_{12}}+\ldots . .+C_{n} e^{-t / \tau_{n}}
$$

From this form, the time constants can be extracted using some curve fitting software, such as the Matlab curve fitting toolbox. The time constants for the two curves are as follows:

Gate Point: $\tau_{1}=7.51 \times 10^{-6} \mathrm{~s}, \quad \tau_{2}=5.68 \times 10^{-5} \mathrm{~s}$ Inner Gate Point: $\tau_{1}=1.62 \times 10^{-7} \mathrm{~s}, \quad \tau_{2}=3.50 \times 10^{-6} \mathrm{~s}, \quad \tau_{3}=5.12 \times 10^{-5} \mathrm{~s}$ 
Notice how the latter two time constants of the inner gate point almost match the two time constants of the point on the outside of the GaN transistor. This makes sense as logically, the first time constant corresponds to the heating of the GaN transistor itself, whereas the next two correspond to heating of surrounding shells of material. Since the gate point is not located right at the interface, the time constants do not match perfectly. The second time constant must then correspond to the heating of the silicon substrate. Finally, the third time constant corresponds to the heating of the gold bumps. The threerung RC network representing this behavior is shown in Figure 31.

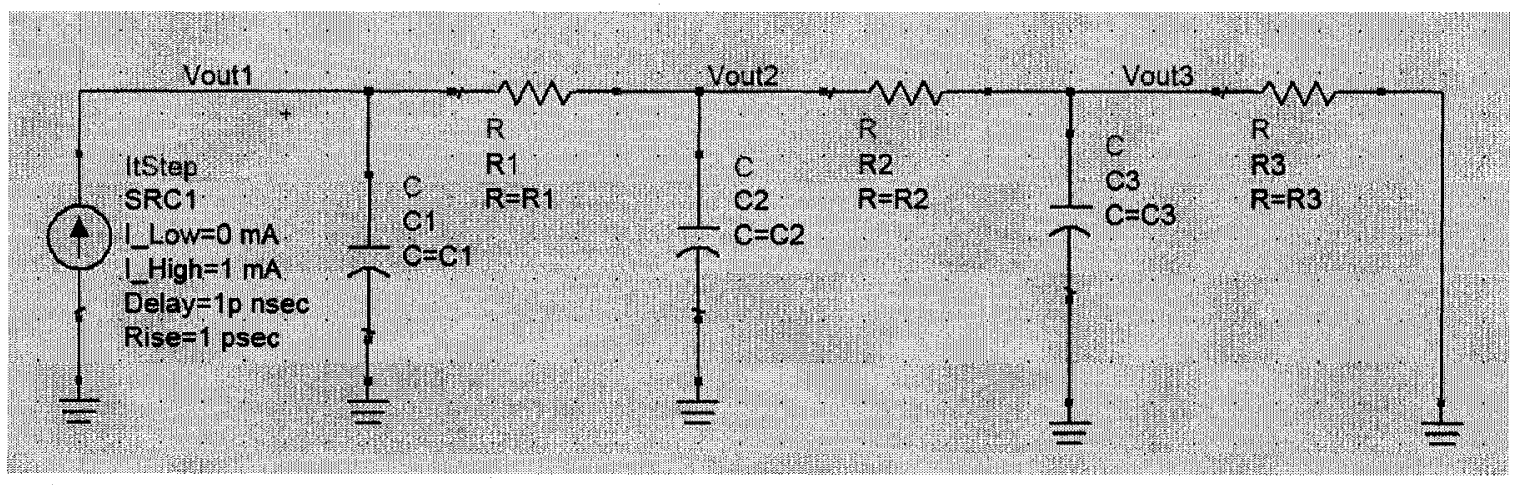

Figure 31: Three-rung RC network used to model transient behaviour

The power applied to the transistor is represented by a step impulse current source, as current represents thermal power in the electro-thermal analogy. The voltage in this case represents temperature, and hence, the ground is the boundary condition of the model. The three time constants are represented by the RC pairs in the network. R1 represents the thermal resistance between the gates and the edge of the $\mathrm{GaN}$ island, $\mathrm{R} 2$ represents the thermal resistance between the gold bumps and the edge of the $\mathrm{GaN}$ and finally represents is the thermal resistance between the gold bump and the package. 
Therefore, Vout1, Vout2 and Vout3 represent the temperature at three interface points between different shells.

Because the thermal resistance of the $\mathrm{GaN}$ is nonlinear, nonlinear resistors are needed for high accuracy, which is beyond the scope of this work. Let us however, examine the transient voltage of Vout2, which corresponds to the transient data of the gate point. If $R I$ is made sufficiently large, then the transient behavior of Vout 2 only depends on $R 2, C 2, R 3$ and $C 3$. By setting the time constants as RC pairs and altering the voltages a fairly accurate fit has been achieved.

Values for $R 2$ and $R 3$ of $615 \Omega$ and $600 \Omega$ respectively, give corresponding capacitances of $9.24 \mathrm{nF}$ and $0.27 \mathrm{nF}$. A resistance of $3 \mathrm{k} \Omega$ is used for $R 1$ as this yields the proper steady-state value, but because of the nonlinear nature of the resistance, the transient fit is quite poor. The corresponding capacitance of $C 1$ is $54 \mathrm{pF}$. Figure 32 plots the transient data and the fit generated for the temperature at the node Vout2. 

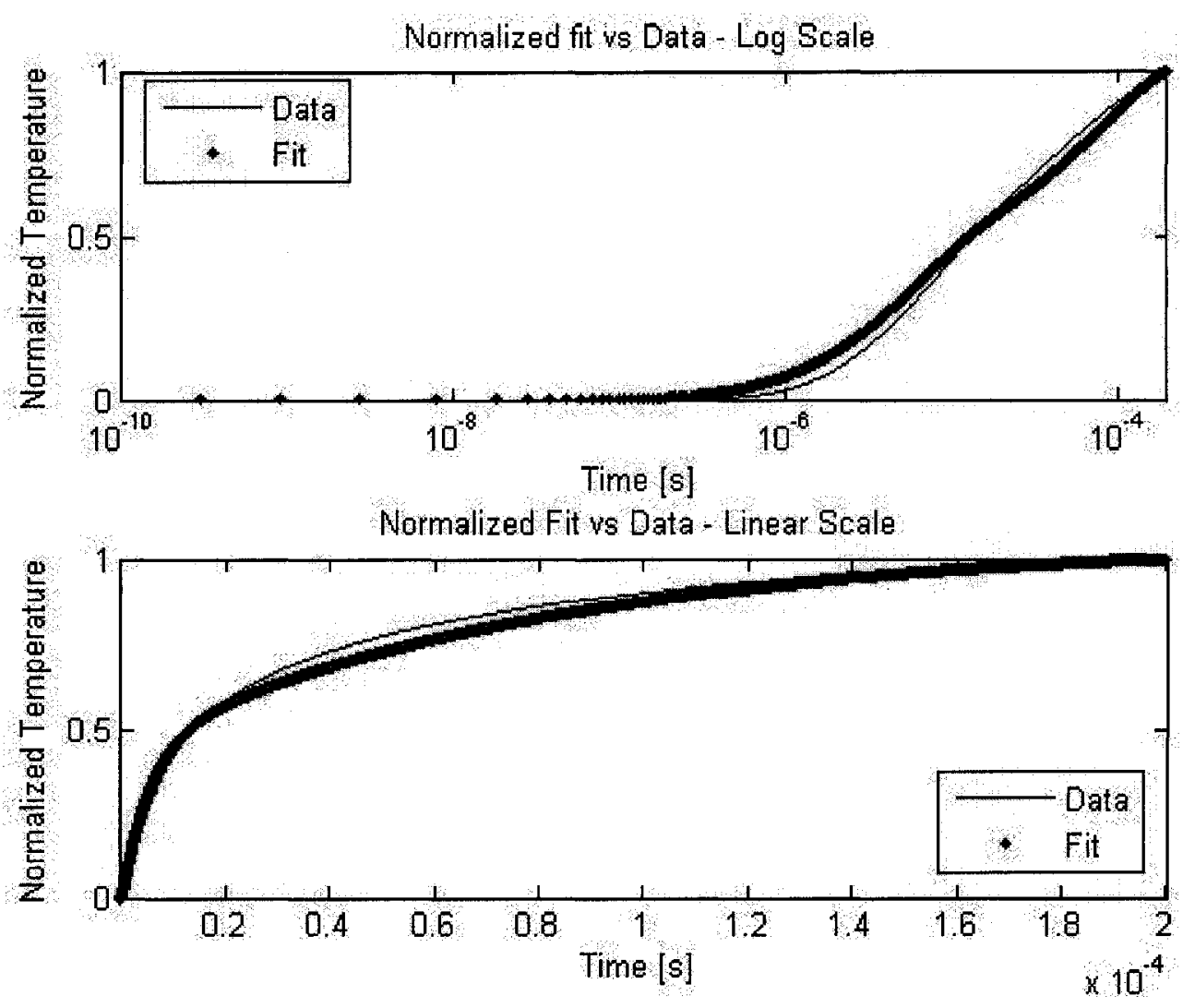

Figure 32: Transient fit for Gate point using a three-rung RC network

The above suggests that this RC network can be used to model the thermal behavior of this chip. The $\mathrm{R}$ and $\mathrm{C}$ values also correspond well to the real physical situation. It is expected that $R 1$ would be greater than $R 2$ and $R 3$ because as the heat spreads out in a radial fashion, the spherical shell has little surface area due to the small transistor region. The small capacitance of $C 1(54 \mathrm{pF})$ is expected as the region of heating is small compared to the gold bumps and the silicon substrate. The capacitance of $C 2$ is also the largest as expected because the silicon substrate is the largest part of this model. The gold bumps have a smaller capacitance value, but similar resistance to the silicon 
region. This is explained by suggesting that the resistance of the gold bumps includes some of the underlying region as the boundary is at the inner edge of the gold/silicon interface. In addition, the higher thermal conductivity of the gold compensates for the smaller radial width of the cooling pattern of the gold bump compared to the silicon substrate.

It has been shown that the thermal behavior of this chip can be approximated with a simple RC network. Unfortunately, the complex nature of the nonlinear $\mathrm{GaN}$ resistance does not allow for a good transient fit for regions inside the gate. However, there is evidence that suggests that a more complex compact thermal model made from an RC network can be used to accurately predict the thermal behavior of this chip. 


\section{Chapter 6}

\section{Improving the Thermal Performance of GaN HEMTs on Silicon Substrates}

\subsection{Overview}

The results from chapter 4 suggest that the main thermal challenge of the GaN and CMOS integration is not the heating of the surrounding silicon area, but rather the hot-spot generated in the $\mathrm{GaN}$ transistor itself, which will limit performance. An improved thermal design is needed in order to minimize these effects. Simulations have shown that the cause of the hot-spot in the GaN transistor is the silicon substrate. Some proposed solutions include liquid micro-jet cooling [Bhunia, 2004] and lateral overgrowth to create air channels under the GaN substrate [Kopp, 2001]. While both of these techniques may be effective, they are complex and not cost-effective, and therefore, not viable for mass production.

Simple, cost-effective solutions are proposed for both surface-mount and flip-chip boundary conditions in this chapter. Steady-state simulations are performed with these changes, while examining the maximum device temperature.

\subsection{Surface-Mount Back Trenching}

Thinning the silicon substrate can noticeably improve the maximum device temperature of the GaN HEMT as shown in chapter 4. However, even with a $50 \mu \mathrm{m}$ 
substrate, the high temperatures are still an issue in the device. A simple approach to reducing the internal device temperatures is to etch a trench into the backside of the wafer and fill it with a metal that has a high thermal conductivity. This metal could then provide a low thermal resistance channel between the $\mathrm{GaN}$ transistor and the surface mount package.

This technique is quite simple from a processing standpoint. These steps should take place at the end of the process, as they can be performed concurrently with the backside metallization of the chip. Firstly, one needs to thin the wafer to the desired thickness. A thick backside deposition of oxide could be used as an etch mask. Once the backside lithography is performed and the oxide is removed, the silicon etch can take place. A dry etch is probably the best choice here because it can be anisotropic. The GaN island acts as a natural etch-stop for the silicon layer due to its relative "hardness" compared to silicon. Finally, once the oxide mask is removed, sputtering techniques or plating can be used to fill in the trenches and coat the backside of the wafer with metal. The only concern from a fabrication standpoint would be the large stress imposed by the metal in this trench on the GaN and silicon. This can be mitigated by the choice of a soft metal to fill the trench.

The improvement in maximum temperature for difference sized trenches centered under the GaN island is shown in Figure 33. 


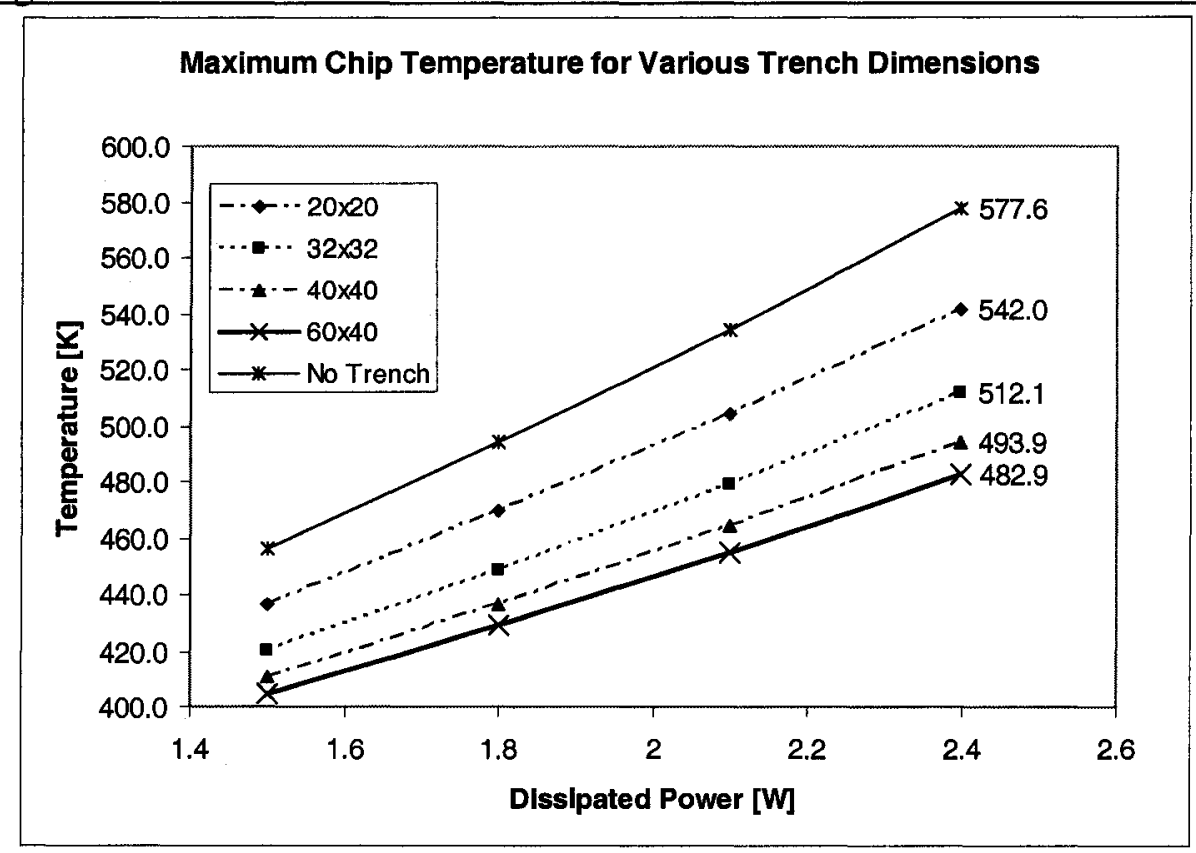

Figure 33: Improvement in maximum device temperature using backside trenches surface-mount package

An improvement in maximum temperature of almost $100 \mathrm{~K}$ is achieved using a trench of $40 \mu \mathrm{m} \times 60 \mu \mathrm{m}$ for a power dissipation of $2.4 \mathrm{~W}$. Not only is the maximum temperature lowered, but the temperature difference between the gates is as well. The temperature both across and along the gates is shown in Figures 34 and 35 for a power level of $1.8 \mathrm{~W}$. 


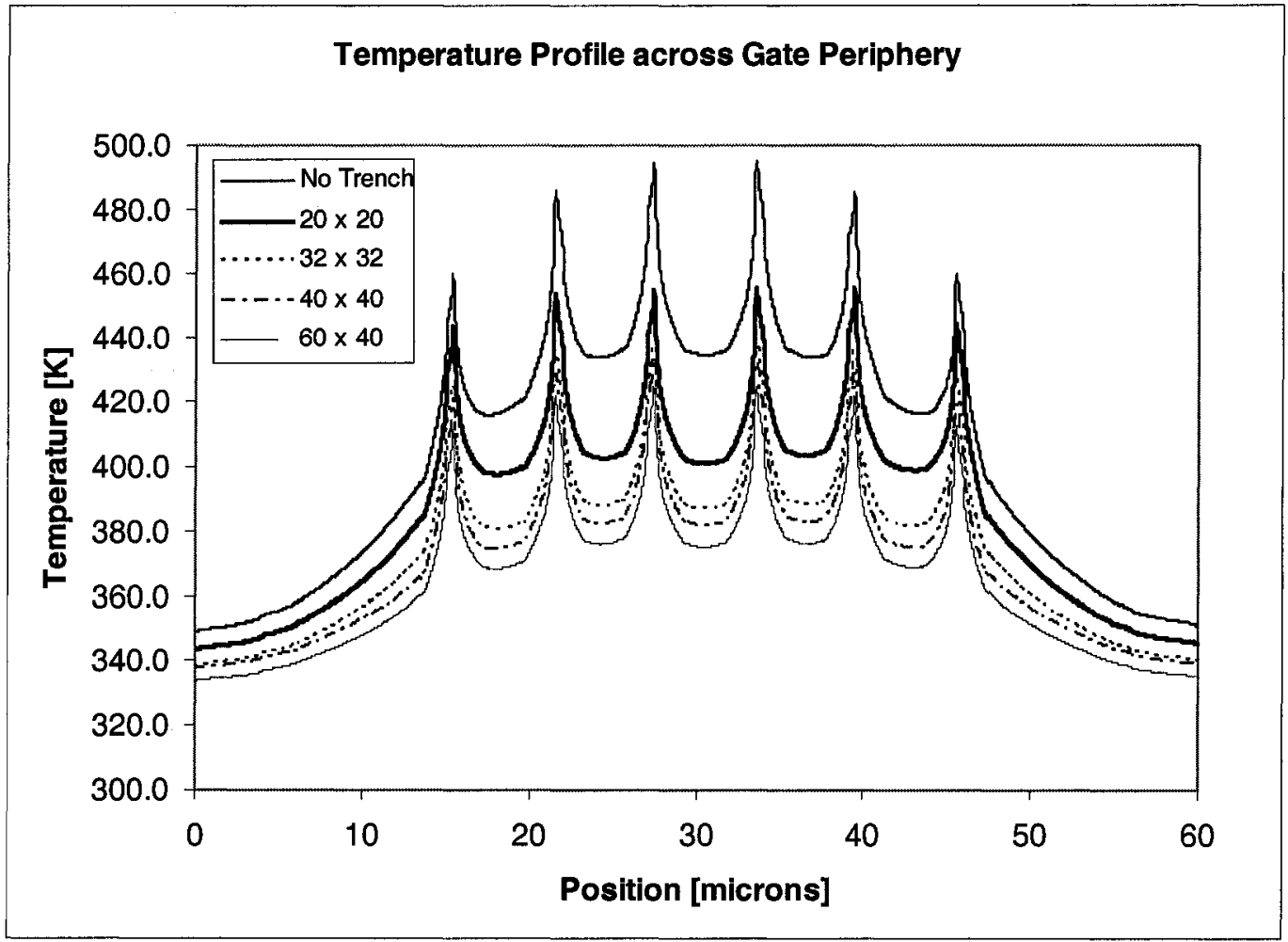

Figure 34: Temperature profile across gate periphery for various trench dimensions $\mathbf{- 1 . 8} \mathbf{W}$

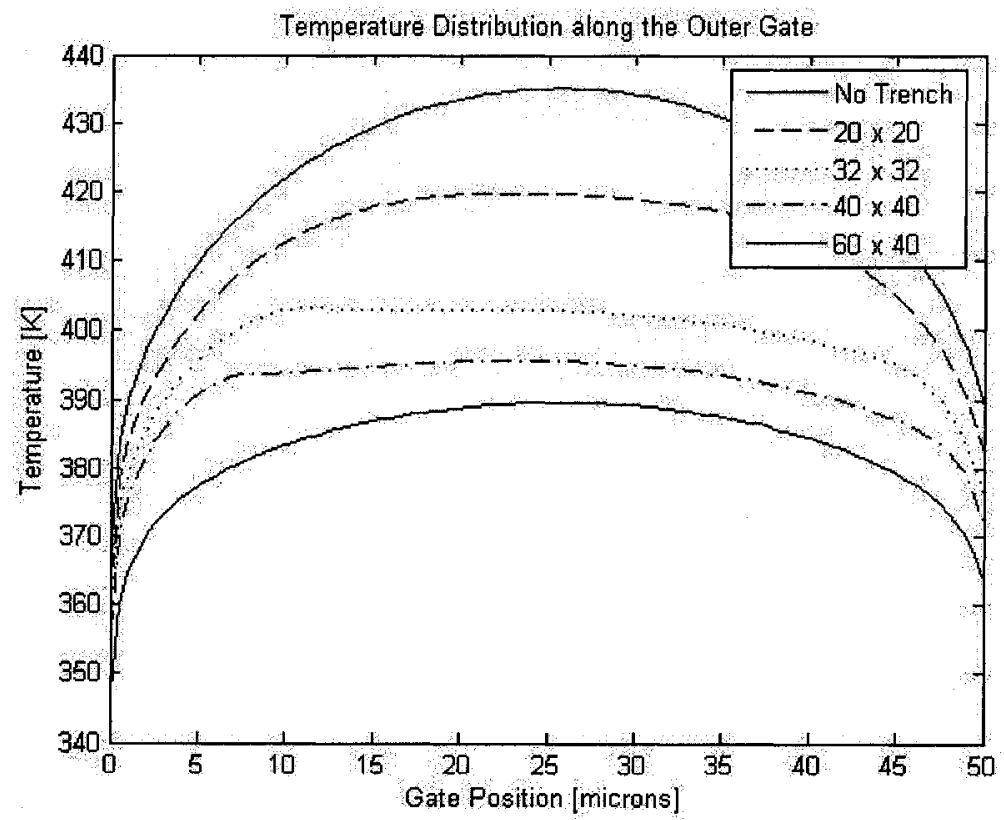

Figure 35: Temperature distribution along outer gate - surface-mount package, $1.8 \mathrm{~W}$ 


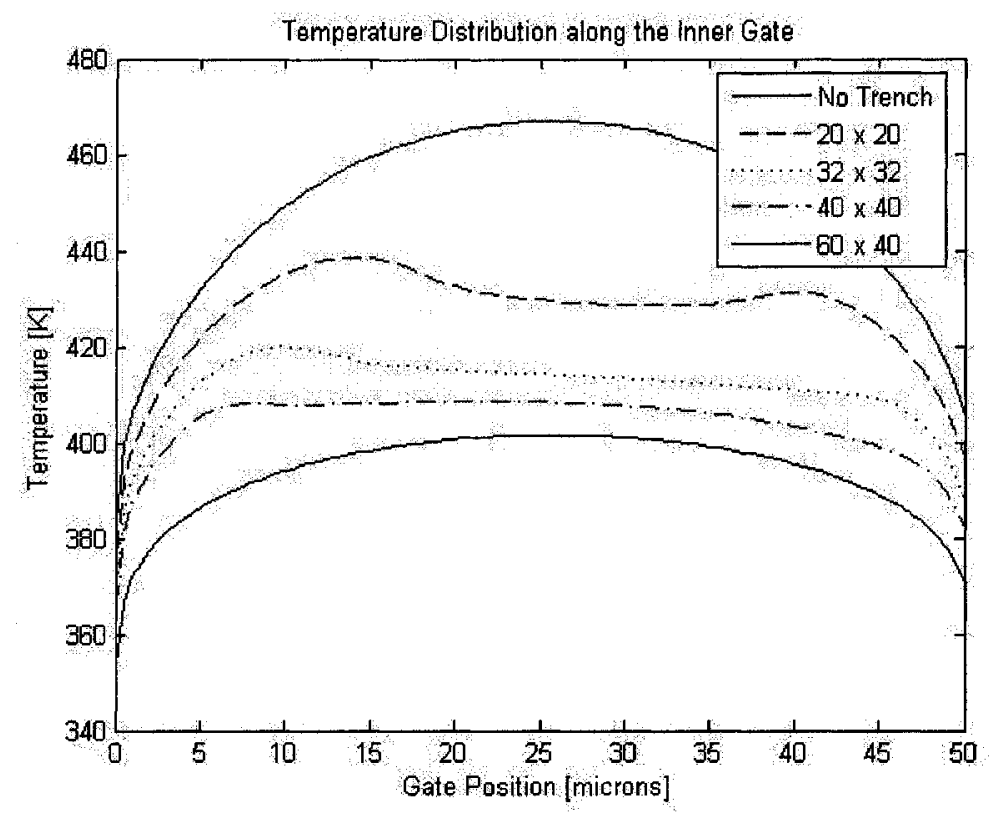

Figure 36: Temperature distribution along inner gate - surface-mount package, $1.8 \mathrm{~W}$

It is also evident in both plots that there is a large difference in effectiveness between the $20 \times 20$ trench and larger trenches. This is most likely a result of the fact that the $20 \times 20$ micron trench has a much smaller area than the gate periphery. The trench allows for a more uniform temperature distribution along the length of both the inner and outer gates. The temperature difference between all the gates is also improved by the trench.

The back trench technique provides a low thermal resistance path to the package, which should allow the heat to flow primarily down to the mount rather than spread into the interface regions. Figure 37 shows the temperature distribution along the silicon/oxide interface across the chip. 


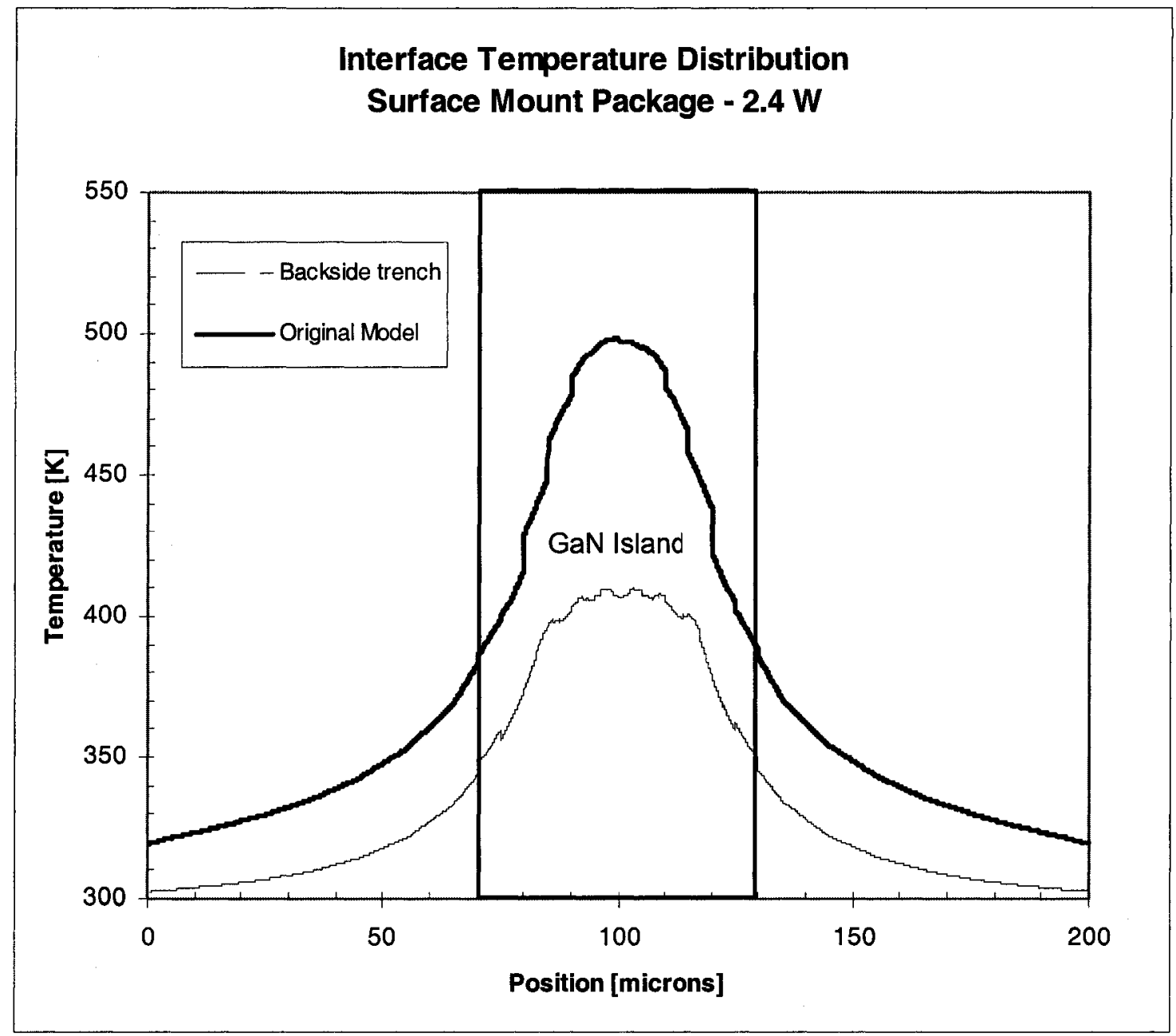

Figure 37: Effect of a 32 x 32 micron backside trench on the surface mount package

The preceding figure shows that the trench allows for heat to escape under the transistor resulting in less heat spreading into the silicon substrate. There is an approximate $20 \mathrm{~K}$ improvement in the interface region, with the temperature reaching a maximum of approximately $340 \mathrm{~K}$ at the edge of the $\mathrm{GaN}$ transistor and decreasing to almost $300 \mathrm{~K}, 70 \mu \mathrm{m}$ away. This shows that the effect of the trench is two-fold. Firstly, it drastically improves the temperature distribution in the HEMT device itself. Secondly, it prevents the surrounding silicon from heating up by providing a low thermal resistance path to the package. 


\subsection{Flip-Chip Thermal Management}

The flip-chip boundary condition poses a greater challenge in terms of packaging as there is no way to avoid thermal conduction through the silicon substrate since the heat flows laterally to the gold bumps. One obvious improvement would be to move the bumps right to the edge of the transistor. This way, the bumps form a thermal barrier between the CMOS and GaN transistors. This method however, can complicate the circuit design as there is no way to connect the transistors together. The large gold bumps located in close proximity to the transistor may also result in some electromagnetic interference.

A solution to this problem is to use smaller vias which connect the source pads to a large metal heat spreader, much like a bump. These can also be placed right on top of the transistor source metal. The vias should not affect the CPW performance as they connect vertically from the transistor periphery from the source, which is traditionally used as the circuit ground. These vias can subsequently connect to a large metal block that can spread the heat out in an efficient manner. Simulations have shown that the via dimensions are important as the overall cross-sectional area determines the heat flow to the spreader, and subsequently to the package.

Although there is no backside boundary condition in the flip-chip package, using the metal trench technique as described in 6.2 is still quite beneficial. While the heat cannot flow out of the backside of the chip, the metal acts as an efficient heat spreader, much like using a substrate of higher thermal conductivity such as $\mathrm{SiC}$. A total of $6,10 \mathrm{x}$ 
$10 \mu \mathrm{m}$ vias were used in combination with a $32 \times 32 \mu \mathrm{m}$ trench to demonstrate this cooling. The vias are spaced symmetrically from the gates with three on each source pad. The vias are $10 \mu \mathrm{m}$ thick, and subsequently connect to metal heat spreaders, which are also $10 \mu \mathrm{m}$ thick. By having a total thickness of $20 \mu \mathrm{m}$, the top of the heat spreader and the gold bumps can be mounted flat on a package. A standard $300 \mathrm{~K}$ topside boundary condition is used. The trench used is exactly the same as that of section 6.2 , but this time there is no backside boundary condition.

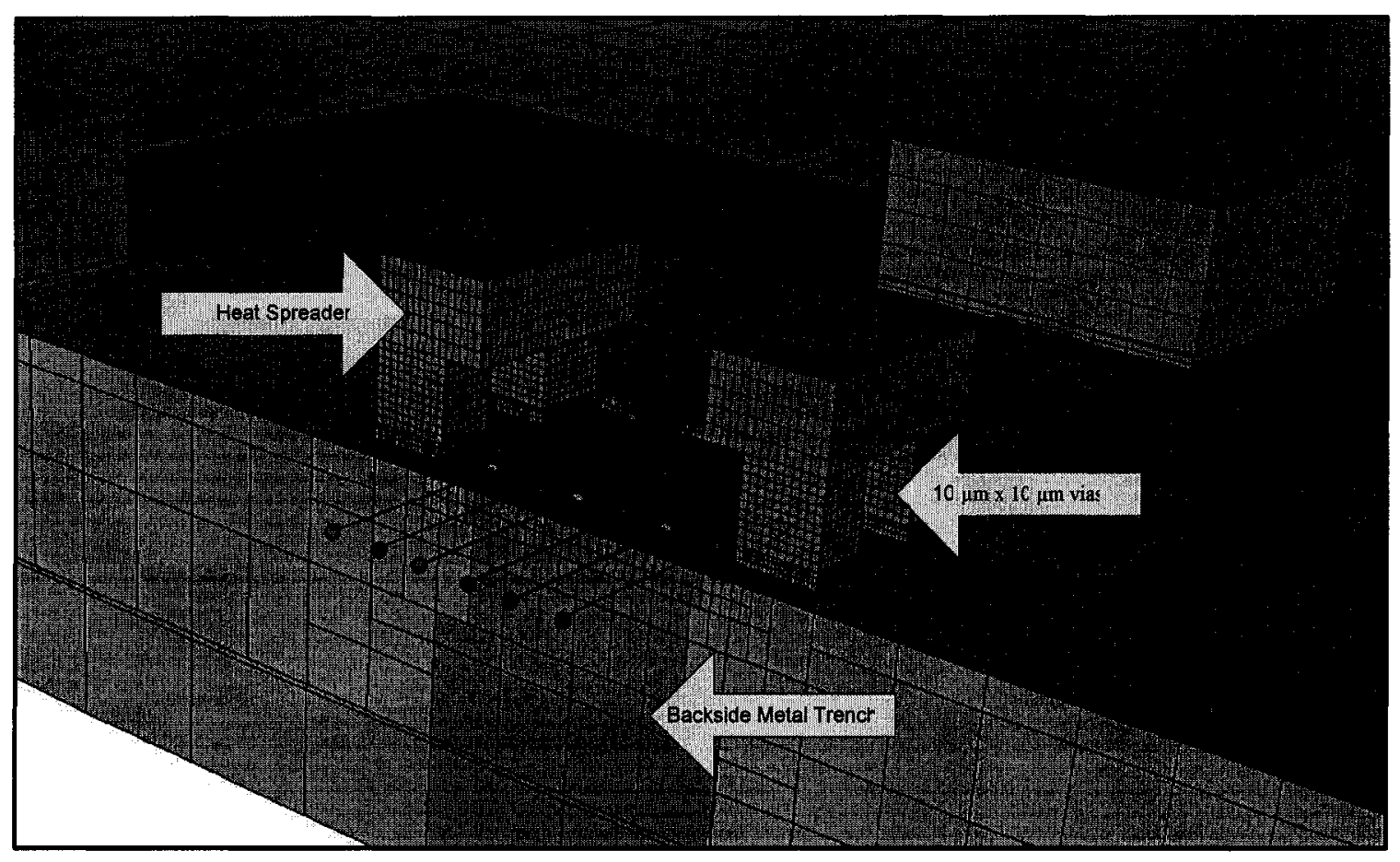

Figure 38: ATAR model cross-section showing the source pad vias as well as backside trench

Both techniques show reasonable temperature improvements in the 20 to $40 \mathrm{~K}$ range depending on the power level used. When used in combination, the maximum chip temperature can be reduced up to $70 \mathrm{~K}$ for a power of $2.4 \mathrm{~W}$ (Figure 39 ). 


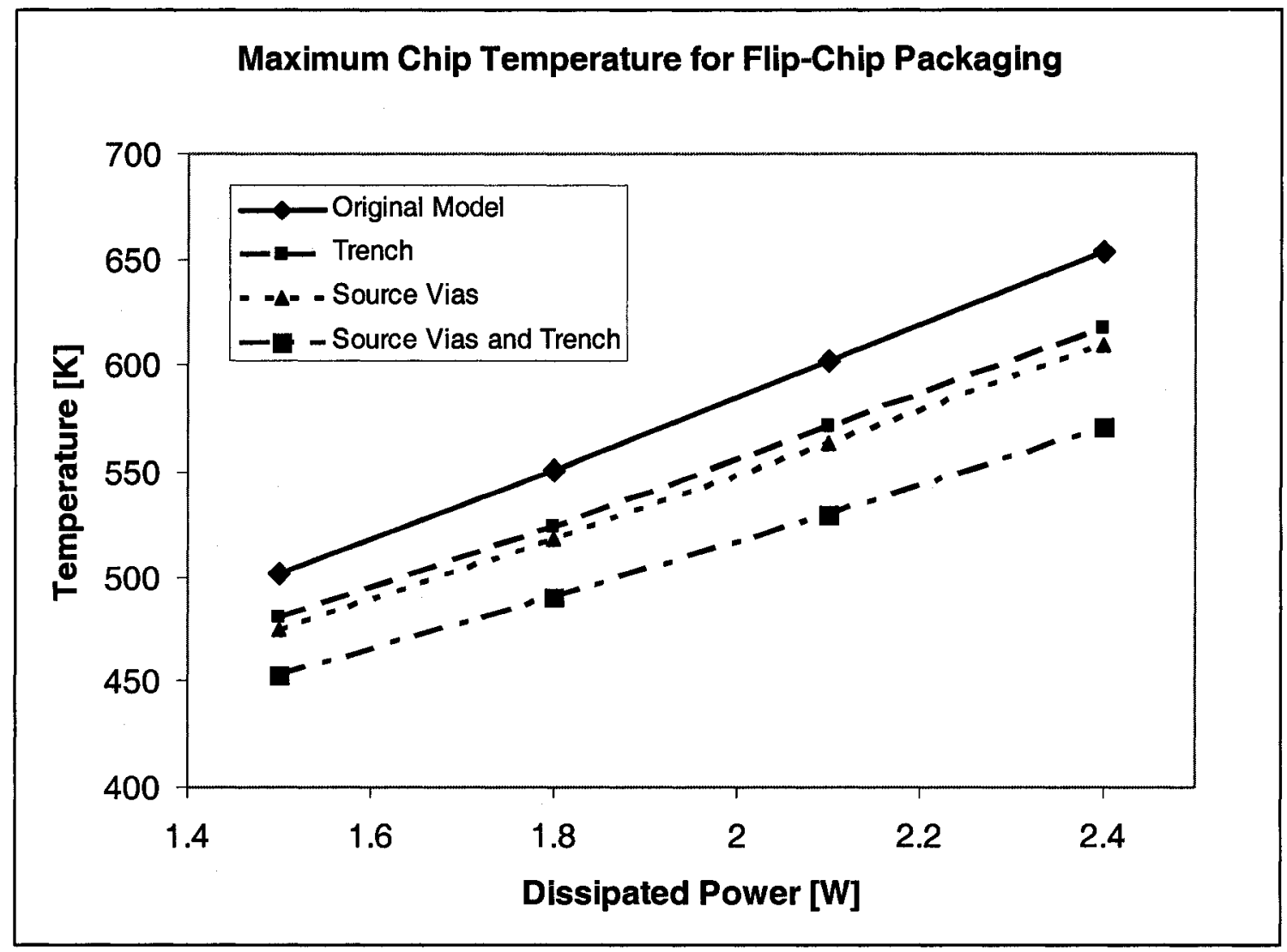

Figure 39: Effects of different cooling strategies for the flip-chip package

Both the proximity of the vias to the gate periphery and the size of the backside trench will affect the performance of these techniques. Ideally, one would put the vias as close as possible to the gates in order to maximize the cooling.

There is also a large thermal improvement in the surrounding silicon/oxide interface, especially perpendicular to the source contacts, as the source metal vias act as a thermal barrier. Figure 40 shows the distribution of temperature at the silicon surface for a flip chip package with a power level of $2.4 \mathrm{~W}$. 


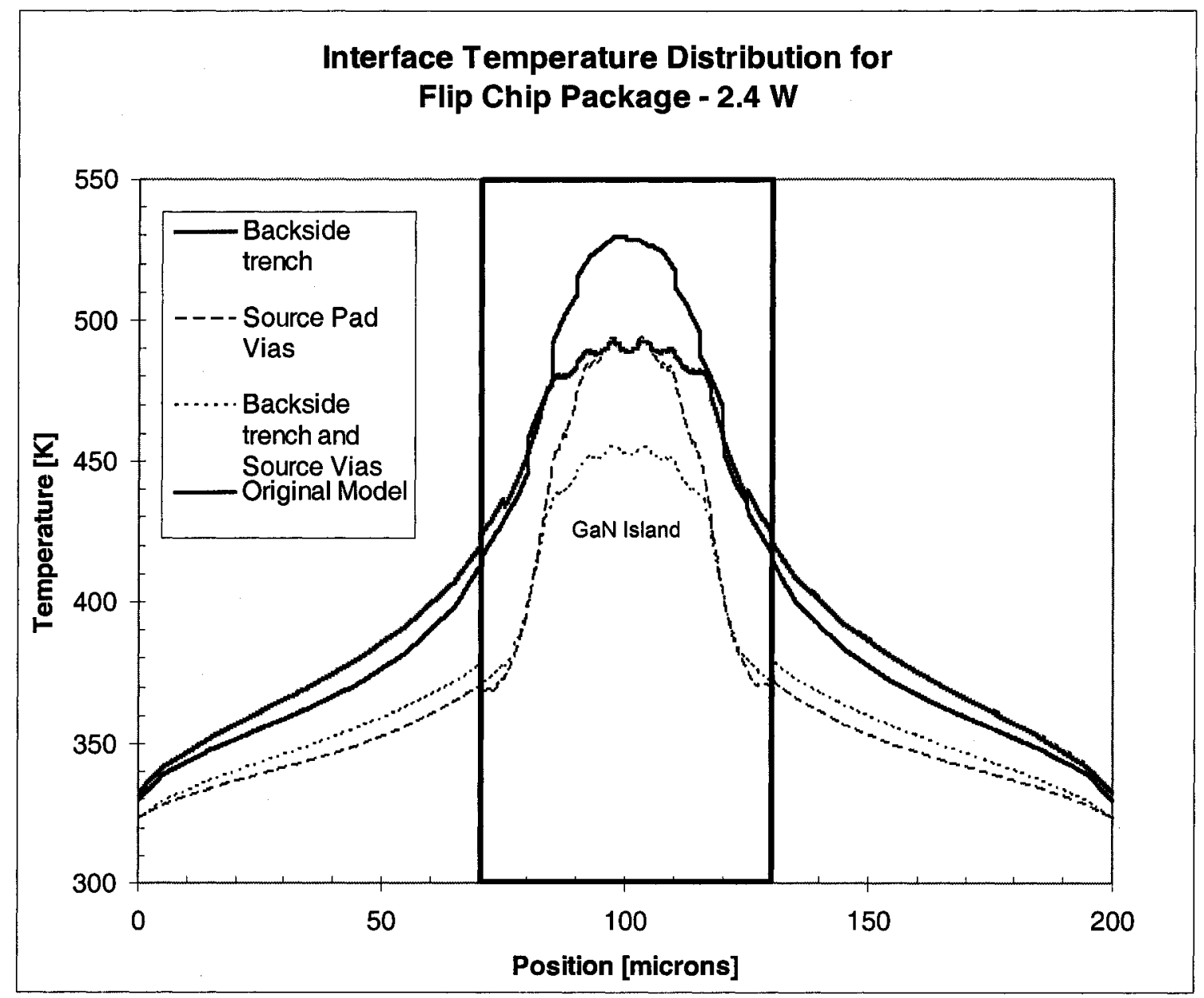

Figure 40: Effect of source pad vias and backside trenches on the flip chip package at the silicon/oxide interface

The backside trench alone does not improve the interface temperatures around the GaN island due to the lateral nature of the heat flow along the surface of the chip. As shown in previous plots, the trench simply spreads the heat at the surface of the HEMT. The addition of the source pad vias greatly decreases the interface temperatures, regardless of the inclusion of a back trench. This is important as the interface temperatures can become significant at high power levels. The combination of both the 
trench and the vias provides an effective cooling scheme, as the heat generated in the HEMT is spread throughout the device with the trench, but is blocked off from moving into the interface by the source metal vias. The gate and drain sides of the transistor show higher temperatures as there is no low thermal resistance path to the package in these directions. The contour plot of the interface in Figure 41 demonstrates this effect.

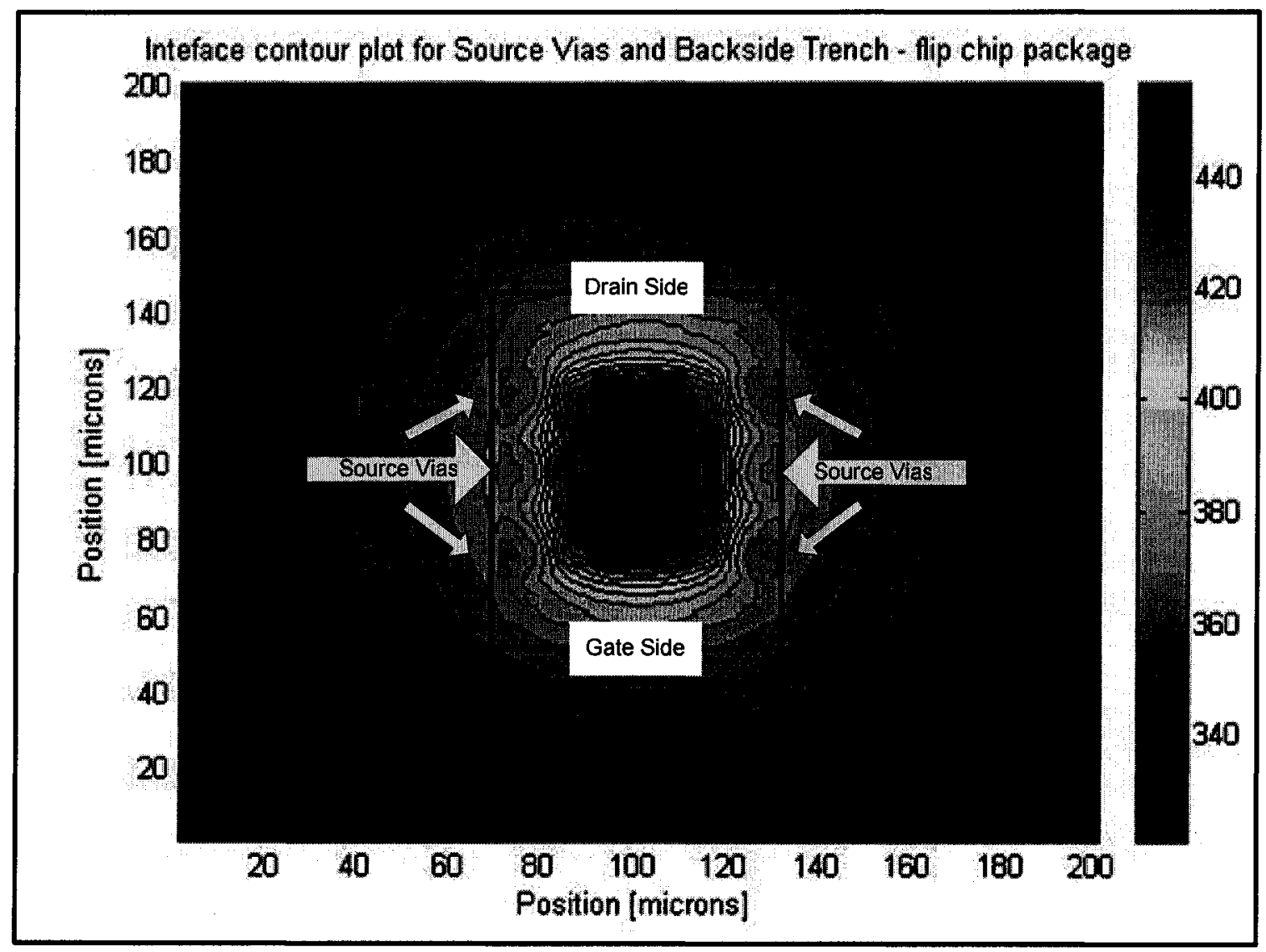

Figure 41: Interface contour plot for flip-chip package $\boldsymbol{- 2 . 4} \mathrm{W}$

The cool spots generated by the source vias are identifiable on the transistor. There are also higher temperatures towards the gate side of the transistor than the drain side due to the different metallization. 


\subsection{Summary}

The use of metal heat spreaders in the form of either trenches or source vias is a simple, effective way to remove heat from the $\mathrm{GaN}$ transistor. Although these methods are not as effective as liquid micro-jet and cryogenic cooling, they are cost-effective and relatively efficient. The replacement of the backside of the GaN with metal rather than silicon mimics a substrate of much higher thermal conductivity, akin to using silicon carbide. Stress issues from thinning the wafer and backfilling with metal may arise in fabrication, but may be minimized with some careful design. The use of source vias allows heat to be effectively removed in a flip-chip package in addition to providing an effective thermal barrier between the CMOS and GaN devices. 


\section{Chapter 7}

\section{Conclusion}

\subsection{Thesis Summary}

This work explored the thermal implications of the monolithic integration of CMOS circuitry with AlGaN/GaN high-power HEMT devices on the same silicon substrate. ATAR, an in-house 3-D thermal modeling tool, was used to simulate a typical $300 \mu \mathrm{m}$ wide GaN HEMT for two boundary conditions, corresponding to a flip-chip and surface-mount package. Steady-state simulations demonstrated that the area surrounding the GaN island is fairly well isolated from the heat generated by the power transistor for the surface-mount boundary condition. The flip-chip package poses a larger challenge due to the lateral nature of the heat flow to the contact bumps. Although maximum temperatures of only $415 \mathrm{~K}$ at the edge of the $\mathrm{GaN}$ island for a power dissipation of 2.4 W were determined, there exists a significant thermal gradient along the silicon/oxide interface which must be accounted for. The negative effects of this gradient can diminish CMOS performance, especially at high frequency and for analog circuits where close impedance matching is required. The effects can be mitigated by using techniques such as common-centroid layout, in which the gates of balanced transistors are interdigitated such that each one experiences a similar thermal gradient .

The effects of substrate and metallization thickness have been examined. The surface-mount model showed significant improvement in maximum temperature as the substrate thickness was reduced to $50 \mu \mathrm{m}$, suggesting that this would be an essential step 
in improving thermal management. Conversely, an increase in metallization thickness showed negligible improvement in temperatures on the flip-chip model, especially in the surrounding silicon region. The very high internal temperatures of the $\mathrm{GaN}$ device proved to be the dominant thermal issue in the model, as it is very well thermally isolated by the high-resistivity silicon substrate, making this the major obstacle in efficient thermal design. Results showed that the temperature distribution in the gate periphery was quite varied, which adversely affects device performance. Simple solutions to this issue include enlarging the gate area by increasing the size of the $\mathrm{GaN}$ island and the gate-to-gate spacing, but this leads to a tradeoff between performance and cost because as the size increases, the yield per wafer decreases. In order to ameliorate the thermal behavior, one must design the gate periphery with the application in mind. For example, lower frequency applications should use longer gates, as heat can be dissipated more efficiently from the pinch-off region. At high-frequency operation, the required short gate length may be compensated with an increased gate-to-gate spacing and narrower transistors.

Transient simulations were performed to investigate the possibility of developing a simple compact thermal model using an RC network. A simple three-rung RC ladder was used to model the temperature at the GaN/Silicon interface, using the transient data to determine time constants. A more complex RC network with non-linear resistances is needed to model the temperature at the heat source, due to the non-linear nature of the $\mathrm{GaN}$ resistance and the complex nature of the transistor layout. The development of an accurate thermal compact model that can predict the temperature distribution of the inner regions of the $\mathrm{GaN}$ device is left for future work. 
In order to overcome the major challenge of the high-resistivity silicon-substrate, a backside trenching technique is proposed. By using the $\mathrm{GaN}$ as an etch-stop layer, a metal backfill is possible. This essentially replaces the substrate under the GaN, but still allows for a silicon substrate in the CMOS region. Significant improvements for both the flip-chip and surface-mount models were achieved using this technique. However, it should be noted that using this method may have detrimental effects on the reliability of the chip, as it will be much more fragile due to the added stress of the metal fill. A large via and heat sink on the source is also useful in cooling the chip, as well as providing a thermal barrier between the power transistor and potential circuitry.

The integration of CMOS with GaN power transistors appears to be possible from a thermal standpoint. Concerns may arise from thermal gradients in the silicon region immediately surrounding the GaN power transistor, but can be overcome using proper device design and layout techniques, as well as the cooling system proposed in this work. The major obstacle in performance appears to be the high-resistivity silicon substrate, which causes extremely high temperatures in the HEMT. A quick investigation into using an RC compact thermal model to predict temperature has shown that a more complex network of resistors and capacitors will be able to predict the transient behavior for all regions of the model. Finally, a simple technique to improve the thermal performance of the model has been explored and shows promise for reducing both internal and surrounding temperatures of this proposed technology. 


\section{References}

[Eastman, 2002] L.F. Eastman, U.K. Mishra, "The Toughest Transistor Yet", IEEE Spectrum, Vol. 39, No. 5, May 2002.

[Yu, 1998] E.T. Yu, P.M. Asbeck, "Schottky barrier engineering in III-V nitrides via the piezoelectric effect", Applied Physics Letters, Vol. 73, No. 13, Sept. 1998.

[Vetury, 2001] R. Vetury, U.K. Mishra, "The Impact of Surface States on the DC and RF Characteristics of AlGaN/GaN HEMTs", IEEE Trans. on Electron Devices, Vol. 48, No. 3, March 2001.

[Dumka, 2004] D.C. Dumka, C. Lee, "AlGaN/GaN HEMTs on Si substrate with 7 W/mm output power density at $10 \mathrm{GHz}$, IEEE Electron Device Letters, Vol. 25, No. 7, 2004.

[Johnson, 2004] J.W. Johnson, E.L. Piner, "12 W/mm AlGaN-GaN HEMTs on Silicon Substrates", IEEE Electron Device Letters, Vol. 25, No. 7, 2004.

[Kuball, 2002] M. Kuball, J.M. Hayes, "Measurement of Temperature in Active High-Power AlGaN/GaN HEMTs Using Raman Spectroscopy", IEEE Electron Device Letters, Vol. 23, No. 1, Jan. 2002.

[Anholt, 1995] R. Anholt, "Electrical and Thermal Characterization of MESFETs, HEMTs and HBTs", Norwood, MA: Artech House, 1995. 
[Bejan, 2003]

A. Bejan, A. D. Kraus, "Heat Transfer Handbook", Hoboken, NJ: John Wiley \& Sons Inc., 2003.

[Celo, 2001]

D. Celo, "Modeling of Thermal Coupling in Multifinger Bipolar Transistors" M.S. thesis, Carleton University, Ottawa, ON, Canada, 2001.

[Guo, 2004]

X. Guo, "Efficient Thermal Simulation Using Model Reduction Techniques”. M.S. thesis, Carleton University, Ottawa, ON, Canada, 2004.

[Wachutka, 1990] G.K.Wachutka, "Rigorous Thermodynamic Treatment of Heat Generation and Conduction in Semiconductor Device Modeling", IEEE Trans. on Computer-Aided Design, Vol. 9, No. 11, November, 1990.

[McAlister, 2006] S.P. McAlister, J.A. Bardwell, "Self-heating and the Temperature Dependence of the DC Characteristics of GaN HEMTs", Journal of Vacuum Science and Technology, Vol. 24, pp. 624-628, 2006.

[Borgarino, 2001] M. Borgarino, R. Menozzi, "Reliability physics of compound semiconductor transistors for microwave applications", Microelectronics Reliability, Vol. 41, pp. 21-30, July, 2001.

[Tan, 2006] W.S. Tan, M.J. Uren, P.W. Fry, "High Temperature performance of AlGaN/GaN HEMTs on Si substrates", Solid-State Electronics, Vol. 50, pp. 511-513, February 2006. 

1999.

[Smy, 2001]

T.Smy, D. Walkey, “A 3-D Thermal Simulation Tool for Integrated Devices - ATAR", IEEE Trans. on Computer Aided Design of ICs and Systems, Vol. 20, No. 1, January, 2001.

[Kusamitsu, 1999] H. Kusamitsu, Y. Morishita, "The Flip-Chip Interconnection for Millimeter-Wave GaAs MMIC", IEEE Trans. On Electronics Packaging and Manufacturing, Vol. 22, No. 1, Jan. 1999.

[Kawamura, 2005] T. Kawamura, Y. Kangawa, "Investigation of thermal conductivity of GaN by molecular dynamics", Journal of Crystal Growth, Vol. 284, pp. 197-202, 2005.

[Darwish, 2004] A.M. Darwish, A.J. Bayba, H.A. Hung, "Thermal Resistance Calculation of AlGaN-GaN devices", IEEE trans on Microwave Theory and Techniques, Vol. 52, No. 11, 2004.

[Hauck, 2000] T. Hauck, T. Bohm, "Thermal RC-Network Approach to Analyze Multichip Power Packages", $16^{\text {th }}$ IEEE SEMI-THERM Symposium, 2000.

[Noebauer, 2001] G. Noebauer, "Creating Compact Models using Standard Spreadsheet Software", $17^{\text {th }}$ IEEE SEMI-THERM Symposium, 2001. 
[Rencz, 2003] M. Rencz, V. Szekely, "Non-linearity Issues in the Dynamic

Compact model Generation", $19^{\text {th }}$ IEEE SEMI-THERM

Symposium, 2003.

[Bhunia, 2004] A. Bhunia, K. Boutros, "High Heat Flux Cooling Solutions for Thermal Management of High Power Density Gallium Nitride HEMT", IEEE Inter Society Conf. on Thermal Phenomena, pp75$81,2004$.

[Kopp, 2001] B.A. Kopp, A.J. Billups, "Thermal Analysis and Considerations for Gallium Nitride Microwave Power Amplifier Packaging", Microwave Journal, pp. 72-82, December 2001. 